\title{
Survival on the fringes of society : marginalisation of and hardening among chronic heroin users
}

Citation for published version (APA):

Coumans, A. M. (2005). Survival on the fringes of society : marginalisation of and hardening among chronic heroin users. [Doctoral Thesis, Maastricht University]. Universiteit Maastricht. https://doi.org/10.26481/dis.20060120ac

Document status and date:

Published: 01/01/2005

DOI:

10.26481/dis.20060120ac

Document Version:

Publisher's PDF, also known as Version of record

\section{Please check the document version of this publication:}

- A submitted manuscript is the version of the article upon submission and before peer-review. There can be important differences between the submitted version and the official published version of record.

People interested in the research are advised to contact the author for the final version of the publication, or visit the DOI to the publisher's website.

- The final author version and the galley proof are versions of the publication after peer review.

- The final published version features the final layout of the paper including the volume, issue and page numbers.

Link to publication

\footnotetext{
General rights rights.

- You may freely distribute the URL identifying the publication in the public portal. please follow below link for the End User Agreement:

www.umlib.nl/taverne-license

Take down policy

If you believe that this document breaches copyright please contact us at:

repository@maastrichtuniversity.nl

providing details and we will investigate your claim.
}

Copyright and moral rights for the publications made accessible in the public portal are retained by the authors and/or other copyright owners and it is a condition of accessing publications that users recognise and abide by the legal requirements associated with these

- Users may download and print one copy of any publication from the public portal for the purpose of private study or research.

- You may not further distribute the material or use it for any profit-making activity or commercial gain

If the publication is distributed under the terms of Article $25 \mathrm{fa}$ of the Dutch Copyright Act, indicated by the "Taverne" license above, 


\section{SURVIVAL ON THE FRINGES OF SOCIETY}

Marginalisation of and hardening among chronic heroin users 
Lay out by A.M. Coumans; Printed by Datawyse

Cover design by J.E.M. Caris

ISBN-10:9077903046

ISBN-13: 9789077903049

(6.M. Coumans, Maastricht, 2005

Any parts of this thesis, including gtaphs and illustrations, may be reproduced in any form without permission of the author, provided these are cired completely and reproductions distributed free or at cost-not for profit. For any reproduction with commercial ends, permission must first be obtained from the author. The author would appreciare being sent a copy of any materials in which text or illustrations have been used. 


\title{
SURVIVAL ON THE FRINGES OF SOCIETY
}

\author{
Marginalisation of and hardening among \\ chronic heroin users
}

\author{
PROEFSCHRIFT \\ TER VERKRIJGING VAN DE GRAAD VAN DOCTOR AAN DE \\ UNIVERSITEIT MAASTRICHT, \\ OP GEZAG VAN DE RECTOR MAGNIFICUS, \\ PROF. MR. G.P.M.F. MOLS \\ VOLGENS HET BESLUIT VAN HET COLLEGE VAN DECANEN, \\ IN HET OPENBAAR TE VERDEDIGEN \\ OP VRIJDAG 20 JANUARI 2006 OM 14.00 UUR \\ DOOR \\ ANNA MONICA COUMANS
}




\section{Promotor:}

Prof. Dr. R.A. Knibbe

\section{Copromotor:}

Dr. H. van de Mheen

\section{Beoordelingscommissie:}

Prof Dr. F. van Wijmen (voorzitter)

Prof. Dr. M. Berger

Prof. Dr. J. van Os

Prof. Dr. C.E. Sterk, Emory University, Atlanta (USA) 


\section{Content}

Introduction 9

1.1 Chronic heroin users 11

1.2 Drug use in the Netherlands: a historical overview 12

1.3 Research problems and data 13

1.3.1 Research questions 13

1.3.2 Data 14

1.4 The theoretical framework 15

$\begin{array}{lll}\text { 1.4.1 Marginalisation } & 15\end{array}$

1.4.2 Hardening 18

1.5 Guide to the text 20

Reference 21

2 A Drug Monitoring System: keeping a finger on the pulse by triangulation of qualitative and quantitative methods 25

Abstract

2.1 Introduction

2.2 Methodology of the DMS 28

22.1 Survey among drug users 29

2.2.2 Key informants 30

2.2 .3 Community fieldwortk $\quad 30$

2.2.4 Combination of methods used in DMS

2.3 Validity or "Trustworthiness" 34

$\begin{array}{lll}2.3 .1 & \text { Triangulation } & 35\end{array}$

2.3 .2 Other techniques in the DMS 36

2.4 Conclusions 38

Refertences $\quad 39$

3 The process of marginalisation and hardening:

an ethnographic study among chronic heroin users 41

$\begin{array}{ll}\text { Abstract } & 42\end{array}$

3.1 Introduction 43

3.2 Methodology 44

3.2.1 Ethnographic ficldwork 44

$\begin{array}{lll}3.3 & 3.2 .2 & \text { Survey } \\ \text { Results } & 45\end{array}$

Results Backoround characteristics 40

3.3.1 Background characteristics 40

$\begin{array}{ll}3.3 .2 & \text { Marginalisation }\end{array}$

3.3 .3 Hardening $\quad 50$

3.4 Discussion $\quad 55$

3.4.1 Methodological implications 58

$\begin{array}{ll}3.4 .2 & 60 \\ \text { ces } & 61\end{array}$ 
4 Counteractions to marginalisation and hardening among chronic heroin users: a two-case study in the Netherlands

Abstract.

4.1 Introduction

4.2 Methodology

4.2.1 The Drug Monitoring System

4.2.2 Grounded theory and case study design

4.2.3 Survey sample

Results

4.3.1 Background chatacteristics

4.3.2 Marginalisation versus socialisation

4.3.3 Hardening versus solidarity

4.3.4 Catalysts

4.4 Concluding remarks

4.4.1 Marginalisation

4.4.2 Hardening

4.4.3 Catalysts

4.4.4 Conclusions

References

5 Drug use and the role of homelessness in the process of marginalisation

Abstract

5.1 Introduction

5.2 Homelessness and drug use in the Netherlands

5.3 The process of marginalisation

5.4 Hypotheses

5.4.1 Control of clrug use 90

5.4.2 Social dimension of marginalisation 90

5.4.3 Economic dimension of marginalisation 91

5.4.4 Physical dimension of marginalisation 91

5.4.5 Psychological dimension of marginalisation 91

5.5 Research design 91

5.5.1 Sampling design $\quad 91$

$\begin{array}{lll}5.5 .2 & \text { Variables } & 93\end{array}$

$\begin{array}{ll}5.5 .3 & \text { Statistical analysis }\end{array}$

$\begin{array}{lll}5.6 & \text { Results } & 96\end{array}$

5.6.1 Background characteristics 96

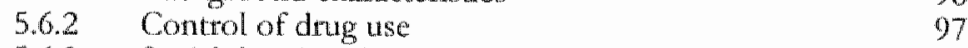

5.3 Social deterioration 98

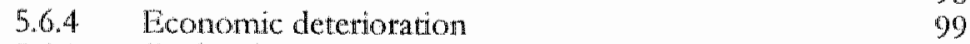

5.6.5 Health deterioration 101

$\begin{array}{ll}5.7 \text { Discussion } & 101\end{array}$

$\begin{array}{ll}\text { 5.7.1 Methodological remarks } & 101\end{array}$

References

5.7.2 Marginalisation and homelessness $\quad 102$

6 The deteriorating effects of crack among chronic heroin users: a two case study in the Netherlands 107

$\begin{array}{ll}\text { Abstract } & 108\end{array}$

$\begin{array}{ll}6.1 \text { Introduction } & 109\end{array}$

$\begin{array}{lll}6.2 & \text { Methods } & 111\end{array}$

6.2 .1 Community fieldwork 111

$\begin{array}{ll}\text { 6.2.2 Survey among drug users } & 112\end{array}$ 
$\begin{array}{lll}6.3 & \text { Findings } & 113\end{array}$

6.3.1 Marginalisation and hardening 114

6.3.2 Factors moderating the disrupting effects of crack $\quad 120$

6.4 Conclusions and discussion $\quad 121$

6.4.1 Methodological limitations 122

References

$\begin{array}{ll}6.4 .2 & \text { Implications for drug policy } \\ 123\end{array}$

$7 \quad$ Street-level effects of locall drug policy on

marginalisation and hardening: an ethnographic study

among chronic drug users

$\begin{array}{ll}\text { Abstract } & 128\end{array}$

$\begin{array}{ll}7.1 \text { Introduction } & 129\end{array}$

$\begin{array}{ll}7.2 & 132 \\ & \text { Methods }\end{array}$

7.2.1 Ethnographic community field work 132

7.2 .2 Survey 132

7.2.3 In-depth interviews and interviews with key informants 133

7.3 Results 134

7.3.1 Background characteristics 134

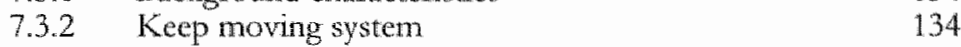

$\begin{array}{lll}7.4 & \text { Concluding remarks } & 141\end{array}$

7.1.1 Effects on marginalisation and hardening $\quad 141$

7.1.2 Discussion 142

7.1.3 End conclusion and recommendations 144

$\begin{array}{ll}\text { References } & 145\end{array}$

8 Concluding remarks 149

$8.1 \quad$ Introduction 151

$\begin{array}{lll}8.2 & \text { Conclusions } & 151\end{array}$

8.2.1 Marginalisation and hardening 151

8.2.2 Counteracting mowements to marginalisation 153 and hardening $\quad 153$

8.2.3 Amplifying factors $\quad 154$

8.3 Methodological remarks 155

$\begin{array}{ll}8.4 & 158\end{array}$

$\begin{array}{ll}\text { 8.4.1 Marginalisation } & 158\end{array}$

8.4.2 Hardening 159

8.4.3 Moderating factors of matginalisation and hardening 160

$8.5 \quad$ Implications for future drug policy 161

$\begin{array}{ll}\text { Refenences } & 162\end{array}$

$\begin{array}{ll}\text { Summary/Samenvatting } & 165\end{array}$

$\begin{array}{ll}\text { Dankwoord } & 173\end{array}$

$\begin{array}{ll}\text { Curriculum vitae } & 175\end{array}$ 

Chapter 1

\section{Introduction}





\section{$1.1 \quad$ Chronic heroin users}

Throughout the twentieth century, the domain of illegal drugs and its users has received considerable interest from politicians and policy makers, as well as from the media and scientists. Ever since the Dutch Opium Act became operational in the Netherlands in 1919, mainly under pressure from the USA (Korf, 1995a), heroin use and its perception has changed from being an individual (and medicalised) issue towards a major social problem. American as well as British and Dutch historians and researchers (Acker, 2002; Berridge, 1999; Courtwright, 1982; de Kort \& Korf, 1992; van de Wijngaart, 1988) have noted that since 1920 s, it is not the medical consequences but rather the criminalisation of drugs and drug users (e.g. its illegal status, the black markets) that partly constitures this social drug problem. This is not to say that all drug-related problems are due to drug prohibition, but rather that drug law enforcement has contributed to the very problem it aimed to defeat. Grapendaal \& Leuw (1995) call this phenomenon the ultimate paraclox of all drug policy:

The basic predicament is that attempts to limit the availability of illegal drugs tend to increase their damaging (social) effects as well as their psychological and economic attractions. The more drugs are tabooed and forcefully repressed, the more its users will tend to be marginalized, criminal, beaters and sources of diseases and the more the world of drug use will offer attractive perspectives for earning money and living a meaningful life in deviant subcultures. (1995, page 7)

Even within the pragmatic and normalising approach in the Netherlands, this paradox is still relevant. According to Engelsman (cited in Grapendaal et al., 1995, page 7) the Nethetlands currently takes a position between a war on drugs and legalization. This implies that overall the "Dutch approach" does not seek a solution to the drug problem, but rather aims at "coping", which implies the minimisation of negative consequences of drug use and the "...preparation of society to optimally live with it..." (Baanders, 1989 cited in Grapendal et al., 1995, page 6). Only recently, several Dutch studies pointed in the direction of a more repressive climate towards drug users (Barendregt et all, 2000; Barendregt et al, 2003; Barendregt et al., 1998; Garretsen et al., 2003; Lempens et al., 2003). Despite of the Revised Opium Act in 1971, several illegal (hard) drugs have still been (chronically) used by different categories of drug users in the Netherllands (see also section 1.2 addressing historical developments). As is commonly known, use of drugs and its related lifestyle has several dimensions, including the medical, psychological, social, and economic. These dimensions can be used as a descriptive outcome of drug use and its associated lifestyle. Conversely, chronic drug use can also be described as arising from an already deteriorated medical, psychological or social background. Although this thesis acknowledges all possible dimensions of drug use, it focuses on the social dimension and emphasises the deteriotation in the social position of drug users. Since this change in the social position of drug users over time is best documented by concentrating on chronic drug users, the present study focused on (nearly) daily users of opiates (e.g. methadone, heroin) 
and other drugs (e.g. cocaine, amphetamines). The deteriorating social position of this category differs from that of other marginalised groups, such as immigrants of mentally ill peoplle. In the first place because chronic drug users generally do not have the shared social status that ethnic groups usually have and, secondly, because the voluntary element of drug use is absent among, e.g., mentally ill people or ethnic groups. Continuing the use of illegal drugs will therefore cause a stronger social reaction than mental illness.

To characterise our category more precisely it has to be noted that the mean age of our study population is about 40 years, and most of them started their drugusing career about 20 years (or longer) ago with heroin. Some of our study population may have started their use from an alteady marginalised background, others started their use as recreational, and another group used drugs as selfmedication (e.g. to tepress psychological or physical symptoms). Today, the major part of our study population consists of poly-drug users, implying that, besides heroin, they have added one or more kinds of drugs to their arsenal (e.g. cocaine, pills, cannabis and alcohol).

On the societal level, this category of chronic poly-drug users is generally distinguished from the category recreational drug users. Several studies have focused on recreational use of drugs, such as MDMA and powder cocaine, and most of them characterise these users as non-deviant subcultures (for example: Bellis et al, 2003; Cohen, 1989; Grinspoon \& Bakalar, 1976; Hunt \& Evans, 2003; Korf, 1995a; Maxwell, 2003; Nabben \& Korf, 1999; Phillips \& Whyne, 1980; ter Bogt et al., 2002). However, there are too few (colhort) studies to allow drawing more definite conclusions about the extent to which recreational users may become the next generation of chronic drug users.

The remainder of this chapter focuses on a historical overview of drug use in the Netherlands (section 1.2), the research problems and data (section 1.3), the theoretical framework (section 1.4), and a guide to the research addressed in this thesis (section 1.5).

\subsection{Drug use in the Netherlands: a historical overview}

Already in the 1800 s many substances, such as cannabis, cocaine and opiates (opium) were used in the Netherlands, often on medical prescription but also for recreational purposes or for self-medication (De Kort \& Korf, 1992). However, this overview starts from around the 1950 s when, due to criminalisation, "substances" became socially reconstructed into "drugs".

In the decades following world war II, several drugs made their (re)entrance in the Netherlands, statting with the introduction of cannabis in the early 1960 s. Atound 1965 opium, amphetamines and LSD were starting to get popular among (mainly) experimenting young white males (Grund, 1993). Heroin, however, was not introduced on the Dutch drug markets until the end of the $1960 \mathrm{~s}$. At first heroin was mainly consumed by experimenters, and some more experienced (multiple-drug) users who injected the drug (Grund, 1993). Under the influence of 
sharply decteasing prices in the early 1970s, the use of heroin spread in about a decade among three different categories. It started in 1971 with Dutch (deviant as well as non-deviant) youngsters taking up heroin use. Around 1974, a second category coming from ethnic groups (the Surinamese; the South Moluccan and second generation Moroccans) started to use heroin. Towards the end of the 1970 s, also German drug users entered the Dutch scene.

From 1980 on there was a spread of cocaine among two separated and initially different categories; i.e. the population of young unemployed living in larger cities, and chronic heroin users. In addition, in the 1980 s methadone became a major form of "sociomedical" control in the Netherlands.

In $1987 / 1988$, a new drug was added to the existing ones, MDMA (XTC or Ecstasy). This drug was used almost exclusively in the house subculture (ter Bogt et al., 2002) and became widespread in this setting in the 1990s. By the end of the 1980 s also drugs related to MDMA, such as amphetamine, LSD and psilocybine, appeared to make a revival (Grund, 1993).

When we concentrate on the question how this history has affected the category initial chronic heroin users, we can conclude that most of them have now become poly-drug users. Focusing on the impact on the use of heroin, since 1990 a decrease in the incidence of heroin users is observed by Swierstra (1990) and more recently by experts from Dutch drug aid agencies (Moll \& Sokmans, 2005 in: NRC Handelsblad, a Dutch newspaper). Thus, the use of heroin has become stable among the older category of (initial) drug users. Contrary to van de Wijngaarts' expectation in 1988 (van de Wijngaart), in several Dutch open drug scenes, the use of cocaine (mostly crack) has now superseded that of heroin (Coumans \& Knibbe, 2002a; Lempens et al., 1999). Although there are some indications that heroin is used incidentally by crack users, there has been no increase in heroin-related helpseeking behaviour among this category.

\subsection{Research problems and data}

\subsubsection{Research questions}

This study was guided by the following research questions:

1. How is the shift in social position of chronic heroine users related to deterioration in social, economic and health aspects?

2. How are the changing social relations between chronic heroin drug users related to deterioration in social and economic functioning?

3. Which specific factors increase the rate of deterioration of chronic heroin users?

With respect to the third research question, we chose to concentrate on the impact of four factors: local context, homelessness, crack cocaine, and a repressive policy. 
Although it is not an explicit question in this thesis, it is important to have some notion about the extent of the phenomena of this study. Using several types of estimators, in 1998 and 2002 the number of chronic heroin users in Parkstad Limburg has been estimated to be 800 (Coumans \& Knibbe, 2002a; Coumans et al., 2000). In 1995 the population of hard drug users in Rotterdam has been estimated at 4000 using the capture-recapture method (Bieleman et al., 1995). A more recent estimation in Rotterdam resulted in an estimated number of 5000 hard drug users; the number of problematic hard drug users was estimated at about 3000 (Biesma et al, 2004).

\subsubsection{Data}

General population studies and more specific surveys are to some extent useful to register trends and developments in recreational drug use (Bongers, 1998; Lammers et al., 2000). However, such techniques are less appropriate to describe populations of chronic drug users. Firstly, there are relatively few of these drug users and, secondly, these people generally cannot be reached by standardised survey studies. The population of chronic drug users is a so-called "hidden population" (see also Chapter 2). Therefore, we used an ethnographic method to come into contact with this population that is "hidden" for standardised survey techniques, but not for the general population: in their eyes, it is the most visible category of drug users. In fact, it is just this visibility that curtently makes it the target of police measures, health care programs, and the subject of many items in the media.

The theoretical concepts of this study emerged inductively out of analyses of ethnographic field notes that were gathered by the Drug Monitoring System in Parkstad Limburg. Parkstad Limburg is a region that comprises the city of Heerlen and seven neighbouring municipalities (i.e. Brunssum, Landgraaf, Kerkrade, Voerendaal, Simpelveld, Nuth, and Onderbanken). At the time this study was performed there were about 300,000 inhabitants in this region. Parkstad Limburg is located in the south of the Netherlands, close to the borders of Belgium and, especially, Germany. Another important socio-demographic characteristic of this region is the relatively high proportion of unemployed citizens (about $10 \%$ in 2004 , compared with about $5 \%$ on a national level). Taking into account the small city centre of Heerlen, it is not surprising that currently hetoin users draw attention of local residents or travellers, and often are viewed as a nuisance by the same public.

The data from the ethnographic field notes were complemented with data from interviews with key informants, and from a survey sample among chronic heroin users (see also Chapter 2), 


\subsection{The theoretical framework}

Using an "emic" or insider's view (Sterk, 2003), we observed that the life of many chronic hetoin users can be characterised by decline. Firstly, we observed a decline of the position of the heroin user within cimlstity and his or her relation with core institutions within society (e.g. family, education, work, income and health care). Throughout this thesis, this kind of decline is labelled as marginalisation. Secondly, also relationships betwen drug users were characterised by deterioration. In order to survive, social relationships between drug users become tough and increasingly instrumental; whereas real social support from fellow users as well as non-using relatives of friends decreases. To adapt to the new circumstances, drug users commonly earn their money with illegal activities (stealing money or drugs, shoplifting, selling drugs, or prostitution). This kind of decline is labelled as hardening.

In this section, the terms marginalisation and hardening are further elaborated.

\subsubsection{Marginalisation}

In 1928 Robert Park, a sociologist from the Chicago school, was the first to elaborate the identity of the "marginal man":

... a man living and sharing intimately in the cultural life and traditions of two distinct peoples; never quite willing to break, even if he were pernitted to do so, with his past and his traditions, and not quite accepted, because of racial prejudice, in the new society in which he now sought to find a place. He was a man on the margin of two cultures and two societies, whenever completely interpenetrated and fused...(1928, page 892)

Park's concept has recently been revisited by Weisberger (1992), who developed a more general theory of marginality and made it applicable to a variety of cases. Weisberger (1992) criticised Park's concept for not including the range of possible reactions to marginality, and emphasised the structure of "double ambivalence - ambivalence toward the marginal person's native culture and ambivalence toward the "host" culture" (Weisberger, 1992). In today's conception and usage of the concept of marginality the elements of being "betwixt and between' of Park's definition and the double ambivalence of Weisberger's elaboration are still relevant. However, today ambivalence often refers to the insecurity of the marginalised about their identity, and confusion on the side of society about what constitutes the core of the identity of the marginal man; i.e. does the drug user identify him or herself as a "drug user" or as a "normal citizen" who should not be harassed about his drug-using habit, and does civil society view the drug user as someone who distracts him or herself from essential societal values and conventions or as a normal cirizen with an unpleasant habit? Moreover, marginality is not always applied as being betwixt and between a separate original and host culture and possible reactions to that position. When speaking about 
marginality of subcultures that emerged out of one mainstream society (such as the homeless or mentally ill), marginality generally refers to living in the margins of civil society and processes of a deteriorating position within that same society.

Also in the literature a variety of ways has been developed of how to view the phenomenon of marginality and marginalisation (Anderson \& Levy, 2003; Buiks, 1983; Crewe, 1997; Hall, 1999; Hall et al, 1994; Hussong, 1998; van Gelder \& Sijtsma, 1988). These studies have several elements in common; i.e. marginalisation is a process rather than a state, it includes a shift in position and it results in a category that is disenfranchised. Most studies also recognise more dimensions of marginalisation, i.e. economic, health, and social dimension (Buiks, 1983; Hall, 1999. Hall et al., 1994; Hussong, 1998; van Gelder \& Sijtsma, 1988). However, these studies differ in terms of the background of marginalisation or in their description in terms of risks only, or both risks and chances. The studies of Builks (1983) and van Gelder \& Sijtsma (1988) both indicate factors related to the status of an immigrant or ethnic background. Hall et al. (1999) studied marginalisation in the context of enhancing nursing knowledge and focused more in general on vulnerable populations (e.g. lesbians and women cletical workers), Ford and Yep (2003) focused on disenfranchisement of a variety of groups and individuals and Hussong (1998) concentrated on adult men and women in a central city area. With respect to whether a description of marginalisation is double edged, contrary to Buiks who focused on the negative implications of marginalisation, van Gelder and Sijtsma stressed the fact that marginalisation should be understood in terms of deterioration as well as chances. Hall et al. (Hall, 1999; 1994) identified seven properties of marginalisation and related them not only to developing illness, but also to acquired capacities that foster survival.

Whereas Robert Park concentrated on immigrants who had moved from one society to another, only recently Anderson \& Levy (2003) applied Park's concept of marginality to older injectors and described their marginal position as being unable to retutn to "the old school" (i.e. the drug world from their youth), but at the same time not capable of adapting to "the new school" (the current drug scenc).

The present study describes the marginal position of dug users as a position in which drug users do not fully participate in the mainstream (or conventional) society and at the same time are not accepted naturally by their fellow users unless they develop several survival techniques. "Not fully participating in mainstream society" is a main aspect of marginalisation and covers all dimensions of life (social, economic, physical and psychological health). Thus, we agree with Buiks (1983) that marginalisation refers to decreasing possibilities to participate in core institutions of society, varying from primary contacts (friends and family) to health care, education and work. Our concept of marginalisation is also in line with that of Buiks (1983) in that it is a process, rather than a state. Moreover, we agree with van Gelder \& Sijtsma (1988) that marginalisation implies not only risks but also the development of specific strengths and skills to survive.

Other concepts have also been developed that are closely related to marginalisation, such as social exclusion (van der Velden \& Spietings, 1999; Watt, 
2001), stigmatization (Goffman, 1963; Link \& Phelan, 2001; Link et al., 1997), labelling (Becker, 1963; Goldberg, 2001), secondary deviance (Goldberg, 2001; Kaplan, 1996; Klemke, 1988; Oetting, Deffenbacher et al., 1998; Oetuing, Donnermeyer et al., 1998), deviance amplification (Klemke, 1988), the social breakdown syndrome (Gruenberg, 1974) and oppression illness (Singer, 1999). Whereas marginalisation is a wider concept, stigmatisation, labelling, secondary deviance and deviance amplification are more cryptic. These four concepts are relevant in our conceptual framework, because they offer good descriptions on the interaction level. Social exclusion as well as the social breakdown syndrome are in line with out theoretical framework in that they share some basic elements with marginalisation. Both concepts are described as dynamic (i.e. as a process) and multidimensional (i.e. problems on all aspects of "full citizenship": income, work, education, housing, health care etc). The reason that we chose marginalisation is that social exclusion applies to socially recognisable groups with a low status and limited chances, such as immigrants, Muslims, or gypsies. Since the category of chronic heroin users is heterogeneous in nature, such a common status cannot be assumed. Oppression illness is "a product of the impact of suffering from the trauma of social mistreatment and, at some level, believing one does not deserve to be treated any better" (Singer, 1999, page 39). Thus, oppression illness may be a possible outcome, rather than an equivalent of marginalisation. The social breakdown syndrome does not fit with our theoretical framework of marginalisation in that it refers to individual processes within a clinical (psychiatric) setting.

Apart from drug users, marginalisation has been applied to many different categories of people, such as hard-to-reach groups of adults and children (Milboume, 2002), diwerse categories of HIV patients (Amaro \& Raj, 2000), mentally ill (Johnstone, 2001; Olson \& Sanders, 2000), street children (Rizzini, 1995; Snodgrass Godoy, 1999), adult men and women in a central city atrea (Hussong, 1998), Puerto Rican crack dealers (Bourgois, 1996) and immigrants (Builks, 1983; Eldering \& Knorth, 1997; van Gelder \& Sijtsma, 1988).

Although both drug using and non-drug using categories are to some extent subject to social reactions based on individual characteristics (labelling), these reactions vary widely as do the opportunities to return to (mainstream) social society. The difference between marginalisation among chronic heroin users compared with other subpopulations labelled as marginal, is that in the case of drug users deviancy is mostly conceived by society as an 'acquired' status, rather than a status ascribed because someone belongs (mostly from birth on) to a specific subpopulation (e.g. immigrants). This means that for drug users it is thought that they conid have chosen not to start using drugs, while immigrants, street children, and the mentally ill are hardly in the position to choose for their position and social identity (Tucker, 1994, page 7). Consequently, one of the possible routes for the non-drug using categories to return to mainstream society is emancipation in order to be accepted. In the eyes of society, one of the few acceptable pathways towards socialisation for drug users involves abstinence or at least rejecting his or her own drug-using habit. 
Other possilile reactions from both society and the drug users themselves concentrate atound the right to use drugs, criminalisation, minimisation of negative consequences of drug use (harm-teduction) and legislation of heroin. To society, the tight to use drugs without being punished (decriminalisation) or legislation does not play a dominant role, whereas among drug users themselves this issue is often seen as one of the conditions to survive and re-socialise. In the Netherlands, a harm-reduction approach is currently the most popular way to view and handle drogs and drug use. However, this perspective is seen by society as a pragmatic solution to reduce drug-related nuisance, whereas for drug users it is more deleological in that it means a possible toute out of the drug scene towards patticipating in society in an acceptable way. The same contrast applies to viewing heroin as a medicine, which should be provided on medical prescription (medicalisation), which is becoming more popular both among society and drug users. However, even in Dutch society disapproval of drug use (criminalisation) is still the dominant way to view drugs. To some extent drug users must have internalised this perspective, taking into account the direct and indirect negative consequences of this view.

\subsubsection{Hardening}

According to Weisberger thete are four possible responses to matginality: 1) return to the original culture, 2) transcendence by overcoming the opposition of the two cultures by creating a third way, 3) assimilation by absotbing the host culture's standards, and 4) protse by refusal or incapability to resolve the ambivalence of marginality. When applying these responses to our study population, return to the original (or mainstream) culture is not the most likely reaction for chronic hetoin users. If we consider abstinence as an indicator of return, it is commonly known and shown by the literature that abstinence without interference ("natural recovery") is not reached by more than about 35\% (Swierstra, 1987). Likewise, evaluations of therapeutic communities show that about $30 \%$ of the drug users is abstinent one year after the treatment. In the category we observed in Parkstad Limburg, most drug users have participated in one or mote treatment programs aimed at abstinence.

Transcerdence in the sense that drug users create a way in which they aim to surpass or reconcile the two cultures usually requires large economic and social tesources and is therefore rare among drug users. One example, however, is commitment to an interest group for drug users aimed at handling issues that drug users and their non-drug using environment share (such as establishing a drugusers toom that offers rest and protection, and at the same time diminishes drugrelated nuisance).

Assimilation implies that drug users absorb the standards of the drug scene. The extent to which drug users succeed in this absotption shows large variation and is closely related to survival skills. As Anderson \& Levy (2003) have shown, older drug users often do not possess the physical strength and abilities to fully 
participate in today's drug scene. They describe poise as the most appropriate reaction:

(..) The older injectors we studied adopt a position of poise to their predicament by clinging to self-identity and cultural values of the past. while ralking an increasingly marginal position within the new. Although they protest their dislocation, they perceive themselves powerless to adjust to the social norms and physical denands of full membership in the drug world that currently exists. (...) being an older IDU in today's drug scene is fraught with loneliness, stress and fear of victimisation. (2003, page 762 )

This segment covers some main elements of the phenomenon of hardening. In fact, Anderson and Levy (2003) described the core of hardening, when they argue that older injecting drug users become marginalised among the marginal.

Also elsewhere in the literature several aspects of hardening have been described before (Anderson \& Levy, 2003; Gtapendaal et al., 1995; Grund, 1993; Preble \& Casey, 1969; Vetbraeck, 1984). The yeats of these publications also show that hardening is not a time-bound phenomenon. Back in 1969, Preble and Casey argued that to surwive in the drug scene, a heroin user has to be "allat, flexible and resourceful". 'They also stressed the instrumentality of social relationships:

Usually, addicts today will associate in pairs (partners), but only for practical purposes: in a criminal effort which requires two people (as when one acts as lookout, while the other commits a burglary), to share in the price of a bag of heroin, to assist in case of an overdose of drugs, to share the use of one set of works (the paraphernalia used to inject heroin). Thete is no longet a subculture of addicts based on social cohesion and emotional identification, but tather a loose association of individuals and parallel couples. Heroin users commonly say, "T have no friends, only associates." (1969, page 8)

The aspects of instrumentality, the lack of solidarity and developing illegal activities to gather money for drugs is also emphasised by earlier as well as curtent Dutch ethnographic researchers (Grapendaal et al, 1995; Verbracck, 1984).

In the present study, we agree with Anderson \& Levy about the stressful circumstances in today's drug scene and the need of survival skills. In addition, we acknowledge that especially older injecting drug users take an increasingly marginal position within the drug scene. However, our population of chronic drug users was more diverse and therefore out descriptions show more vatiations in how they adapt to the hectic circumstances of the drug scene. Although our study population consisted for a large patt of older heroin users, we could differentiate between drug users placed high or low in the hierarchy. However, this is not to say that the older drug users are always the weakest or most marginalised. On the contrary, we noticed that older drug users had already adapted to their (manginalised) lifestyle, while new or younget drug users first had to "fight" for their place in the hierarchy (see also Chapter 3). 
All in all, although the aspects of instrumentality, lack of solidarity and the developments of certain skills and abilities have been described in the literature, to out knowledge these aspects have never been integrated in a systematic description of one phenomenon: that of hardening. This study aims at describing the process of hardening as a process of adlaptation to the drug scene in which the aspecrs of instrumentality and the developments of economic skills are invaluable means to survive.

\subsection{Guide to the text}

The core concepts of marginalisation and hardening are developed using data that were gathered by ethnographic fieldwork, one of the pillars of the Drug Monitoring System (DMS). Other pillars, such as interviews with key informants and a survey sample, were used to complement and verify the ethnographic field data. In Chapter 2 the DMS is explained and its scientific basis is discussed by means of several "trustworthiness" criteria (Lincoln \& Guba, 1985). Especially the value of triangulation, i.e. the combination of quantitative and qualitative methods, is extensively elaborated in this chapter.

In Chapter 3 the theoretical concepts of marginalisation and hardening are elaborated. The process of deteriorating relationships with society (marginalisation) and deteriorating relationships between drug users (hardening) is explained by means of the Parkstad Limburg ethnographic data. The information in this chapter provides the basis for all remaining chapters.

In Chapter 4 the influence of the local context is explored in order to determine whether local scenes of chronic heroin users ate characterised by marginalisation and hardening alone or complemented by counteracting movements.

Chapter 5 focuses on the role of homelessness in the process of marginalisation towards hardening. In this study homelessness is seen as an important turning point in the process of marginalisation that on the one hand fundamentally decreases possibilities to reintegtate in society and, on the other, exposes the drug user 24 hours a day to hardening. While the theoretical framework was developed using qualitative data, in this chapter quantitative data were used to place certain qualitative observations into a population perspective. In this study, crack appeared to have amplifying affects on processes of marginalisation and hardening. In Chapter 6 these deteriotating effects of crack aniong chronic heroin users are further explored and related to more contextual factors, such as the circumstances where drugs are consumed and the local drug policy. For this part of the study ethnographic and survey data of Parkstad Limburg and Rotterdam were used. 
Another important influencing factor on marginalisation and hardening is a repressive local drug policy. In Chapter 7 the potentially deteriorating impact of repression is elaborated by means of survey data gathered in 2002, ethnogtaphic field data, and interviews with key informants and dnig users.

Finally, in Chapter 8 the main conclusions are summarised and related to the research problems. The value of this study is placed in a methodologicall and a theoretical perspective and implications are described for (future) drug policy.

\section{References}

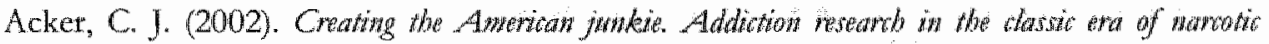
control. Baltimore, Maryland: The Johns Hopkins University Press.

Amaro, H., \& Raj, A. (2000). On the margin: Power and women's HIV risk reduction strategies. Sex Rolts, $42(7 / 8), 72349$.

Anderson, T. L., \& Levy, J. A. (2003), Marginality among older injectors in today illicit drug culture: Assessing the impact of ageing. Addition; 98, 761-70.

Barendregt, C., Lempens, A., \& van de Mheen, D. (2000). Drugs kopen op strat. Achtergronden en motieven wan Rotterdamse druggebruikers die bij stratdealers kopen/ Buying drugs at the street. Background and motwes of Rotterdam drug users who buy from street dealers. IVO Bulletin, 3 (1), 1-19.

Barendregt, C., van der Poel, A., \& van de Mheen, D. (2003). De mobiele telefoon in de harddrugsscene van Rotterdan/ The cellular phone in the Rotretdam hard drug scene. IVO Bulletin, $6(1), 1-20$.

Barendregt, C. P., Blanken, P., \& Zuidmulder, I. J. (1998). Drugshandel en oxerlast int Rotterdam. I/O bullktin, jaargang 1 (2), 1-24.

Becker, H. S. (1963). Ottsiders. Studies in the sociology of deniance. Oxford, England: Free Press Glencoe.

Bellis, M. A., Hughes, K., Bennet, A., \& Thomson, R. (2003). The role of an international nightlife resort in the proliferation of tecreational drugs. Addiction, 98, 1713-21.

Berridge, V. (1999). Opium and the peopte. Opiate we awd drug woutrol polioy in minetemth and warly Awemtieth century England. New York: Free Association Books.

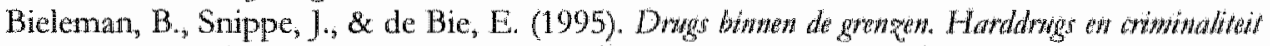

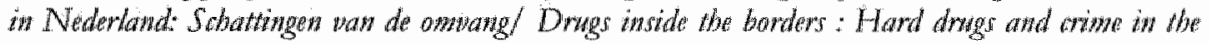
Netherkands: Estimations of the extent. Groningen: Bureau Intrawal.

Biesma, S., Snippe, J., \& Bieleman, B. (2004). Aard, owwang en atwobititeit wan

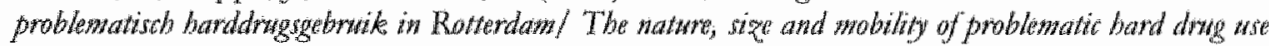
w Rotterdaw. Groningen/Rotterdam: Intraval.

Bongers, I. M. (1998). Problem drineing annong general popwations: A pwblic beals issme. Addiction Research Institute (TVO), Rotterdam.

Bourgois, $P$. (1996). In search of masculinity. British Jownal of Criminology, $36(3)$.

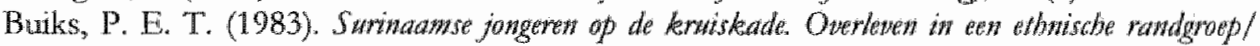

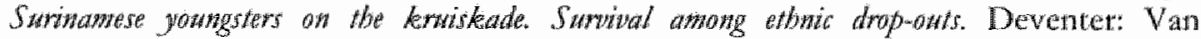
Loghum Slaterus.

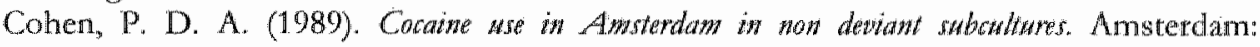
Department of Human Geogtaphy, University of Amsterdam.

Coumans, A. M., \& Knibbe, R A. (2002). Draggebruiken in Parkstad Limburg" Trewds en profielen. Reswitaten wan bet Drag Monitoning System 2001-2002/ Drug wsers in Partestad 


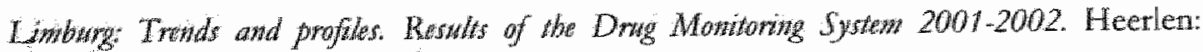
Addiction Reseach Institite (NVO).

Coumans, A.M., Neve, R, \& Mheen van de, D. (2000). Het prowes van marginalisening ext

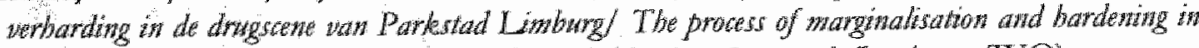
the Parkstad Limburg drag stene. Rotterdam: Addiction Resterch Institute (IVO).

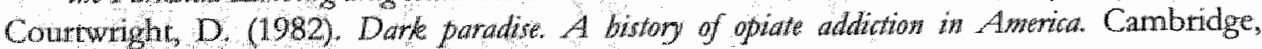
Massachusets: Harvard Unversity Press.

Crewe, M (1997). How marginal is a "marginalised group"? Socid Science o Medicine, 45 (6), $967-70$.

de Kort, $M, \&$ Korf, D.J. (1992). The development of drug trade and drug control in the netherlands: A historical petspective. Crime. Law and Sorial Change, 17, 123-44.

Eddering, I., \& Knorth, E. J. (1997). Marginalisering van allochtone jongeren en insicofactoren in hun dagelijks leven/Marginalisation of cthnic youngsters and risk factors in their everyday life. Kind en Adolesent, 18, $2-14$.

Ford, L. A, \& Yep, G. A. (2003). Working along the margins: Developing communitybased strategies for communicating about health with marginalized groups. In A. M.

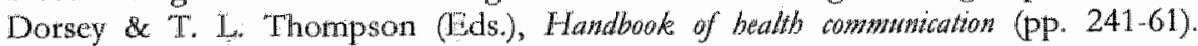
Mawwah, New York: Lawrence Enlbaum Associates, Publishers.

Garretsen, H., van de Mheen, D., \& Wits, E. (2003). Het jaar 2003: Verslavingsbeleid

overschaduwd door velligheidsbeleid/ The year 2003: Overshadowed by a policy of public security. IVO Bulletin, $6(5)$.

Goffman, E. (1963). Singma. New Jersey: Englewood Cliffs.

Golldberg, T. (2001). Becoming a problematic consumer of natcotics. Swbitane Use Miswse, $36(0-10), 1297-322$.

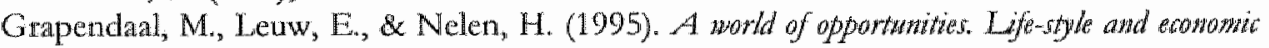
behotwor of beroin addits in ansterdan. New York: State Unversity of New York Press.

Grinspoon, L.., \& Bakalar, J. B. (1976). Cocaine: A drag and its social evolution. New York: Basic Books.

Gruenberg, E. M. (1974). The social breakdown syndrome and its prevention. In G. Caplan (Ed.), Amerian bandbok of psychiatry, part in New York: Basic Books.

Grund, J.-P. (1993). Dizg wse as a sacial ritual. Functionality, symbalim and determinants of selfregulation. PhD Thesis, Erasmus University Rotterdam, the Nethetlands.

Hall, J. M. (1999). Marginalization revisited: Critical, postmodern, and liberation

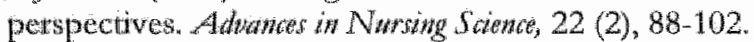

Hall, J. M, Stevens, P. E, \& Meleis, A. I. (1994). Marginalization: A guiding concept for valuing diversity in nursing knowledge development. Adwawes in Nurstigg Sciente, 16 (4), $23-41$.

Hunt, $G_{\text {, }}$ \& Exans, $K$. (2003). Dancing and drugs: A cross-national perspective. Confenporay Drug Problens, 30, 779-814.

Hussong. M. (1998). Marginal institwional partioipation: An agragate examination of sociat control theow. PhD Thesis, University of New Mexico, USA.

Johnstone, M.-I. (2001). Stigma, social justice and the rights of the mentally ill: Challenging

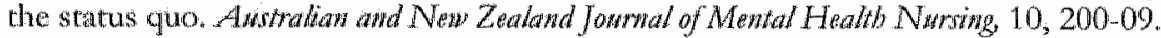

Kaplan, H. B. (1996). Empitical validation of the applicability of an integrative theory of deviant behavion to the study of drug use. Joxthral of Dryg Irsores, 26 (2), 345-77.

Klemke, L. W. (1988). Deviant modes of adaptations to a deviant involvement. Deviant Bebation, $9,225-39$.

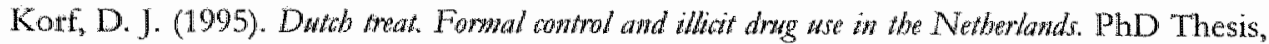
Ansterdam: Thesis publishers. 


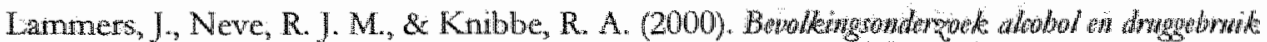

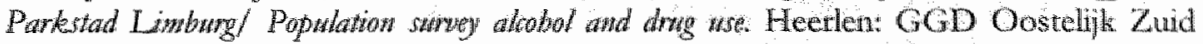
Limburg/Universiteit Masstricht/Addiction Research Institute (IVO) Rotterdarn.

Lempens, A., Barendregt, C., Zuidmulder, L., \& Blanken, P. (1999), Kumerken van Rotterdannse gebruikers: Enkele resultaten wan de survey "drugs, huisvesting, schulden en gezondheid'/ Characteristics of Rotterdam drug users: Some results of the survey 'drugs, accommodation, debts and health'. WV Bulltitin, $2(3), 1-20$.

Lempens, A., Wildschut, J, wan der Most, D., \& Knibbe, R. A. (2003). "wa do twhmlutuing".

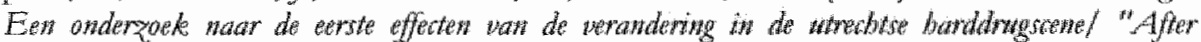

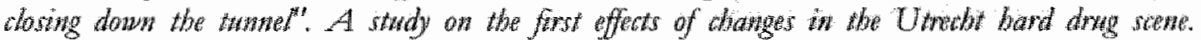
Rotterdam: Addiction Research Institute (IVO).

Lincoln, Y. S., \& Guba, G. (1985). Naturalio ingum. Newbury Park, CA: Sage Publications.

Link, B. G., \& Phelan, J. C. (2001). Conceptualizing stigma. Amwal Remen of Sockogy, 27. 363-85.

Link, B. G., Struening, E. L., Rahav, M., \& Phellan, J. C.. (1997). On stigina and its consequences: Evidence from a longitudinal study of men with dual diagnoses of mental illness and substance abuse. Joumal of Health and Social Bethowor; 38 (2), 177-90.

Maxwell, J. C. (2003). The response to club drug use. Cument Opintos in Pgithatn, 16 (3), $279-89$.

Milboutne, L. (2002). Unspoken exclusion: Experiences of continued matginalisation from education among 'hard to reach' groups of adults and children win the UK. British Jownol of Sociology of Eduation, 23 (2), $287-305$.

Moll, H. \& Sokmans, D. (2005). Generatie heroinegebnikets verdwijnt geruisloos van straat Voor jongeren zijn junks een schrikbeeld/ Whole generation of hetoin users silently disappears from the street. For youngsters junks are a spectre. NRC Handelsblad, 17-01-2005.

Nabben, T., \& Korf, D. J. (1999). Cocaine and crack in Amsterdam: Diverging subculturcs. Jowmal of Drug Issues, 29 (3), 527-652.

Oetring, E. R., Deffenbacher, J. L., \& Donnermeyer, J. F. (1998). Primary socialization theory: The role played by personal traits in the etiology of drug use and deviance: II. Substane Use es Misuse, 33 (6), 1337-66.

Oetring, E. R., Donnemeyer, J. F., \& Deffenlyacher, J. I.. (1998). Primary socialization theory. The influence of the community on drug use and deviance. III. Sishomo Use Miswse, 33 (8), 1629-65.

Olson, T., \& Sanders, R. L. (2000). Ethmicity, marginalusation and mental ilmess in Hawait. Ditablitity è Socaty, $15(3), 463-73$.

Park, R. F. (1928). Human migration and the marginal man. The American fownd of Socklogy, $33,881-93$.

Phillips, J., \& Whyne, J. (1980). Cocaine: Reality of wyth. New York: Avon Books.

Preble, E., \& Casey, J. J. (1969). Taking cate of business - the heroin users life on the strect. Intermational Journal of the Addictions, 4 (1), 1-24.

Rizzini, I. (1995). Children in the streets: Latin America's lost generation. Cbildren and Youdls Senties Rewiew, 17 (3), $391-400$.

Singer, M. (1999). Why do Puerto Rican injection drug users inject so often? Ambropology Medicine, $6(1)$.

Snodgrass Godoy, A. (1999). "our right is the right to be killed". Making rights real on the streets of Guatemala City. Childhood, $6(4), 423-42$.

Sterk, C. E. (2003). Drug research: Ethnogtaphies or qualitative works. International Journal of Drug Poticy, $14(1), 115-18$. 
Switertua, 1 (1987). Heroineverslaving: Levenslang of gaat het vanzelf over Een knart ceuw buitenlandse follow-up studies/ Heroin addiction: Life-long or just passing: A quarter of a century of follow-up studies abrond. Tydstorif wor Alobol. Drugs en Andere Pyibatrope Stoffer, $13(3), 78-92$.

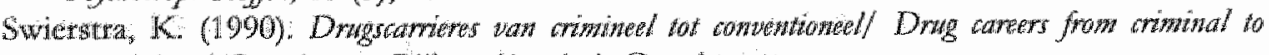
contwentintial Groningen: Rijksuniversiteit Groningen.

wet Bogt, T., Engels, R. Hibbel, B., Wel van, F., \& Verhagen, S. (2002), "dancestacy": Dance and MDMA use in Dutch youth culture. Contemponary Drag Problem, 29, $157-$ 181.

Tucker, M. (1994). Director"s foreword. In R. Ferguson, M. Gever, T. T. Minh-ha \& C.

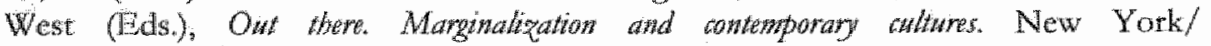
Cambridge/London: The New Muscum of Contempotary Art/ The MIT Press.

van de Wijngart, $\mathrm{G}, \mathrm{F},(1988)$. A social history of drug use in the Netherlands: Policy outcomes and implications. Joumal of Drug Issmes, 18 (3), 481-95.

vart det Velden, T., \& Spierings, $\mathrm{F}^{*}$. (1999). Notite. De deur op slot: Zelf- en woningverwatlozing/ The door locked: Neglecting the self and the home. Gedrag en

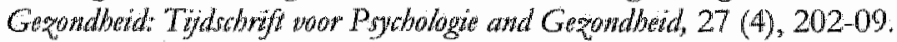

van Gelder, P. J., \& Sijtsma, J. H. (1988). Horse roke en kansen/ Horse coke and opportumites. Ansterdam: Insatute for Social Geography, University of Amsterdam.

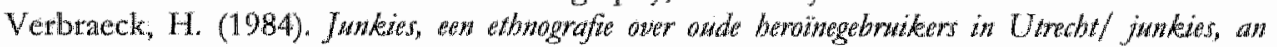
atbrograpby about aged beroin wers in Utretht. Utrecht: Stichting WGU.

Watt, G. (2001). Policies to tackle social exclusion. British Medical Jourmal, 323 (7306), 17576.

Weisberger. (1992). Marginality and its directions. Sociological Dinections 7 (3), 425-46. 


\section{Chapter 2}

\section{A Drug Monitoring System: keeping a finger on the pulse by triangulation of qualitative and quantitative methods}

This Chapter is based on the article "A Drug Montoring System: keeping a finger on the pulse by triangulation of qualitative and quantitative methods", by Dike van de Mheen, Moniek Coumans, Cas Batendregt and Agnes van der Poel (subritted to Addiction Research \& Theory). 


\begin{abstract}
Since the data of the present study were gathered by a Drug Monitoring System, this chapter focuses on the methodology of this research system. A Drug Monitoring System is a locai tesearch system, continuously collecting data on hard drugs, drug users and related issues. The methodology of the Drug Monitoring System combines qualitative and quantitative methods, i.e. community fieldwork, interviews with key informants and a bi-annual drug user survey. The system has been developed inductively: theory and methods were developed from daily practice. The present chapter aims to provide a scientific and methodological foundation for a Drug Monitoring System. In addition, application of the different methods used an a Drug Monitoring System is discussed in relation to the present stidy.

Qualitative research methods are appropriate for reseatch among "hidden populations". Questions with respect to internal and external validity were incopporated in the system by applying the criteria of Lincoln \& Cuba (1985): credibility, transferability, dependability and confirmability, all teferting to the overall criterion of "trustworthiness". "The following strategies have been applied to meet the criteria of "trustworthiness": triangulation, prolonged engagement, persistent observation, member checks, peet debriefing, negative case analyses, thick description and reflexive joumal. Methodological triangullation used in a complementary model appears to be an important tool. In conclusion, a Drug Monitoring System can provide policy makers and care providers with evidencebased information about developments and trends in drug use.
\end{abstract}




\subsection{Introduction}

Monitoring can be seen as a method of signalising trends and developments. An important characteristic of monitoring is its power to combine an epidemiologic and social science approach. It demands a targeted combination of quantitative methods, including the repeated measurement of standardised core indicators, as well as qualitative methods on questions dictated by the empirical social reality at the current time and place. Monitoring gathers continuous information on a specific phenomenon, in our case the use of (hard) drugs; over an extended period of time. The aim is to keep a finger on the pulse.

By monitoring phenomena over a longer period of time, trends can be spotted. This yields important information for policy, prevention programs and treatment. However, the benefit of a monitoring system is not always obvious. Although a monitoring system can be running for a long period of time without any obvious effect in society, such a system can still be fruitful.

To have its use for policy, a monitoring system must be a 'management information system', based on scientific methods. 'This implies that information is gathered, ordered, and analysed on a systematic and continuous basis. In addition, frequency tables and simple analyses must be continuously available, information must be updated frequently, and qualitative data (e.g. ethnographic fieldwork) must be coded and ordered continuously. Theoretically, there is a cyclic process: a monitor provides information for a more evidence-based local drug policy (also with respect to treatment and prevention), and the local drug policy influences the research issues and data collection.

This chapter focuses on a specific kind of monitor, i.e. a Drug Monitoring System. Griffiths et al (2000) described the use of Drug Monitoring Systems, based on work for the European Centre on Drugs and Drug Addiction (EMCDDA). They gave a worldwide overview of existing Drug Monitoring Systems and described their use in terms of operational level, structure, function, range of data sources and investigation methods. One of the systems described by Griffiths et al. is the Dutch Drug Monitoring System (DMS; van de Mheen, 2000).

The DMS is a local research system (carried out in several localities/regions in the Netherlands) continuously collecting both quantitative and qualitative data about drugs, drug users and related issues. The target population is the group of hard drug users. Its small-scale design allows the use of ethnogtaphic research methods to provide insight into situations, developments and trends. The results inform local policy makers, dnu-treatment agencies and others about the dynamics of the local drug scene. The community-based research methods of the monitor allow a quick reaction to developments and give possibilities to effectively describe the effects of policy implementation. The continuous character and the integration of different research methods strengthen the study above the level of just an ad hoc measurement. The main research topics are: characteristics of the drug users' group, buying and using of drugs (type of drugs, location of drug use, route of administration, mechanisms of self-regulation), work and income, housing, and physical and mental health of drug users (Addiction Severity Index problems) 
(Hendriks et al, 1991). Important is the focus of the DMS on the drug user in his or her natural environment, of "the daily life". Within this natural enviromment the meaning of a described phenomenon can be interpreted in its context (setring) (Zimbetg 1984). Important is the focus of the DMS on the drug user in his or her natural enwitomment, of "the daily life". Within this natural environment the meaning of a described phenomenon can be interpreted in its setting (Zinberg, 1984). Data for the DMS are mainly collected by means of reports from communty fieldwotkers, interviews with key informants, and a bi-annual drug user survey. These methods will be described below.

The DMS method was designed in the 1990s (Hendriks et al., 1994), and further developed during daily practice. Experience of researchers and fieldworkers guided the choice of the most appropriate methods, combining sources of information, and creating new methods of sampling and data collection. These give the DMS a substantial practical power, which has proven useful for local policy (van de Mheen, 1999). However, the scientific basis of the monitoring system, especially questions with respect to internal and external validity, has never been documented. The present paper aims to provide a scientific and methodological foundation for a DMS.

Research questions are:

1. What are the main methodological elements in the system?

2. What is the scientific basis of the system in terms of validity?

In addition, this chapter discusses the application of the DMS methodology in relation to the piesent study.

\subsection{Methodology of the DMS}

The DMS combines thee methods that are complementary: a survey among drug users (quantative method), a network of key informants (qualitative method) and community fieldwork (qualitative method). These methodological elements are shown in Figure 2.11 and described in section 2.2.1 to 2.2.3. Section 2.2.4 focuses on the combination of the three methods. 


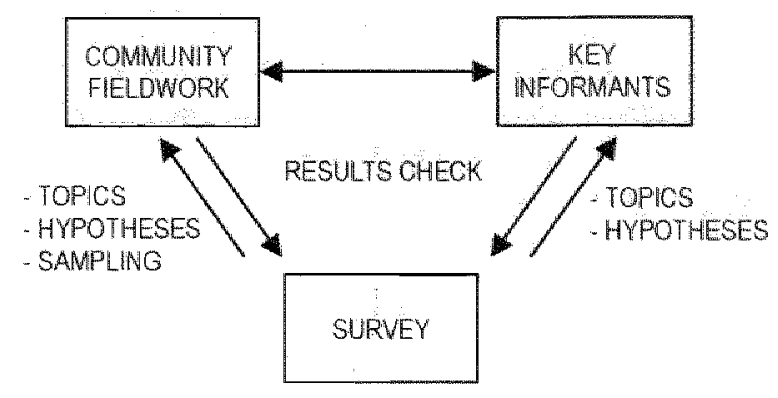

Figure 2.1: Complementary methods used in the Drug Monitoring System

\subsubsection{Survey among drug users}

Initially, information is gathered by surweys among drug users themselves. Depending on the study population and specific research questions the survey uses different methods, e.g. written questionnaires and (semi) structured interviews. The surveys are carried out every two years among 100 to 200 respondents, depending on the size of the local population. Sampling methods used are snowball sampling, network sampling and targeted sampling (for more details see Batendregt \& van der Poel, 2005; Coumans \& Spreen, 2003).

The questionnaire is partly based on the Addiction Severity Index (Hendriks et al., 1991). The duration of one interview ranges from 30 minutes to 1.5 hours. Analyses are conducted by means of SPSS software and comprise simple statistical procedures, such as "descriptives", "frequencies", "cross tabulations" and "ttests". For every bi-annual survey a new sample is taken.

In the present study a mixed sampling design was used consisting of a combination of network sampling, targeted sampling and convenience sampling. We used the 1999 Parkstad Limburg survey sample as a background to: 1) describe the basic processes of marginalisation and hardening (Chapter 3 and Chapter 4), 2) elaborate on the role of homelessness in the process of marginalisation (Chapter 5), and 3) describe the impact of crack on the marginalisation and hardening of chronic heroin users. The survey sample of 2002 provided a quantitative background in order to further describe the street-level effects of local drug policy on marginalisation and hardening. 


\subsubsection{Key informants}

A network of key informants reports regularly about phenomena and developments in and involving drug use, on the basis of their work, position, and memliership of a group, or expert experience. They belong to representatives of care providers, local policy makers, police, different groups of users, and groups related to users (e.g. drug dealers). Each year one or two rounds of formal interviews take place (individual or in focus groups), in which the general monitoring items are complemented with a certain focus, e.g. "mobility" or "health". In addition, key informants report on an informal basis about their findings based on observations of and conversations with members of the study populations.

The network consists of about 10 to 15 key informants. The interviews last on average 1 hour and are done with the help of a pre-structured checklist. All interviews are tape-recorded and typed out verbatim. The most informative interviews, in the sense of focus or perspective of the key informants, are coded and analysed with the software program Ethnograph (Seidel, 1998).

For the purposes of the present study we used interviews that were conducted in 2002 with 11 key informants. These interviews focused on the street-level level effects of a repressive policy on marginalisation and hardening (Chapter 7). However, the value of this particular method is limited because each key informant perceives only one part of reality from their own viewpoint. This limitation means that verification by and support from other sources of information (e.g. survey and fieldwork data) is necessary.

\subsubsection{Community fieldwork}

Community fieldworkers are drug users or ex-drug users who report about events and phenomena of the drug scene. They are familiar with the common concepts and operations from their knowledge and experience with the scene and have easy access to the targeted research group. "They carry ont a gtear part of the DMS fieldwork, and interview drug users for the bi-annual survey. Community fieldworkers play an important role in the DMS. They: 1) describe and localise the population of hard drug users on the local level, 2) make and keep contact with (groups of) users, or to speak generally, develop a "research alliance" between hard drug users and the research team, and 3) are helpful in interpretation of the research data (Blanken \& Barendregt, 1998; Blanken et al., 2000; van de Mheen, 2000). Drug users' participation means that some of them are selected on the basis of their background, knowledge, and experience with drug use and the concurrent life style.

Community fieldworkers are hired on a freelance basis and, after a short training, the development of their ethnographic skills is subject to continuous attention of the researcher. 
In the present study a total of 292 Geld notes were written in the petiod May 1998 to December 2002 by the researcher, by four coordinating fieldworkers, and by five freelance community fieldworkers.

The community fieldworkers and the researcher observe and interact with the drug users in their own natural environment. After each field session these observations and interactions are written down in so-called field notes. In order to distinguish personal thoughts and questions from pure observations or interactions, the field note also contains reflections on these experiences. After writing up the entire field note, the text is structured according to the three elements of observation, interaction and reflection. Each field note is evaluated with the researcher and at the end of each field note the fieldworker is required to formulate at least one question about the content of the note. These questions serve as guidance for future fieldwork sessions. In the present study we noticed that, besides the questions at the end of a field note, our fieldwork sessions were often guided by the actual situation that was encountered.

The field notes are entered in Word and analysed with the software program Ethnograph (Seidel, 1998). For the coding of the data a standardised code list has been cleveloped in accordance with researchers of the Drug Monitoring Systems in Rotterdam and Utrecht. This code list consisted of four columns; the first column contained general codes (such as "police", substances" or "health"), the second. consisted of sub-codes (such as "cocaine", "prices" or "psychological health"), in the third column a short description of the code word and in the foutth column additional remarks were made about how to use the code. In the present study, besides this standardised code list, we also applied so- called 'free coding'. This kind of coding is also called open coding and refers to more specific codes that are not covered by the standardised list. These codes were often more abstract and context related. Examples of open codes used in the present study ate: "hietarchy", "basing", "control", or "stress". All codes were first written down in the margins next to the corresponding text segments and then the codes were imported in Ethnograph.

The next step was to try and achieve abstraction by reflecting on each code and on connecting codes. First, all text segments were printed out in Ethnograph for each code word and read through carefully. This process was guided by writing memoranda, i.e. notes reporting on ideas and recurrent themes "Then the code words were reflected on, connected with similar codes, and then placed in a "code tree" (Figure 2.2). Diagramming was also an important tool used to achicve abstraction. 


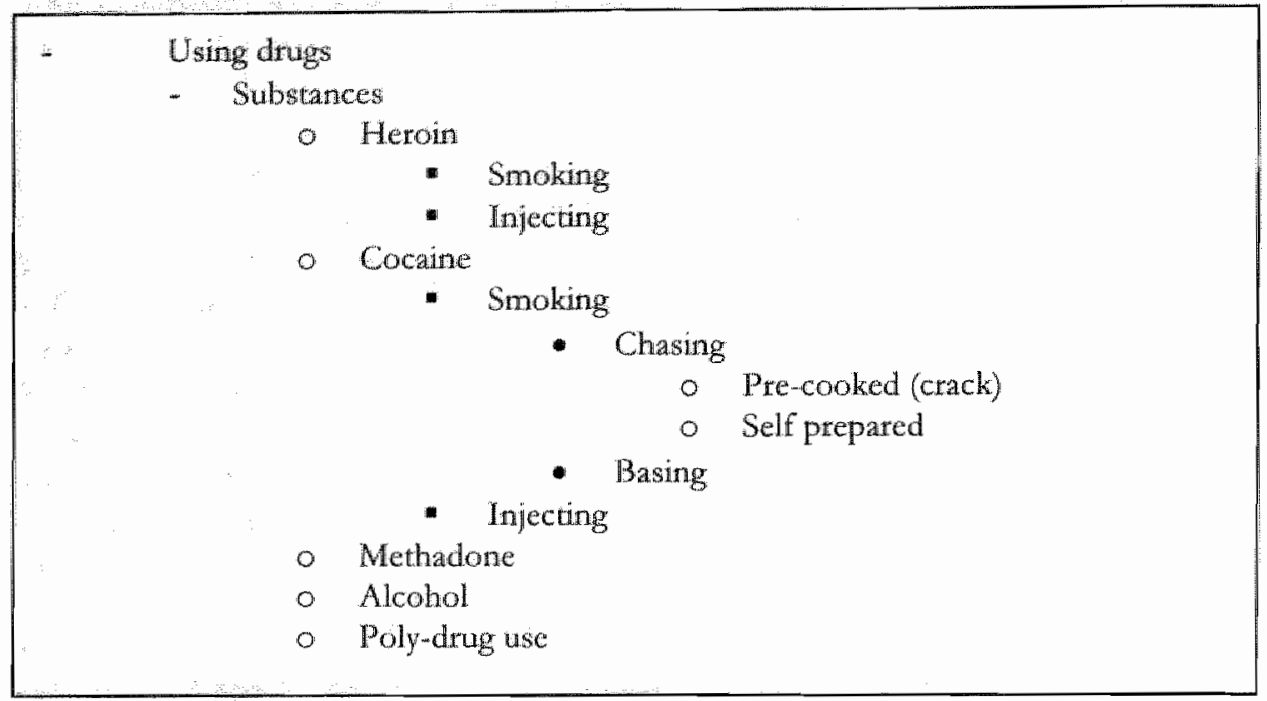

Figure 2.2: Example of one part of a "code tree"

Only when these initial steps have been taken for a considerable part of the field notes (at least 50), does selection of the core categories become possible. Core categories cover what appears to be the most relevant for the DMS and the data that are gathered. In the present study the categortes "marginalisation", "hardening" and "catalysts" appeared to be the thread that connected almost every code. Thus, selection of the core categories did not take place randomly but was based on a systematic procedure, guided by knowledge, intuition and experience. Coding in this phase is also indicated as 'selective coding', which directly leads to the emergence of (core) concepts (i.e. marginalisation, hardening, and catalysts). Agar described this analytic process as follows:

I need to lay out a couple of stretches of transcript on a table so I can look at it all at once. Then I need to mark different parts in different ways to find the pattern that holds the text wogether and ties it to whatever external frame l'm developing. "The software program here would be easy to solve. You'd need to be able to quickly insert different coloured marks of different kinds at different points so you could see the multiple connections across the text all at once, sort of a multithread DNA lays on the text so you could look at the patterns that each thread revealed and then the patterns among the patterns (Agar, 1991 p193 in Seidel, 1998).

The above clearly illustrates the important role of software programs (such as Ethnograph or Kwalitan): i.e. to categorise, sort and select data without being hampered by huge piles of paper requiring the researcher to 'cut and paste'. In the present study, the last step of the analysis consisted of reading the remaining (uncoded) field notes to search for new information, to make some refinements 
and to identify possible deviant cases. This process was also guided by writing memoranda. Whereas initially the memoranda contained all emerging thoughts; ideas and questions, the content became increasingly abstract and finally served as the basis for the final report.

\subsubsection{Combination of methods used in DMS}

The DMS is a research project in which qualitative methods are essential. Drug users can be viewed as a "hidden population". The term "hidden population" euphemistically refers to "those who are disadvantaged and disenfranchised: the homeless and transient, chronically mental ill, high school dropouts, criminal offenders, prostitutes, juvenile delinquents, gang members, runaways, and other "street people"- those we are all aware of to one degree or another, yet know so little about" (Lambert, 1990, page 1). The study of Pearson (2001) among inner city drug users in London (UK) is a good example of research among such a hidden population.

Ethnography is one type of qualitative research and is by nature fundamental and exploratory, and usefull for topics about which little is known. It gives the researcher the opportunity to understand the world as seen by the respondent within the context of the respondent's everyday life (Strunin, 2001).

According to Sterk (2003, page 3): "the applied nature of drug research is ideal for critical ethnography, in which the individuals who are part of the study, through their participation, gain a better understanding of their reality and also insights for potential change".

Qualitative methodology has made an enormous development in the last decades. This development started with the publication of Glaser and Strauss (1967), which explains the "grounded theory", followed by more publications about qualitative methods and analysis (Chenitz \& Swanson, 1986; Denzin, 1978; Miles \& Huberman, 1984). Qualitative methods are useful in the exploratory stages of the research project, where they will help to clarify or even set the research question, provide conceptualisation and generate hypotheses for later research. They may also be used to interpret, qualify or illuminate the findings of quantitative research and to test hypotheses. Qualitative methods are very useful to help policy makers understand the context in which policy will be implemented (Murphy et al., 1998).

Qualitative research methods are applied (at least in the DMS) in different ways, combined with quantitative methods. Firstly, qualitative research is used as a precursor to quantitative research. Secondly, it can be used to explain unanticipated or inconclusive findings from quantitative studies. Thirdly, qualitative research is used to generate hypotheses (Murphy \& Dingwall, 1998). Qualitative methods can also be used independently, i.e. not combined with quantitative methods; however, that is not the case in the DMS.

The importance of qualitative methods in understanding the dynamic nature of the drug scene and relating problems, has become evident from the literature (Lambert et al., 1995). Also in the public health and epidemiology the monopoly of 
quantitative research has been replaced by a growing attention for qualitative research (Bourgois, 2002; Jones, 1995; Mackenbach, 2001; Savage, 2000). Classical epidemiology can be seen as a "black box": it produces figures that do not provide insights in the mechanisms of causality (Mackenbach, 2001). In (social) drug research quantitative and qualitative researchers have a great deal to offer each other. Bourgois (1985) formulates this as follows: "The absence of a dialogue between epidemiological and qualitative researchers - especially ethnographers who engage in cultural anthropology's version of participant-observation methods - is a failure from the perspective of both pragmatic positivism of public health and also the critical theory of anthropology".

\subsection{Validity or "Trustworthiness"}

According to Lincoln \& Guba (Lincoln \& Guba, 1985, page 301) we use different terms to refer to the naturalistic (or qualitative) equivalents of the validity criteria that are used in quantitative research. All these different terms refer to the overall criterion of "trustworthiness".

The equivalent of internal validity in quantitative research can be found in credibitity: the probability that the findings will be found to be credible and to be apptoved by the "constructors of the multiple realities being studied" (Lincoln \& Guba, 1985). The equivalent of external validity can be described as transferability, or: to what extent can we transfer the findings to other contexts? Strictly speaking it is impossible to reach external validity by qualitative research (Lincoln \& Guba, 1985, page 300). However, we afgue that transferability is achieved by the generalisation of theoretical statements, which may guide policy makers but have to be tested through application in other contexts. Dependability in qualitative research accounts for the quantitatively used criterion of reliability in terms of (in)stability and "factors of phenomenal or design induced changes" (1985). Comfinmability is the qualitative equivalent of objectivity; it emphasises the characteristics of the data, instead of the characteristics of the researcher.

In the DMS, according to Lincoln \& Cuba (1999), several strategies are performed to meet the trustworthiness criteria. To meet the criterion of credibility and dependability, we used triangulation, prolonged engagement, persistent observation, member checks, peer debriefing, and negative case analyses. "To account for the criterion of transferability, we applied "thick description", and confirmability was accounted for by writing a reflexive journal.

These techniques are described below; we start with triangulation since it applies to the DMS as a whole. 


\subsubsection{Triangulation}

Triangulation is the combination of different sources leading to better knowledge or, according to Nutbaum (amongst others Denzin, 1978), it gathers evidence from different sources: the more consistent the evidence from different sources, the more the validity of the results can be presumed. In other words: triangulation is a method applying more than one approach to answer the same stent the evidence from different sources, the more the validity of the results can be presumed. In other words: triangulation is applying more than one approach to answer the same question.

Commonly, the following forms of triangulation are distinguished (Kelle, 2001):

- Triangulation of data: different sources of information are used deriving from, e.g., client dossiers, minutes of meetings, publications and interviews with key informants

- Triangulation of researchers: more than one researcher is involved in data collection and analysis. This may be useful if researchers have different theoretical or methodological backgrounds

- Triangulation of methods: different methods (usually quantitative and qualitative) are used to study the research subject, e.g. focus groups, individual interviews, participant observations.

Triangulation does not represent a single methodological concept but has different understandings, of which the twomost commonly used are that of triangulation as mutual validation, and triangulation as the integration of different perspectives on the same investigated phenomenon (complementary model) (1978).

Denzin (1998) and Maxell (Maxell, 1998) define triangulation in the sense of checking the validity and reliability of the findings (mutual validation). As opposed to relying on one single form of evidence or perspective as a basis for findings, multiple forms of diverse and redundant types of evidence are used to reduce the risk of systematic distortions inherent in the use of only one method (Denzin, 1978). Methodological triangulation refers to a synergetic effect: evidence from different sources increases the confidence in research findings. Or, in other words: a hypothesis which has survived a series of tests with different methods could be regarded as more valid than a hypothesis tested only with one single method (Morse, 1991; Murphy et al., 1998).

However, other authors warn against the use of triangulation in this way (Kelle, 2001). Research results would only be usable for mutual validation if they relate to the same phenomenon, since only then can different results correctly be interpreted as indicators of validity problems. If one method is related to a different aspect of the same phenomenon, or even a different phenomenon, then one should expect a different result. In that case the methods are complementary (1991; 2000; 2003). Morse (Morse, 1991)emphasises the complementary model. This is the use of at least two methods, usually qualitative and quantitative, to address the same research topic. Or, in other words: emphasises the 
complenentary model: This is the use of at least two methods, usually qualitative and quantitative, to address the same research topic. Or, in other words: information from one data source can provide background information for another data source, or control or supplement data from another source. When a single method is inadequate, triangulation is used to ensure that the most comprehensive approach is taken to solve a research problem. According to Morse, methodological triangulation can be classified as simultaneous or sequential. Simulitaneous means that qualitative and quantitative methods are used at the same time: there 1 s limited interaction between datasets during the data collection; findings complement each other at the end of the study. Sequential means that results of one method are essential for planning the next method. Qualitative methods are completed before the quantitative methods are implemented or vice versa. Methodological triangulation is a method of obtaining complementary findings that strengthens research results and contributes to theory development rather than duplicating findings (1967).

In our DMS the model of complementarity is mote appropriate than the model of mutual validation. We combine qualitative and quantitative methods to supplement each other. Neither qualitative nor quanutative methods used as a single method provides sufficient information to describe or understand the complete social process. The different methods relate to different aspects of the same phenomenon. The phenomenon under study is the scene of hard drug users. The information gathered from key informants (qualitative interviews), community fieldwork (qualitative participant observations), and a survey among drug users (quantitative questionnaires) elucidates different views (e.g. the perspective of the drug users, the perspective of environment) on the same research subject.

In the DMS we had no a priori theoretical framework. The process is primarily inductive, and qualitative methods have the highest priority. An inductive process means that the theory is developed qualitarively and complemented by quantitative methods. The process is more sequential than simultaneous; this is shown in Figure 1. For example, information from key informants and community fieldwork influences the focus of the bi-annual survey among drug users. "This fits with the original ideas of Glaser and Strauss (Watters \& Biernacki, 1989) that results obtained by qualitative methods ate particularly well suited to develop theory. The results can guide survey researchers in both $s$ in both sample construction and research question development (1985, page 314).

\subsubsection{Other techniques in the DMS}

Prolanged engagernent implies considerable investment (above all, time) to know the culture of the drug scene and to develop trust. To prevent distortions, in the DMS the fieldworkers interact with drug users in their own environment (e.g. lowthreshold services or dealing addresses). Fieldworkers had to decide whether they preferred to be a "fly on the wall", or a "wasp" constantly asking (sometimes annoying) questions. A potential pitfall of this latter technique was "going native"; 
to over-identify with the research subject and thus lose the research perspective. In the DMS we tried to prevent this, for example by not taking part in an interest group for drug users. Persitent obsenation implies that only things that ane relevant are incorporated in the study. In the DMS it was important to develop antentas to drstinguish between relewant and irtelevant issues. Therefore we used the basic questions of the DMS (see Introduction, section 2.1), and the specific questions the fieldworker was required to formulate at the end of each field note. A possible pitfall is "premature closure", or focusing too soon on specific issues. In the DMS, this meant maintaining an open mind for new phenomena, such as an increasing number of youngsters using crack. According to Lincoln \& Guba "the mewber beck is the most crucial for establishing the credibility of the findings" (Geertw, 1973). Data, analytic categories, interptetations and conclusions are tested with members of the research population. Reconstructions made by the researcher must be recognisable to the respondents. In the DMS this meant that dnig users were offered an opportunity to respond to the research findings. This was accomplished by, e.g, organising a focus group for key informants and drug users in which the findings were presented. Peer debriefing means that in all phases of the research the researcher discusses his or her thoughts, ideas, analyses and conclusions with a "peer": a (colleague) researcher who tries to play the devil's advocate. The goal of this technique is to explicate important aspects (e.g. wotking hypotheses) that might otherwise remain implicit in the head of the researcher. In the DMS, researchers from different cities played the role of each other's peer and an external advisor was employed to (temporarily) play the tole of a peet without judging the researcher.

Negative case andyris means that, similar to statistical tests, findings are more and more generalised to all cases during the process, by actively seeking deviant cases. After studying these cases, the hypothesis can be (re)adjusted until it covers all cases without exception. In the DMS this technique implied that we tried to describe all categories of drug users, including all possible variations. Thick description (1985) holds that descriptive data describing certain themes in a pithy way ate incorporated in the report; the intention is that interptetations and findings be strengthened by these data thus made more credible. Such consideration about the data enables an outstander to judge whether of not transfer to another context is appropriate. In the DMS we used quotations from interviews and field notes to support descriptions of the topic of interest.

Finally, the reflexive jowmal is a general strategy, which can be applied to account for all criteria and can also be used in quantitate research. There are several possible applications of this technique: e.g. the researcher makes notes about his or her own behaviour and personal thoughts and considerations, and/or keeps a record with methodological decisions. In practice this meant that during the DMS survey a log book was kept, and the field notes allowed room for personal reflections on the observations. 


\subsection{Conclusions}

This chapter presents scientific evidence for the methodology of (particularly) drug monitoring. We defined a monitoring system as a "management information system $^{\text {"n }}$, based on scientific methods. The aim is to keep a finger on the pulse, and thereby signal trends and developments.

The methodology of the DMS combines qualitative and quantitative methods, i.e. community fieldwork, intervicws with key informants and a bi-annual drug user survey. Qualitative research methods, especially ethnographic research, appear to be appropriate methods for research among "hidden populations", and thus for the DMS.

We showed that, although our Drug Monitoring System was not developed from an a priori theory, there is a sound scientific methodological basis for the results it has yielded and will yield. The system has been developed inductivelly: theory and methods were developed from daily practice. Questions with respect to internal and external validity are incorporated in the system, by applying the criteria of Lincoln \& Cuba : credibility, transferability, dependability and confirmability, all referring to the overall criterion of "trustworthiness". We showed that in a DMS it is possible to include strategies to meet the criteria of "trustworthiness": triangulation, prolonged engagement, persistent observation, membet checks, peer debriefing, negative case analyses, thick description, and a teflexive journal.

Especially the technique of triangulation is an important tool in a drug monitoring system. In our system we used methodological triangulation in a complementary model. That means that information gathered with one method is used to supplement the results from other methods, and to provide background information for, or to study in depth the results from, other methods. We believe that this model is more appropriate in drug monitoring than the validation model, in which the aim is to duplicate findings (checking validity) by use of other methods.

Generalisability of transferability is shown to be of importance in qualitative research where the theoretical statements are applicable to other target populations. In our case, theoretical concepts of marginalisation and hardening which are important in the drug scene under study, can be applied also to populations of, e.g., alcoholics or homeless people.

We conclude that it is possible to develop an integrated drug information system, in which data collected from different sources and by different methods are subsequencly evaluated, that has a scientific methodological basis. Such a monitoring system can provide policy makers and care providers with accurate information about developments and trends in (hard) drug use, which serves a more evidence-based local drug policy, also with respect to treatment and prevention. 


\section{References}

Barendregt, C., \& van der Poel, A. (In Press). Tracing selection effects in three nonprobability samples. Journal of Swbatane Uire.

Blanken, P., \& Batendregt, C. (1998). Veranderingen in de aanbod-en vtaagzijde van de illegale drugsmarkt in Rotterdam: Enkele resultaten van het Rotterdams Dnug Monitoring Systeem 1995-1997/ Changes ins supply and demand on the illegal drug market: Some results of the Rotterdam Drug Monitoring System 1995-1997. MVO Bulletin, 1 (1), 1-11.

Blanken, P., Barendregt, C., \& Zuidmulder, L. (2000). Community Fieldwork: Bringing

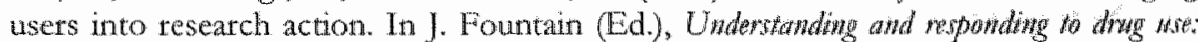
The rote of qualitative reseants. Lisbon: EMCDDA.

Bonrgois, P. (2002). Anthropology and epidemiology on drugs: 'The challenges of crossmethodological and theoretical dialogue. Intemational jownal of Drag Polwo, 13, 259-69.

Chenitz, W. C., \& Swanson, J. M. (1986). From practice to growded heop. Qwallatiw westam in mursing. California: Addison-Wesley Publishing Company.

Coumans, A. M., \& Spreen, M. (2003). Drug use and the role of homelessmess in the process of marginalization. Swbstace Usa Misuse 38 (3-6), 311-38.

Denzin, N. K. (1978). The researth at. Chicago: Aldine.

Geertz, C. (1973). Thick description: Toward an interpretative theory of culture. In Geerta, C. (Ed.), The interpretation of calthms (pP. 3-30), New Yonk: Basic Books.

Glaser, B. G., \& Strans, A. L. (1967). The dirconety of grounded theory: Strategites for qualitative reseanh. New York: Aldine.

Giviffths, P., Vingoe, L., Hunt, N., Mounteney, J, \& Hartnoll, R. (2000). Drug information systems, early warning and new drug trends: Can Drug Monitoring Systems become

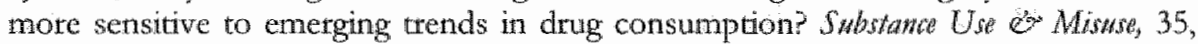
811-44.

Hendriks, V. M., Blanken, P., Adriaans, N. F. P., \& Vollemans, L. C. (1994). Cowitinue

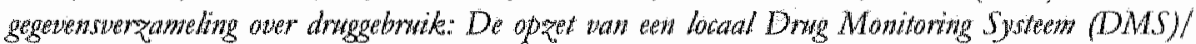
Contimous datarollection about drwg ase: The design of a local Drug Monitoring Systen (DMS). Rotterdam: Addiction Research Institute (IVO).

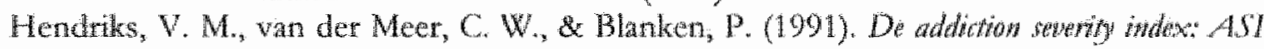

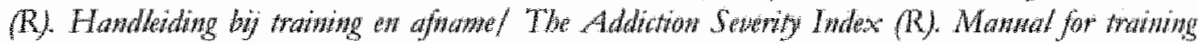
and adminstering Rotterdan: Addiction Reseatch Institute (TVO).

Jones, R. (1995). Why do qualitative researche Brivis Medial Jowntol, 311 (2).

Kelle, U. (2001). Sociological explanations between micro and macro and the integration of

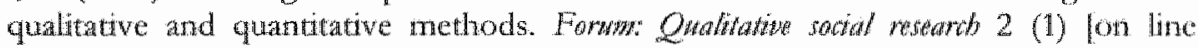
journal. 2005, from hrtp/Lualicative-rescarch net/fgs/fgs-cnghtom

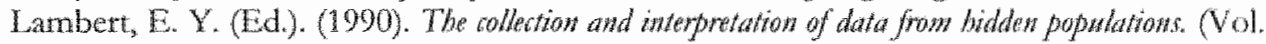
NIDA Rescarch Monograph 98). Rockville: NDDA.

Lambert, E. Y., Ashery, R. S, \& Needle, R. H. (Eds.). (1995). Qwalitwive methods in drug abuse and HTV researh Nol. NIDA Research Monograph 157). Rockville: NIDA.

Lincoln, Y. S., \& Guba, G. (1985). Naturalistic inquing. Newbury Park, CA: Sage Publications.

Mackenbach, J. P. (2001). Paradigma, succes en toekomst van de matschappelijke gezondheidszorg/ Paradigm, success and futute of public health. Tydsobrft Sociate

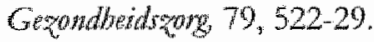

Maxell, J. A. (1998). Designing a qualitative study. In L. Blickman \& D. J. Rog (Eds.), Handbook of applind soctal researb mothods. Thousand Oals: Sage Publications. 
Miles, M. B. \& Huberman, A. M. (1984). Quaditatitu data anabysis. A sounce bare of wew wathods. Beverly Halls: Sage Publications.

Morse, I. M (1991). Approaches to qualitative-quantitative methodological triangulation. Nursing Researth, 40, 120-23.

Morse, J. M. (2000). Qualitative generalisibility. Quafinative Health Rexearb, 9, 5-6.

Morse, M (2003). Principles of mixed methods and mulwimethod research design. In A. Tashakkori \& C. Teddlic (Eds.), Hondbook of mixed wathod. Thousand Oaks: Sage Publications.

Murphy, II, \& Dingwall, R. (1998). Qualitative methods in health services research. In

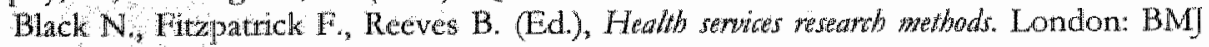
Publications.

Murphy, İ, Dingwall, R. Greatbatch, D., Parker, S., \& Watson, P. (1998). Qualitatiwe research methods in health technology assessment: $A$ review of the literature. Health Telonology Assesswen, 2, 1-273.

Nutbaum, D. (1999). Evaluatie vain ootzak en gevolg in gezondheidsberonderingsprojecten. aanpassing van onderzocksmethoden an interventiemethoden/Evaluating cause and effect in health promotion programs: Matching rescarch methods to

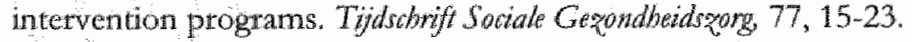

Pearson, G. (2001). Nomal drug use: Ethnographic fieldwork among an adult network of recreational drug users in inner London. Substance Use Misuse, 36, 167-200.

Savage, J. (2000). Ethnograpty and heal th care. British Medical Jommal, 321, 1400-02.

Seidel, J. (1998). Ethnograph W5.0 a user's guide. Thousand Oaks/ London: Scolari, Sage Publications Software.

Sterk, C. E. (2003). Drug reseatch: Ethnographies or qualitative works. Intemational Jonnal of Drug Polig, 14 (1), 115-18.

Strunin, L. (2001). Assessing alcohol consumption: Developments from qualitative research methods. Sodal Saina er Medicine, 53, 215-26.

van de Mheen, D. (1999). Netherlands reseanch and development on substance wse and addiction. Paper presented at the Netherlands Addiction workshop and Binational Symposium on Drug Abuse, October 19-20.

van de Mheen, D. (Ed.). (2000). De Rotterdanse dragscene onder de loup. Resultaten vas 5 jaar drug

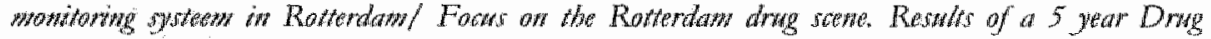
Monitoning System in Rotordam. Rotterdam: Addicion Research Institute (IVO).

Watters, J. K, \& Bienacki, P. (1989). Targeted sampling: Options for the study of hidden populations, Social Problems, $36,416 \cdots 30$.

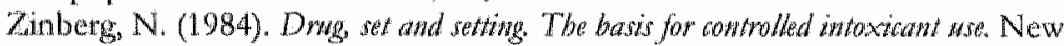
Haven/London: Yale University Press. 


\section{Chapter 3}

\section{The process of marginalisation and hardening: an ethnographic study among chronic heroin users}

This chapter is based on the article "The process of marginalisation and hardening. An ethnographic study among chronic heroin users", by Moniek Coumans, Ronald Knibbe and Dike van de Mheen (submitted to Addiction Research \& Theory). 


\begin{abstract}
The life course of chronic heroin users can be described as a process of matginalisation and hardening. This process is negatively influenced by two socalled catalysts: use of crack and homelessness. 'The ethnographic method, complemented by survey data of chronic heroin users $(n=103$ ), has been used to substantiate marginalisation and hardening.

Marginalisation is a process in which the drug user loses connection with primary relationships and core institutions of society. Hardening refers to the development of specific skills in order to survive witbin the tough world of the drug scene. The results of this study offer insights into our how drug users manage their daily lives in relation to both the larget society and the drug scene, and may have important implications for decision-making related to a successful drug policy.
\end{abstract}




\subsection{Introduction}

Although there has always been considerable interest in the natural life course of drug user (Anderson \& Mott, 1998; Biernacki, 1986; Goldberg, 2001; Grapendaal et al., 1995; Klingemann, 1999; Prins, 1995; Rosenbaum, 1981; Swierstra, 1987; 1990; Yares, 1990) these studies concentrated mainly on the initial or the final phases of their careers and to a lesser extent on the acrual processes of deterioration and adaptation to new circumstances.

The present study focuses on (nearly) daily users of heroin, cocaine and other drugs and aims to characterise the various shifts in their position in society and changes in the relationships between chronic heroin users in order to better understand their life course.

Data were gathered by ethnographic fieldwork in the Dutch region of Parkstad Limburg, which is located in the south of the Netherlands near the borders of Germany and Belgium. Parkstad Limburg comptises the city of Heerlen and seven surrounding municipalities (about 300,000 inhabitants), and is nationally known as a drug problem area. The drug-using population and the related problems are mainly concentrated in the city of Heerlen.

A grounded theory approach to our ethnographic fieldwork data showed that a drastic deterioration covering all aspects of life can be observed among chronic heroin users. Two types of deteriotation emerged from our data; i.e. a deterioration in the social position of chronic heroin users within society, and a detetiotation in the position a drug user needs to acquire within the population of chronic heroin users.

Generally speaking there is some consensus that negative consequences of drug use should be understood in terms of interactions between the effect of the drug itself, the individual who uses the drug (set), and the social context of the drug users (Zinberg, 1984). However, only few studies describe more specifically from the perspective of the drug users how deterioration actually takes place and how it is linked to the social position of the drug user. In the present study we chose to use "marginalisation" as an umbrella term to refer to the actual process of deterioration of social contacts, economic circumstances and health, as well as to the dynamics behind this deterioration as expressed in the social reaction of society. We distinguish three dimensions to describe the deterioration of chronic drug users in society: i.e. social contacts, economic circumstances and health.

Regarding the deterioration of relationships between heroin users, we observed that this process starts with the drug user's dependence on the hectic drug scene to obtain drugs, and becomes more apparent when they lose the economic and social resources to withdraw from that scene. We have used the term 'hardening' to indicate this latter process. Most studies that focused on how drug users manage their daily life did not systematically describe the development of relationships between chronic heroin users. (Buiks, 1983; Grapendaal et al., 1995; Grund, 1993; Grund et al., 1991; Hughes et al., 1974; Johnson et al., 1985; Preble \& Casey, 1969; Sterk, 1999; Sterk-Elifson \& Elifson, 1993; Verbraeck, 1984; 1990). The present study focuses on the influence of social processes (more specifically on the social 
network) and economic functioning (more specifically on how to get money) on the deterioration between chronic drug users. Thus, hardening has the same dimensions as marginalisation. Since the deterioration in health coincides more with a change in social position in society than with social processes between drug users, with respect to hardening only the social and economic dimension are elaborated.

In addition more specific factors that increase the degtee of deterioration, which we refer to as catalysts, ate addressed.

The research questions of this study were:

1. How is the shift in the social position of chronic heroin users related to deterioration in social, economic and health aspects?

2. How ate the changing social relations between chronic heroin drug users related to deterioration in social and economic functioning?

3. Which specific factors increase the rate of deterioration of chronic heroin users?

\subsection{Methodology}

This study uses data from the Drug Monitoring System (DMS), a Dutch project for signalling trends and developments in urban drug scenes. The DMS gathers ethnogtaphic data, survey data among samples of drug users, and data from interviews with key informants. Since we focus on the perspective of the drug user, data from key informants are not used in this study.

\subsubsection{Ethnographic fieldwork}

For the DMS in Parkstad Limburg (1998-2000) eight community fieldworkers gathered data by participant observation on a (nearly) daily basis. Community fieldworkers were selected for their knowledge of and experience with the drug users' lifestyle, and their connection to networks of drug users. Five fieldworkers were actual drug users and therefore could visit locations that others could not easily access; being a member of the study population they were highly suitable to reflect the view of the drug users. However, the use of "indigenous interviewers" is known to produce some practical and ethical problems. Power et al. (1996) mentioned the need for carefull recruitment, training and supervision, and the potential for relapse. However, since we used drug users as community fieldworkers and interviewers, relapse is less relevant in our case. Moreover, recruitment was done by carefully interwiewing several candidates, then each fieldworker was trained 'on the job' and was closely supervised at least once a week.

After each fieldwork session the fieldworkers wrote down their observations (which resulted in 119 freld notes) in the form of observations, interactions, and reflections. Reflections refer to all the questions and thoughts the fieldworker has 
about their observations and interactions; these served as first analyses in order to keep the observations and interactions pure. At the end of each field note questions emerging from the reflections were written down with the aim to guide the subsequent fieldwork sessions. "This structuring of the process of data gathering was used to facilitate a grounded theory approach (Strauss \& Corbin, $1990)$, by which the theory gradually emerges from a continuous process of observation, interaction and reflection. The fieldwork data were entered in Word and analysed with the sofware progtam Ethnograph V5.06 (Seidel, 1998).

\subsubsection{Survey}

We used data from a sample survey $(n=103)$ held in 1999 among (nearly) daily users of opiates (heroin and methadone) and other drugs (crack). The survey had a mixed sampling design; i.e. consisted of a combination of network sampling, targeted sampling and convenience sampling.

The methodological background of the nerwork sample is described in detal elsewhere (Coumans \& Spreen, 2003; Spreen, 1999; Spreen \& Coumans, 2001). Of the 103 respondents, 40 were randomly recruited from a list of 435 users registered by the local drug agency. Another 21 drug users (alters) were wandomly selected from a list of drug users who did not visit the aid agencies but were named by the 40 original respondents. Because we aimed to include at least 100 drug users, we approached an additional 27 participants by targeted sampling. This means that we recruited respondents by approaching drug users at their regular locations and asked each thitd person to participate. Since we expected an under-representation of heroin prostitutes, an additional 15 respondents were approached at locations where prostitutes work (convenience sampling').

The 40 registered clients were approached by local social workers, received written information and were asked to sign a consent form. The reward for the interview was 15 guilclers (66.82). At the end of the interview the respondents were asked to mention an additional (maximally) 10 users. Pet respondent, two nonregistered users were randomly selected of which one had to be approached by the respondent. This respondent could then earn an additional 15 guilders (66.82) by contacting the fieldworkers with the selected alter. All 21 alters that could be reached participated; 19 of the respondents either did not name any non-registered drug users, or those that were mentioned could not be traced.

The respondents were interwiewed by 8 interviewers $(6$ were drug users themselves and 2 were members of the research team) who had been intensively trained for this job.

The questionnaite was based on earlier DMS studies in Rotterdam (Lempens et al., 1999) and on the Addiction Severity Index (Hendriks et al. 1991). One section addressed individual characteristics (demogtaphics, living circumstances, income, debts, drug-using behawiour, health and help-seeking behaviour) and the second part asked for information about the alters and was specifically constructed to estimate the size of the population. 
Each intervicw lasted 1 to 1.5 hours. Simple staristical analyses were conducted with SPSS sofrware and comprised simple statistic procedures, such as 'descriptives', "frequencies', 'cross-tabulations' and 't-tests'.

\subsection{Results}

\subsubsection{Background characteristics}

Using several types of estimators, the number of drug users in Parkstad Limburg has been estimated to be 800 (Spreen, 1999; Spreen \& Coumans, 2000; Spreen \& Coumans, 2001).

In our study population the mean age was 37 years (standard deviation 8 years) and $75 \%$ was male. The majority $(76 \%)$ was Dutch of origin; the remainder being from other European countries $(16 \%)$ or from outside Europe $(8 \%)$. Most drug users used at least heroin $(88 \%)$ or cocaine $(80 \%)$ in the month preceding the interview. About $50 \%$ of the sample used methadone, $78 \%$ also smoked crack, and $40 \%$ also injected their drugs.

Additional demographic details on income, employment status and place of residence are reported in the sections addressing marginalisation (see 'Economic dimension'), hardening (see 'Getting money') and homelessness.

\subsubsection{Marginalisation}

\section{Losizg control}

The process of marginalisation starts when a drug user loses control of their drug use. The fieldwork revealed that it is impossible to determine one precise moment when this occurs, but that for a considerable time many opportunities remain before loss of control becomes a fact. Losing control also appeared to be dependent on the quality of social interactions between the drug user and others (see under 'Social dimension').

Our data showed that loss of control is mainly related to the use of heroin, cocaine or pills. Many drug users in Parkstad Limburg started their drug career by using heroin and first lost control while using this drug. Similar to the situation that Knibbe et al. (1987) described for alcohol, for chronic heroin users our data indicate that; from the drug user's perspective, immediate gratification seems to be valued more than social obligations or the fulfilment of positional roles. In other words: when a drug user loses control, obtaining and consuming drugs takes precedence over the other roles in one's everyday life. Being dope sick implies that it becomes more important to get heroin in time and that withdrawal symptoms become an everyday occurrence.

Most drug users in the present study used (at least) both heroin and cocaine $(72 \%)$ and $82 \%$ of the cocaine users were basing. Many of our field notes indicated that basing cocaine ptoduces such a strong craving that users exhaust themselves financially, physically and psychologically by ongoing bingeing (Rosse et al., 1994). 
Addie, a 31-year-old woman, was also at the station. She saw me and came to talk with me. She has 10 guilders $(64,55)$ and was not sure if she wanted to buy coke or do some shopping with this money. After a while she decided to do the shopping and asked me to go with her to the supermarket. She"s not allowed in other supermatkets, because of theft. I asked her about her drug use and she told me that coke was still her biggest problem: "Sometimes I don"t smoke for two days and then $I$ spend four or five hundred guilders (about 6180 to 6230 ), just like that". Addie earns this money by prostitution, she works during the day or at night, or night and day. (...) Her shopping bag also contained a bottle of port. (Field note November 1998).

The data showed that use of benzodiazepines could also be a trigger for further deterioration and thus loss of control. A specific problem with the use of pills with a long half-life is that taking additional pills may result in an overdose. Also, after taking too many pills drug users may no longer be able to account for their (undesirable) behaviour.

\section{Social dimension}

At a certain point in their drug career, many chronic users of heroin lose their connection with society as a whole and with its core institutions. Our data showed the following pattern: initially their drug use concerns the inner self, but with incteased dependency the behaviour becomes less reliable and the drug user becomes alienated from their personal network. The burden of the addiction is extermalised to the family and other close relationships. When the drug user loses contact with his closer personal network the addiction becomes a societal problem, and the burden of the addiction gradually shifts to less close friends and acquaintances, and finally to society as a whole.

This gradual alienation means that the drug user generally becomes dependent on (low-threshold) drug aid agencies, where close friendships and trust are a rare commodity. We observed a cyclic connection between control of drug use (especially of cocaine) and the quality of social telationships. Keeping control implies better maintenance of social relationships, including those outside the network of drug users. Less control implies spending one's days mainly or exclusively among drug users with very little, if any, incentive to control or reduce drug taking.

Drake lives with his parents who also manage his financial situation, because he's afraid to spend too much at once. He's also afraid of deterioration. Although he wants to limit his heroin consumption, he uses methadone and sometimes heroin. He says he'd like to get completely clean, but that's hard, particularly because he often gets lonely and has few contacts outside the drug scene. That why he often visits the Heetlen railway station to talk with old friends. The people in the scene are the only social contacts he"s got left. (Field note February 1999) 
Having stable relationships with primary contacts (family or friends) seems to protect against losing control over drug use. However, having a relationship with another drug user may initiate a cycle whereby both drug users lose control.

Living together with Angela has not been good for either of thems, they pulled each other further down. For some time it went well, according to Woody. They met during their stay in the clinic, and when they were going to live together Angela didn't use anything. However, some time later she started using again (...). Soon she just lay on her bed all day and did nothing but use drugs. She didn't clean the house and didn't get dressed any more. (Field note April 1999)

\section{Economic dinnewsion}

When loss of control has become a fact, it becomes increasingly hard to keep a regular job; only $9 \%$ of our study population had a job. An important condition for having and keeping a job is having a roof ower one's head. Several drug users told us that they had a job before they ended up homeless. Usually a combination of factors leads to the loss of a job, including social circumstances and loss of control of drug use.

I talk with Skinny, a systems analyst and computer programmer who has been addicted for 20 years but has always succeeded in combining his drug use with a job at the $\triangle B P$ (pension fund organisation). During the last few years, however, this has become increasingly hard and at the moment he's on half pay. I ask how things have got this far. He tells me he's using more and more cocaine, which has made it increasingly hatd to keep up appearances. On top of this, he's got into serious financial troubles and has accumulated debts of 50,000 guilders ( $€ 22,727)$. Now he's homeless and regularly sleeps at the night shelter. In the daytime, he spends a lot of time at the OAC (a local low-threshold day-care facility). (Field note May 1998)

Most drug users ( $82 \%$ ) receive an unemployment benefit and this is the main source of income for $72 \%$ of them. Those with an address receive their payment in a bank account and homeless drug users receive cash at the local social service office threc times a month on "payment day"; on this day, we observed that many use their unemployment benefit to buy drugs.

Joe tells me he sees payment day as a day of celebration. For drug users (at least for Joe and Eddie) it's not the same as for other people (like me) who, when they get their money, start to calculate what expenses they have to pay. Drug users think in terms of a certain number of "balletjes wit" (cocaine) and one "balletje bruin" (heroin). According to Joe, they spend a lot of money at once without thinking ahead. (1Field note August 1998)

Buying cocaine implies that the money is spent very quickly. When asked about their income, drug users often referred to other (mostly illegal or criminal) activities, such as dealing drugs, assisting dealers, prostitution, theft and robbery, with or without violence. 


\section{Health dimension}

According to our data, marginalisation is also expressed in the physical and psychological condition of the drug users. We observed several types of physical diseases including lifestyle related illnesses, dope sickness and infectious diseases. According to our field data, chronic heroin users tend to focus on scoting drugs and related activities, which often leads to a pattern of neglecting personal hygiene, wounds, abscesses and other physical discomforts.

Jack tells me his leg aches. From his description 1 deduce he has necrotic symptoms. When I ask if he has already consulted a doctor and if something can be done about it, he answers: "Yeah, yeah, but l'd have to go to hospital for a few weeks and I am too chicken for that, I'm afraid of it." (Tield note February 1999)

Sooner or later in their career, chronic heroin users become dope sick, which is a familiar phenomenon to most of them. Once this occurs, it becomes even more important to get heroin in time, and withdtawal symptoms become an everyday occurtence.

It's obvious that it's still carly. Many drug users are "sick" and everybody is busy with scoring drugs. They don't have any rest and run from one place to the other. (Field note December 1998)

Table 3.1 presents data on those study participants that had been tested and reported infections, and shows that injecting drug users are at highest risk for infectious diseases. Note that these figures are based on self-reports at the time of the interviews.

\section{Table 3.1: Infectious diseases among the study population}

\begin{tabular}{|c|c|c|}
\hline & $\begin{array}{l}\text { Tested drug usetsl) } \\
0 / 0(n)\end{array}$ & $\begin{array}{l}\text { Injecting drug users } 2) \\
f_{0}^{\prime}(\mathrm{n})\end{array}$ \\
\hline Hepatitis B & $26(19)$ & $40(12)$ \\
\hline Hepatitis C & $34(21)$ & $44(11)$ \\
\hline HIV & $12(13)$ & $21(9)$ \\
\hline \multicolumn{3}{|c|}{ 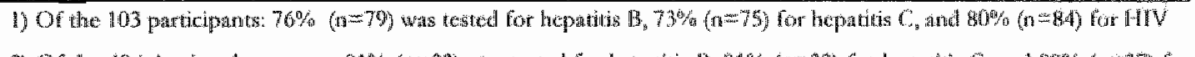 } \\
\hline \multicolumn{3}{|c|}{ 2) Of the 40 injecting drug users: $81 \%$ (n) $=33)$ was tested for hepatitis $B, 81 \%$, $(n=33)$ for hepartis $C$, and $88 \%(n=37)$ for } \\
\hline \multicolumn{3}{|c|}{ HIV. Nore that the percentages do not necessarily reflect the numbers of eases; they have been weighted for participation } \\
\hline
\end{tabular}

Chronic heroin users often look physically different from non-chronic heroin users, and from those who do not use heroin; this difference in appearance is often accentuated by certain diseases or illnesses. Withdrawal symptoms (together with a related behaviour and lifestyle) also become obvious and recognisable, thereby confirming the drug user's marginal position in society. 
When Maud and I arrive at the Royal Cinema we mot Woody, a friend of Angela. He looks tertible. Over the last few months he's lost a lot of weight. Woody used to take good cate of twimself and was well dressed. This has changed recently. Fe spends a lot of time at the rallway station. He's been using drugs for a wery long time. (Fichld note April 1999)

Especially homeless drug users who have lived on the streets for years become visibly ravaged over time.

Hans walks around bare chested. I'm unpleasanty surprised by the number of scars he has on his body. Across his chest he has a vertical scar of about 30 centimetres and there are other scars as well. Furthemore he has a remarkable bulge, the size of a tennis ball, near his stomach. The man looks like someone from a freak show: "Dr. Frankensteins' Gruselkabinet". (Field note June 1999)

Out group of chronic heroin users also had a susceptibility to psychological problems such as depressions, anxiety and hallucinations; almost $50 \%$ reported one ot more of these complaints. Suicidal thoughts $(40 \%)$ or suicide attempts $(23 \%)$ were also frequently reported, as were combinations of psychological complaints. Dewiant behaviour (e.g. aggression) caused by psychiatric problems makes it harder to connect with the rest of society and its cote institutions.

Ftom the medical point of view these psychological problems and accompanying deviant behaviour may be due to a psychiatric condition rather than to (chronic) drug use. However, in a natutal setting it is difficult, if not impossible, to distinguish between behaviour due to a psychiatric problem and deviant behaviour caused by drug use. For example, the behaviour described below could result from crack use, or from a psychiatric condition, or an interaction between both.

Sidi seems to hide awny from the world more and more. He makes a confused impression and nowadays walks with a slump. He also wears his cap over his face and always weats sunglasses. He secms to want to hide away inside his own body. He hardly ever shaves and is often unappronchable. He talks to himself and sometimes becomes very aggtessive for no apparent reason. (Field note Aptil 1999)

\subsubsection{Hardening}

\section{Swrwival of the fittest}

Once entering the drug scene, the user is forced to adapt to a different way of life. In order to survive he has to find and maintain a place in the street life hierarchy, which is determined by tough rules. Factors that detemine a drug user's place in the hierarchy include their atritude and appearance, their control over the drug use, success in getting money, and the location where drugs are bought (i.e. on the street or at a house address). Being a drug tourist or a drug dealer also 
influences one's place in the hierarchy. These factors are discussed separtely below.

One important factor in determining one's place in the hierarchy is the drug user's attitude. Showing vulnerability often leads to becoming a victim; drug users have to be tough or act tough to be held in high regard by others. Drug users who are recognised by others as 'weak' are more likely to become the victim of a robbery than others.

\begin{abstract}
Before we knew it, Vincent joined us and became inarticulately involved in our conversation. Bertram took advantage of the situation and asked if Vincent had at guilder for him. Without any comments, Vincent took out his wallet and gave Bertram 5 guilders $(€ 2,30)$. I noticed that Vincent had about 150 guilders ( $€ 68)$ in his wallet and, because of his condition, I expected him to be robbed soon. Afterwards, Sonja told me that this was exactly what happened. (Field note December 1998)
\end{abstract}

Being successful in getting money ensures a higher place in the hierarchy, as does avoiding being fooled or robbed by other drug users; the robbers themselves have a higher place in the hierarchy than others. Those who buy or use their drugs on the street are lower in the hierarchy than those who buy drugs at house addresses. Buyers on the street are allso more likely to be homeless or work as a prostitute (Barendregt et al., 2000; Coumans \& Spreen, 2003).

Because of its proximity to Germany (about 20 kilometres) and because possession of drugs for own use is rarely prosecuted in the Netherlands, Parkstad Limburg attracts many drug tourists from Germany; this latter group appears to be robbed more often than others. Like most tourists, they spend more money than local drug users and the local drug market takes advantage of this. Finally, we observed that drug dealers have a higher place in the hierarchy than others.

The highest place in the hierarchy is for those who own the most, for those who almost always have something. If you have something to sell or to give away every day, then you are well thought of. If you are someone who just wallst around begging for things, that is less appreciated. (Field note April 1999)

Our observations showed that most drug dealers have a disparaging attitude to their customers. This was expressed in many examples of fake deals and the disrespect shown by dealers to drug users. From the field notes we identified two reasons why dealers generally get away with this behaviour. First, because the drug market is unstable. Drug users feel they cannot choose which dealer to buy from and are dependent on the dealer that happens to be present. Second, drug dealers take advantage of the craving and impatience of their drug-using customers. Especially Antillean drug dealers ate high in the hierarchical structure of the drug scene which (according to our data) could be related to a strong social bond between Antilleans; the everyone-for-himself principle seems less relevant within this particular ethnic group. 


\section{The sorial wework}

The social netwotk of chronic heroin users increasingly becomes one without support from family or non-using friends and consists mainly of othet chronic herow users, as was also reported by Korf (1995a). At the same time, relationships are often chancterised by self-interest and instrumentality. Enduring friendships are rare, and even when longer-term alliances emerge they generally end sooner or later, mainly due to arguments about money. The atmosphere within the social networks is often characterised by 'stress'; i.e. hectic situations, arguments and aggtession (with or without violence).

Were now standing in front of the station. Maud and Inez are having a conversation when I hear shouting and noise. I turn around and see a young Antillean man, Bart, and Raymond have a flaming row. Bart is a dealer who sometimes sells "bolletjes" (small amounts of drugs wrapped in plastic). (...) Raymond stands there with his knife pointed at Bart's stomach. Bart reacts furiously and yells: "Just stab, man. Then I kill youl" From the argument I gather that for some unclcar reason, Raymond thinks Bart owes him a "bolletje" of cocaine. However, Batt disagrees and with a lot of gestures shows he has another opinion. Finally; Raymond gets insecure and retreats, which seems to be a sign for Bast to show even mone bravado and the argument is practically settled. Raymond"s attempt at extortion seems to fail. (Field note April 1999)

During the fieldwork we identified one group that can be characterised mote positively. The Antillean drug users are part of a minotity ethnic group with cultural values stressing the importance of solidarity between Antilleans (as distinct from the individualism in the Dutch culture). Their shared ethnic identity positively influences social contact. Drug use within this group tends to produce less agitation and stress, allowing some degrec of sociability and solidarity. We observed that these drug users also support each other in, for example, housing and drug dealing.

\section{Gothing money}

The above descriptions give the impression that drug users ate always victimised. However, since they are part of the street life, many drug users have to be flexible and show a range of strengths, abilities and skills in their everyday functioning. We observed that strategies to survive are characterised by an (almost) exclusive focus on the short-term and immediate fulfilment of needs, and by a corresponding negligence of long-term goals such as saving money or paying the rent and other recurrent expenses.

'To get money for drugs, they develop a range of mostly deviant or illegal activities such as shoplifting, robbery, assisting a dealer, begging, or cheating one another (Table 3.2). These activities play a major role in the lives of chronic heroin users. Obviously, the priority lies with scoting drugs as soon as possible, rather than becoming rich. 
Table 3.2: Additional sources of income among the study population $\left.(\mathrm{n}=103)^{1) 2}\right)$

\begin{tabular}{ll}
\hline & \\
\hline Prostiturion & 20 \\
Dealing drugs & 12 \\
Assisting a dealer & 8 \\
Selling pills or methadone & 8 \\
Theft (e.g. shoplifting) & 16 \\
Other (including robbery) & 14 \\
\hline
\end{tabular}

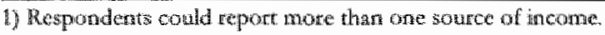

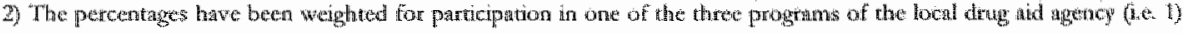

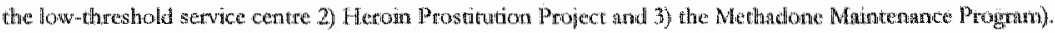

The money paid to the drug dealer is often the last arailable and has probably taken time, trouble and considerable tisk to obtain.

The fieldwork data showed that stealing money or drugs from other drug users is a common phenomenon, and is not considered as serious as stealing from an outsider. Some drug users justify their behaviour by saying that the other 'owes him something'. Surprisingly, drug users often lend money to each other despite knowing that repayment will be very difficult. Selling drugs of bad quality is also no exception, although drug users may (in spite of their dependence) try to behave like assertive customers. Some drug users keep on begging their dealer to give them free (or at least cheaper) drugs.

Apart from the illegal sources of income, some full-rime members of the drug scene earn (part of) their money legally: e.g. by selling the local drug newspaper (44\%) or playing music on the streets (not calculated).

\subsubsection{Catalysts}

Crack

The use of crack and homelessness were the two main catalysts in the life course of chronic heroin users. Crack seems to work as a catalyst only when the user loses control, which usually happens after bingeing (Rosse et al., 1994) and induces problems on the social, economic and health dimensions. We regularly met drug users who had not slept for severall days.

In the tunnel II met Mac who was half asleep and leaning against the wall. When I joined him he complained about his painful feet. Because of his use of coke he hadn't had any sleep for two days and had just been walking around town. His body now demands rest, and Mac is 'burned out'. I wished him good luck and went on. (Field note December 1988)

The survey showed that more users of crack report respiratory problems $(74 \%)$ than users of other drugs $(40 \%)(p=0.01)$. Cocaine was also positively related to the prevalence of certain psychiatric symptoms. About $30 \%$ of the cocaine users reported strong anxiety during the month preceding the interview, 
compared with only $10 \%$ of those who did not use cocaine $(p=0.05)$. About $50 \%$ of those using cocaine and $40 \%$ of those who did not, reported problems keeping their aggression under control $(0.05<\mathrm{p}<0.10)$.

Crack also accelerates the process of hardening. The strong craving often leads to ad hoc coalitions between drug users to be able to buy crack. This instrumental contact and the fact that the one who pays the most has the strongest rights fit in with the hardening perspective. Reactions during the actual smoking of crack (e.g. agitation, paranoia and hostility) also increase hardening. Stress and aggression as a reaction to crack increase when it is crowded, when drug uset's are "hunted" by the police, and when alcohol has been used simultaneously.

\section{Howelenswers}

The survey sample showed that $63 \%$ of the study population either lived with their parents $(5 \%)$, rented a toom $(18 \%)$ or had a house fof their own or for rent; $40 \%$ ); the remaining $37 \%$ was homeless.

The homeless are defined as those who do not have at their disposal or do not make use of (on the long term) private and regular housing or tesidential housing (including hospitals and prisons) or housing with family or friends. It concerns people who drift around for at least four weeks in succession and either spend their thights on the streets, parks, porches and other public places that offer some form of shelter, or spend a limited number of nights (depending on the local regulation) in night shelter facilities (Durch Health Council, 1993).

In this study, we consider homelessness as an outcome as well as a catalyst of marginalisation and hardening. This perspective is similar to that reported by Johnson et al. (1997), in which processes of social selection and social adaptation are proposed to account for the association between homelessness and drug use.

We identified homelessness as a catalyst because, according to our data, it increases the risk of losing control, difficulties in social contacts, keeping a (legal) job, physical illnesses and psychological problems. Compared to drug users who live with a partner, their parents or have a toom, homeless drug users have more problems keeping control of their drug habit. Therefore, one crucial factor for regaining control is getting a roof over one's head.

Dan looked well-groomed. He told me he felt better now that he has a room, which he likes a lot. He pays 250 guilders (E114) and he gets his food from the man he lives with. He is looking for an apartment. "That's easier when you are alteady living somewhere. Then you have time to look around. Now I sleep well and I'm fit. When I lived on the streets this was impossible, then you're occupied with other things, such as scoring drugs. (Field note December 2000)

Moreover, once homeless, most drug users have more difficulty finding another place to live. We observed that one rejection after another leads to feelings of humiliation, shame and a growing awareness of no longer being a normal member of society.

Anger, disappointment and tension can finally lead to more intensive drug use, driving one even further away from regular housing. 
Since homeless drug users spend nost of the day in the drug scene, homelessness also accelerates the process of hardening. Being a full-time member of the drug scene forces the drug user to adjust to street life and develop tough survival sttategies.

\subsection{Discussion}

This study has addressed the social background of deterionation among chronic drug users. The two main perspectives were the shift in the social position of chronic heroin users in society at large, and the social processes between chronic heroin users. To characterise the development in relations between chronic heroin users and the larger society, we used the concept "marginalisation" as an umbrella term. Marginalisation refers to the relationship a drug user has with society and has been described as a process in which individuals or social groups gradually drift away from core institutions of society (Buiks, 1983; Hall, 1999; Hall et al., 1994; Hussong, 1998; van Gelder \& Sijtsma, 1988). Those studies that explicitly investigated marginalisation over a longer life course mainly concentrated on vulnerable populations (Hall, 1999; Hall et al., 1994), hard-to-teach groups of adults and children (Milbourne, 2002), diverse categories of HTV patients (Amaro \& Raj, 2000), the mentally ill (Johnstone, 2001; Olson \& Sanders, 2000), street children (Rizzini, 1995; Snodgrass Godoy, 1999), adult men and women in a central city area (Hussong, 1998), Puerto Rican crack dealers (Bourgois, 1996) and immigrants (Buiks, 1983; Eldering \& Knorth, 1997; van Gelder \& Sijtsma, 1988). The concept of marginalisation is not new, but has mately been applied to drug users. Anderson and Levy (2003) applied Robert Park's concept of marginality to older injectors and described their marginal position as being unable to return to "the old school" (i.e. the dnug wotld from their youth), but at the same time not capable of adapting to "the new school" (the current drug scenc). Singer (Singer, 1999) described "oppression illness" among Puerto Rican injection drug users as a concept closely related to matginalisation. However, oppression illness is "a product of the impact of suffering from the trama of social mistreatment and, at some level, believing one does not deserve to be treated any better" (Singer, 1999, page 39), and in this sense may be a possible outcome, wather than being equivalent to marginalisation.

In the present study, marginalisation emerged from our ethnographic data as the most adequate concept to describe the shifting social position of chroric heroin users.

Compared with studies of marginalisation among other groups, matginalisation among drug users tends to encompass mote aspects of life (e.g. social, economic and health dimensions). In addition, detcrioration among chronic heroin users tends to be more dramatic than among other social groups, perthaps most clearly illustrated by the higher mortality among drug uses than among nonusing groups of the same age (Bargagli et al, 2002). Indicative for the possible relevance of a deteriorating position in society is that variations in the mortality 
rate rend to correlate with the availability of basic provisions for drug users. Secondly, in contrast to other social groups with a marginal position (e.g. ethnic minorivies in the Netherlands), the inferior social position of chronic heroin users does not necessarily originate in being a member of a group with an ascribed lower status, but rather in the individual choice to start using drugs and to continue using drugs despite the consequences. Another distinguishing characteristic of marginalisation among chronic heroin users is that loss of control is the main condition (see Figure 3.1). The main mechanism of loss of control is that positional roles are overtaken by siruational roles (Knibbe et al., 1987). It is generally known that groups writh limited opportunities in a society are most vulnerable to cirug use. Nevertheless, this study has shown that the lifestyle generated by the loss of control over drug use is often the main condition for further deteriotation.

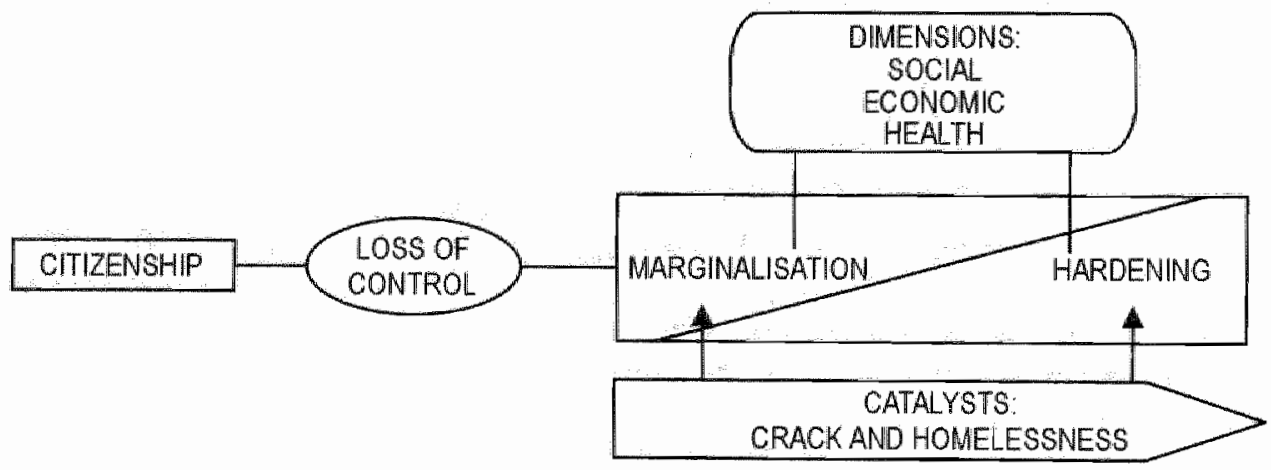

\section{Figure 3.1: Model of the process of marginalisation and hardening}

Since (loss of) control is a culturally-bound phenomenon, we argue that the reaction of society to the drug user's loss of control vaties according to whether or not the drug is illegal. For example, in the case of illegal drugs, tejection by society is expected to be much stronger compared to alcohol-related loss of control. It is important to note that loss of control can manifest in different ways: with heroin it is experienced as the necessity to avoid sickness at all costs, crack use is characterised by avoiding the return to everyday experience, and when using pills loss of control may involve a temporary loss of one's own identity. The ethnographic fieldwork also showed that, from the drug user's perspective, loss of control is not a categorical condition but rather a gradual phenomenon. Recognition of the degrees in loss of control are important in order to understand the extent of marginalisation and the status of a drug user within the drug scene.

To characterise the deterioration in relationships between drug users we used the concept of hatdening. While marginalisation is a concept applied in many studies, hardening is a more specific concept describing a process which, to our 
knowledge, has rarely been systematically desctibed. However, Anderson and Levy (2003) did describe the core of hardening when they argued that older injecting drug users become marginalised among the marginal; the following segment from their paper covers some main elements of the phenomenon of hardening:

The older injectors we studied adopt a position of poise to their predicament by clinging to self-identity and cultural values of the past, while taking an increasingly marginal position within the new. Although they protest their dislocation, they perceive themselves powerless to adjust to the social norms and physical demands of full membership in the drug world that currently exists. (...) being an older IDU in today's drug scene is fraught with loneliness, stress and fear of victimisation. (2003, page 762)

As with marginalisation, the concept of hatdening emerged from our ethnographic field data and indicates that relationships between chronic heroin users become tougher over time. The description of hardening fits the social adaptation perspective elaborated in 1946 by Straus (cited by Johnson et al., 1997, page 438) and in 1978 by Wiseman (cited by Johnson et al., 1997, page 438). It refers to the process in which a substance user adapts to the circumstances by developing survival strategies Johnson et al., 1997). The extent of hatdening corresponds with the extent of marginalisation; when social, economic and materialistic (e.g. housing) resources decrease, the drug user becomes more dependent on the drug scene and has fewer possibilities to withdraw from it (Figure 3.1).

There are reports that the drug scene has specific cultural norms and social rituals that moderate the drug user's struggle for life (Doorn van, 1994; Grund, 1993; Grund et al., 1992). On this point, we agree with Grund in that we see the drug scene as a community "with an agreement upon certain recognised values" (Grund, 1993, page 109-10). We observed that chronic heroin users share the necessity to buy and use drugs and, in that context, they share information useful for those activities. However, we also observed an instrumental use of social relationships to further self-interest rather than solidarity. In this hardening of relationships, the shared cultural background of Antillean drug users offered some protection. All in all, we conclude that, among chronic drug users, the universal needs of interaction, solidarity and harmony are often overruled by survival, instrumentality and individualisation.

In this study we identified the use of crack and homelessness as catalysts of marginalisation and hardening in the sense that they increase the rate of deteriotation. In Parkstad Limburg the intensive use of crack is a relatively new phenomenon; most users (during their drug career) started using the raw variant of coke, but since about 1998 the precooked variant of cocaine has been sold on a large scale around Parkstad Limburg. In the Rotterdam drug scene (where crack has a longer history) there are indications that crack has less impact on daily life (unpublished data). However, crack remains an inherent risk factor for marginalisation and hardening. 
The second catalyst, homelessness, makes it difficult for the drug user to regain control over their drug use and life. Living in the hectic drug scene makes a drug user dependent on low-threshold services, makes it harder to care for hygiene and health, and almost impossible to keep or find a legal job. These circumstances demand adaptation and survival skills. A definite hardening in the lifestyle is necessary to survive. Athough we consider homelessness as a catalyst in the process of marginalisation and hardening, a marginalised lifestyle is of course a risk factor for homelessness (Coumans \& Spreen, 2003).

The results described here may suggest that the process of marginalisation and hatdening is unidirectional in nature, inexorably leading the drug uset to an (undesirable) endpoint. However, we would like to stress the multidirectional natute of marginalisation and hardening, and assume that the process of marginalisation and hardening can be slowed down or even reversed. Marginalisation and hardening are influenced by everyday living conditions, such as the availability of clrugs, keeping or finding a room or apartment, and the availability of (additional) money for drugs. The policy of aid agencies and e.g. police repression may also influence marginalisation and hardening (Coumans et al., In Press). However, because these conditions may differ between tegions, communities and countries; the influences on marginalisation and hardening should be studied in different communities and locations. The present study has focused on an open drug scene (Bless et al, 1995), but dispersed open scenes or hidden scenes may differ in the contextual factors that slow down or accelerate the process of marginalisation and hardening. Future research should explore whether marginalisation and hardening show similar patterns in different scenes and, if so, what the consequences are for our proposed theoretical framework.

\subsubsection{Methodological implications}

\section{Syingy}

Regarding our survey sample, two limitations need discussing. First, studying time-dependent processes (such as marginalisation and hardening) requires a longitudinal design. However, we believe that our observations adequately cover the various stages in the process of marginalisation and hardening because a) most drug users wete able to accurately indicate in retrospect how drug use influenced their life, and b) our observations should be considered as a cross-section of different stages of marginalisation and hardening and therefore capture different manifestations of the drug-using crisis over time.

Nevertheless, to increase the validity and to facilitate the interpretation of results, future studies should preferably have a longitudinal design in which respondents are followed for a longer period of time.

Second, in this study a mixed sample design was used, i.e. a network sampling design was combined with targeted sampling and convenience sampling (among prostitutes). This mixed approach implies that the sampling was not completely at random and, therefore, statistical inference from our sample to the general population is (strictly speaking) not allowed. For such an inference to be made a 
probability sample is needed; the probability of inclusion in the sample must be known and positive for all population members. Therefore, the results presented. here need to be interpreted with caution.

The data from the survey sample were used to complement the findings of the ethnographic fieldwork, rather than to derive conclusions about the main study questions concerning marginalisation and hardening. In our opinion quantification of our core concepts is only valuable if presented in combination with observations from ethnographic fieldwork. To rely purely on a quantification of a phenomenon that is qualitative in nature, would seriously limit the richness of ethnographic data. Without this qualitative foundation the quantitative analyses would be meaningless and interpretation would be very difficult.

\section{Ethnographic research}

The use of ethnographic research constitutes the foundarion enabling us to reach our conclusions. In our opinion the ethnogtaphic method better articulates the daily life experience of chronic drug users than other methods. However, this kind of research also has its limitations.

To test the quality of the findings in the present study, we used the trustworthiness criteria and related techniques as described by Lincoln \& Guba (1985). We describe below the main potential limitations and how we handled them.

One potential distortion of the credibility of our findings was the use of fieldworkers in the drug scene who were unfamiliar to that field. Whether the fieldworkers preferred to operate as observer (the "fly on the wall") or as a participant-observer (the "wasp"), in both roles they influenced the reality that they aimed to observe. Since we also used actual drug users as fieldworkers, we were able to "test" whether this kind of distortion seriously influenced the credibility of our data. We observed that the same aspects of marginalisation and hardening emerged in the field notes of both types of fieldworkers, implying that the undeniable influence of fieldworkers who are unfamiliar with the field did not distort our findings.

Furthermore, it is important to note that the process of analysing ethnogtaphic field notes is always interpretative in nature. In other words, the researcher's reflection and (re)construction of reality does not necessarily reflect the drug user's perspective. The danger exists that the researcher confuses his/her own perspective with the drug user's view. The most important technique to test whether such misinterpretation took place is the "member check": "whereby data, analytic categories, interpretations, and conclusions are tested with members of those stake holding groups from which the data were originally collected" (Lincoln \& Guba, 1985, page 314). We applied this technique in our stady on several occasions. Firstly, during the development of the concepts of marginalisation and hardening, we discussed our reconstruction and interpretations with our drugusing fieldworkers and with drug users we met on the strect. Secondly, we gave the final reports to four drug users in the field and asked for their reaction. Thirdly, a focus group was organised for key informants and drug users to whom the preliminary findings were presented. On all these occasions drug users agreed with 
out descriptions and recognised out interpretations. We acknowledge that some problems exist with this technique, such as common myths that may be shared by drug users, of (in trying to be fair) reconstructing "an average or typical position that tepresents no one's reality" (Lincoln \& Guba, 1985). However, we have no teason to believe that our informants misinformed us about the credibility of our reconstructions.

Finally, because the processes of marginalisation and hardening are temporal and time dependent, the question arises whether the field notes of this study (written up to 6 years ago) are still relevant today. However, observations from the current Drug Monitoring System in Parkstad Limburg (as well as Quick Scans in the same region) indicate that the basic characteristics of chronic heroin users are stable and that processes of marginalisation and hardening still characterise the drug scene today.

\subsubsection{Implications for drug policy}

The description of the process of marginalisation and hardening presented here could be used by professionals and policymakers to generate ideas on how to provide care for this group. From a policy point of view, the category of chronic heroin users described here will profit more from a harm-reduction approach than from an approach focused on treatment (aimed at a drug-free existence) or punishment (Des Jarlais \& Friedman, 2002; MacCoun, 1998; Majoor \& Rivera, 2003; Wodak, 1999). Majoor and Rivera (2003) argued that such an approach should be multidimensional and holistic; moreover, anything that helps a drug user to maintain control over their drug use will slow down or even reverse the process of marginalisation and hardening. This might be achieved by helping chronic heroin users to rebuild and maintain a healthy social network, and to tevive their old relationships outside the drug scene. Also, crack should be the focus of prevention and intervention programs, especially among chronic hetoin users.

More gencrally, we recommend an approach that offers the drug user some rest and safety. For the police this implies that, apart from repressive measures, the most vulnerable categories of drug users should be protected.

An environment that offers protection, safety and rest could moderate the struggle for life. Such a context may also offer betrer conditions to support social relationships that are not purely instrumental, e.g. via low-threshold services or drug consumption rooms. Aid agencies could offer possibilities for employment to increase the drug user's self-tespect and show society that they are able to perform regular activites. Finally, to help chronic heroin users regain control of their lives, aid agencies should link up with their everyday life, preferably via outreach activities such as community-based fieldwork. 
This study has shown that a better understanding of how chtowic heroin users liwe their daily lives, in both the larger society and the drug scene, has implications for a drug policy aimed at the survival of chronic hetoin users and an increase in their quality of life.

\section{References}

Amaro, H., \& Raj, A. (2000). On the margin: Power and women HIV risk reduction strategies. Sex Raler, 42 (7/8), 723-49.

Anderson, T. L., \& Levy, J. A. (2003). Marginality among older injectors in today's illicit drug culture: Assessing the impact of ageing. Addwtron, $98,761-70$.

Anderson, T. L., \& Mott, J. A. (1998). Drug-related identity change: Theoretical development and empirical assessment. Jowmal of Dryg Iswes; 28 (2), $299-327$.

Barendtegt, C., Lempens, $A_{\text {., }}$ \& wan de Mheen, D. (2000). Drugs kopen op strat. Achtergronden en motieven van Rotterdamse druggebruikers die bij stratatealers kopen/ Buying drugs at the street. Background and motives of Rotterdam drug users who buy from street dealers. IVO Bulletin, 3 (1), 1-19.

Bargagli, A. M., Spetati, A., \& Davoli, M. (2002). Mortality anong problem drug users in europe: A project of the European monitoring centre for drugs and drug addiction (EMCDDA). Herom Addition \& Related Clinical Problewn, 4, 5-12.

Biernacki, P. (1986). Pathways from beroin addiotion; recowery whon tratwon. Philadelphia: Temple University Press.

Bless, R., Korf, D. J., \& Freeman, M. (1995). Open drug scenes: A cross-national comparison of concepts and urban strategies. European Addiction Research, 1, 128-38.

Bourgois, P. (1996). In search of masculinity. British Jowrmal of Crimiwology, 36 (3).

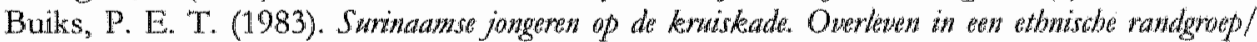

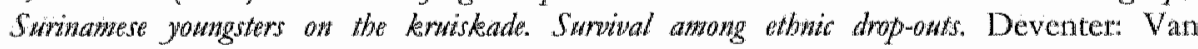
Loghum Slaterus.

Coumans, A. M., Knibbe, R. A., \& van de Mheen, H. (In Press). Street-level affects of local drug policy on marginalization and hardening: An ethogtaphic study among chronic

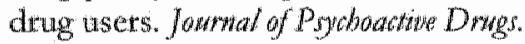

Coumans, A. M., \& Spreen, M. (2003). Drug use and the rolle of homelessness in the process of marginalization. Substance Use of Misuse 38 (3-6), 311-38.

Des Jarlais, D. C., Friedman, S. R. (2002). Strategies for working with injecting drug users: The role of health psychologists in harm reduction. In M. A. Chesney (Ed.),

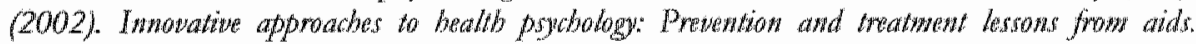

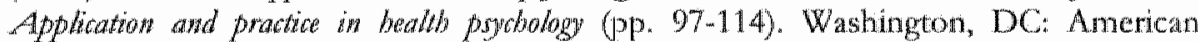
Psychological Association.

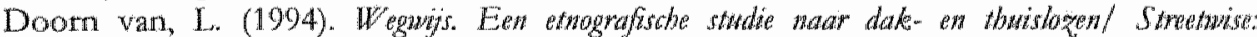
Etwographic stwdy on boweleshess. Utrecht Nederlands Instituut Zotg en Welzijn (NIZW).

Dutch Health Council. (1993). Dakbosbeid en psychiatrishe problemen; adnes aver opwang mor

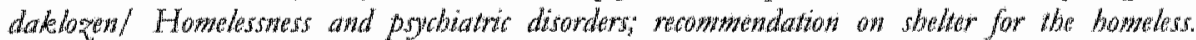
Publication wo. 26/1993. The Hague: Dutch Health Council.

Eldering, L., \& Kunoth, E. J. (1997). Marginalisering van allochtone jongeren en risicofactoren in hun dagelijks leven/ Marginalisation of ethnic youngsters and risk factors in their everyday life. Kind en Adolesent, 18, 2-1.4. 
Goldberg, T. (2001). Becoming a problemadic consuner of narcotics. Swbricance Use es Misuste, $36(9-10), 1297-322$.

Grapendat, M, Leuw, E, \& Nelen, H. (1905). A word of opportantiot. Life-shle and economic belowior of bewin addicts in Amstendam. New York: State Unversity of New Youk Press.

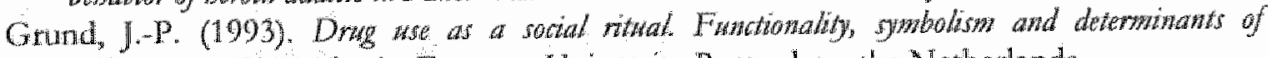
selfregwhtion. PhD Thesis, Erasmus University Rotterdam, the Netherlands.

Grund, J.P., Adriaans, N. I. P., \& Kaplan, C. D. (1991). Changing cocaine smoking rituals in the dutch hetroin addict population. Brivis jowrwal of Addiction, 86, 439-48.

Grund, J. I. C., Kaplan, C. D.; \& de Vries, M. (1992). Rituals of regulation: Controlled and uncontrolled drug use in natural setrings. In N. Heather, A. Wodak, F. A. Nadelmann

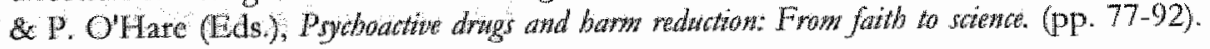
Jondon: Whurr Pubilishets.

Hall, J. M. (1999), Matginalization revisited: Critical, postmodem, and liberation perspectives. Adtwans in Nursing Saince, 22 (2), 88-102.

Hall, J. M. Stevens, P. E. \& Meleis, A. I. (1994). Marginalization: A guiding concept for valuing diversity in nursing knowledge development. Adwances in Norsing Sriente, 16 (4), $23-41$.

Hendriks, V. M, wan der Meer, C. W., \& Blanken, P. (1991). De addiction strerity index. A.SI (R). Handlaiding bij braing en afname/ Tbe Addation Setwerty Index (R). Mannal for training and administeng. Rotterdatm: Addiction Research Institute (NVO).

Hughes, P. H., Parker, R., \& Senay, E. C. (1974). Addicts, police, and the neighbourhood social system. Amerian Jomnal of Orthopsicbitity, 44 (1), $129-41$.

Hussong, M. (1998). Marginal institutional partiopation: An aggrgate examination of social control theory. PhD Thesis, University of New Mexico, USA.

Johnson, B. D., Goldstein, P. J., Preble, E., Schmeidler, J., Iipton, D. S., Spunt, B., er al. (1985). Taking care of business; the economics of crime by beroin abusers. Lexington: Lexington Books.

Johnson, T. P., Freels, S. A., Parsons, J. A., \& Vangeest, J. B. (1997). Substance abuse and homelessness: Social selection or social adaptation? Addiction, 92 (4), 437-45.

Johnstone, M.-J. (2001). Stigma, social justice and the rights of the mentally ill: Challenging

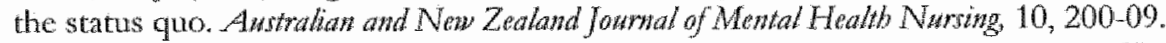

Klingemann, H. K. H. (1999). Addiction careers and careers in addiction. Swbstane Use eso Miws, $34(11), 150526$

Knibbe, R. A., Drop, M. R., \& Muytjens, A. (1987), Correlates of stages in the progression from everyday drinking to problem drinking. Social Soiente Medicine, 24 (5), $463-73$.

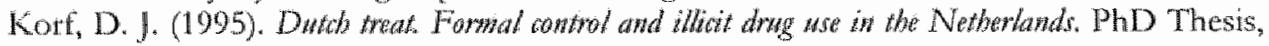
Amsterdan: Thesis publishers.

Lempens, A., Barendregt, C., Zuidmulder, L., \& Blanken, P. (1999). Kenmetken wan Rotterdamse gebriulkers: Enkele tesultaten tan de survey "drugs, huisvesting, schulden cn gezondheid'/ Chatacteristics of Rotrendam drug users: Some results of the survey 'dnugs, accommodation, debts and health'. IVO Bullotin, 2 (3), 1-20.

Lincolu, Y. S., \& Guba, G. (1985). Natwothtic ingury. Newbury Park, CA: Sage Publications.

MacCoun, R. J. (1998). "Toward a psychology of harm reduction. Azyencan Psydbologist, 53 (11), 1199-208.

Majoor, B., \& Rivera, J. (2003). SACHR. An example of an integrated, harm reduction drug

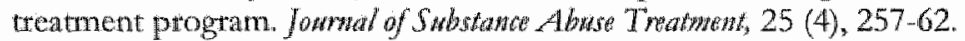

Milbourne, L. (2002). Unspoken exclusion: Experiences of continued marginalisation from education among 'hard to reach' groups of adults and children in the UK. Britis Jourwal of Sociology of Education, $23(2), 287-305$. 
Olson, T., \& Sanders, R. L. (2000). Ethnicicy, marginalisation and mental illness in Hawaii. Disability es Soriety, 15 (3), 463-73.

Power, R, Jones, S., Kearns, G, \& Ward, J. (1996). An ethography of risk management amongst ilicit drug injectors and its implications for the development of communiry

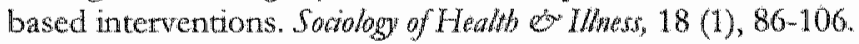

Preble, E., \& Casey, J. J. (1969). Taking care of business - the heroin users life on the street. Inye mational Jownal of the Additions, $4(1), 1-24$.

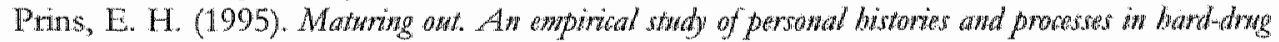
addition. Assen: Van Gorcum.

Rizzini, T. (1995). Childten in the streets: Latin America's lost generation. Children and Yowb Sowides Revien, 17 (3), $391-400$.

Rosenbaum, M. (1981). Women on berin. New Brunswick, New Jersey: Rutgers University Press.

Rosse, R. B., Fay McCarthy, M., Collins, J. P., Alim, T. N., \& Deutsch, S. (1994). The relationship between coke-induced paranoia and compulsive foraging: A preliminary report. Addigtion, 89, 1097-104.

Seidel, J. (1998). Ethyograph 25.0 a wer's guide. Thousand Oaks/ London: Scolari, Sage Publications Software.

Singet, M. (1999). Why do Puetto Rican injection drug users inject so often? Anthopalogy ery Meditine, $6(1)$.

Snodgrass Godoy, A. (1999). 'our right is the right to be killed'. Making rights real on the streets of Guatemala City. Childbood, $6(4), 423-42$.

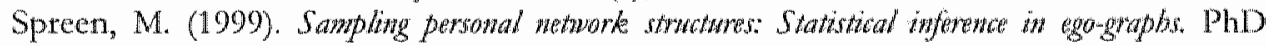
Thesis, Rijksuniversiteit Groningen, the Netherlands.

Spreen, M., \& Coumans, A. M. (2000). Network sampling hatd drug users: A structural analysis of the clients of aid agencies in Heetlen. Kuntitatiew Methoden, 21 (65), 95-112.

Spreen, M., \& Coumans, M. (2001). A note on network sampling in drug abuse research. Connertions. Official Jownal of the International Nerworte for Social Network Anabsis. 24 (3), 44-51.

Sterk, C. E. (1999). Fast liwes. Women who we rawk wane. Philadelphia: Temple University Press.

Sterk-Elifson, C., \& Elifson, K. (1993). The social organization of crack cocaine use: The cycle in one type of base house. Jownat of Dway $I s w n, 23(3), 429-41$.

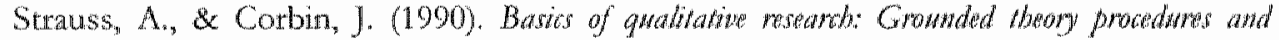
ted hnigtes. Newbury Park, CA: Sage Publications.

Swierstra, K. (1987). Heroineverslaving: Levenslang of gat het vanzelf over Een kwat eeuw buitenlandse follow-up studies/ Heroin addiction: Life-long or just passing? $A$ quarter of a century of follow-up studies abroad. Tyduchrift wow Ahobol. Drugs en Andow Psychotrope sioffen, $13(3), 78-92$.

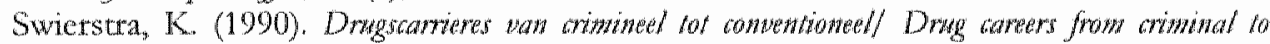
conventional. Rijksuniversiteit Groningen, Groningen.

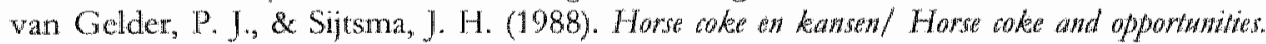
Amsterdam: Institute for Social Geography, University of Amsterdam.

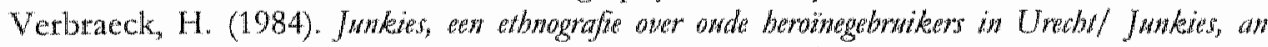
ethograpby about aged beroin wers in Utrecht. Utrecht: Stichting WGU,

Verbraeck, H. (1990). The german bridge: A street hookers" strip. In E. Lambert (Ed.), Tbe collection and interpretation of data from hidden populations (Vol. 98, pp. 146-55). Rockville: National Instinte on Drug Abuse research monograph series.

Wodak, A. (1999). What is this thing called harm reduction? International Jowrnat of Drwg Poligy, 10, 169-71. 
Yates, A. J. (1900). The natutal history of heroin adiction. In D. M. Warburton (Ed), Addition wontwerstes. Amsterdam, the Netherlands: Harwood Academic Publishers.

Znberg, N. (1984). Drwg, set and setting. The basis for controlled intowicant we. New Haven/London: Yale University Press. 


\section{Chapter 4}

\section{Counteractions to marginalisation and hardening among chronic heroin users: a two-case study in the Netherlands}

This chapter is based on the article "Counteractions to marginalisation and hardening among chronic heroin users: a twocase study in the Netherlands", by Moniek Coumans, Dike van de Mheen and Ronald Knibbe. 


\begin{abstract}
To analyse the extent to which marginalisation and hardening alone provide valid descriptions of local drug cultures or should be complemented by counteracting processes (such as socialisation and solidarity), we analysed ethnographic and survey data of chronic heroin users in the Dutch region of Parkstad Limburg and Rotterdam in a two case study design. Although the results show that marginalisation and hardening were relevant to describe the social processes among drug users in both cities, there were more indications for counteracting processes in Rotterdam. The conditions for socialisation and solidarity were: less repressive measures against dealing addresses, the presence of drug consumption rooms and interest groups, the possibility to wotk, being part of a network with shared cultural identity, and the possibility to buy and use drugs in a more protective setting. These results led to further refinement of the original analytical model.
\end{abstract}




\subsection{Introduction}

The concepts of marginalisation and hardening emerged from a grounded theory approach to the everyday life of chronic drug users in a medium-sized city in the Netherlands (Parkstad Limburg; see Chapter 3). Marginalisation refers mainly to the process in which the drug user over time loses contact with primary relations (family and friends) and core institutions of civil society (education, work, aid agencies). However, specific for drug users is that the decline in social relations and social integration is accompanied by a physical, psychological and economic decline. That earlier study (Chapter 3 ) also revealed the deteriotating relationships between chronic heroin users, which we termed "hardening". This refers to a process of social adaptation involving coping with to the new and tough circumstances in which social relationships between drug users are often characterised by harshness. It is important to note that the social and economic dimensions of marginalisation also appear in the description of hardening.

Both marginalisation and hardening are influenced by factors that accelerate or amplify the process, which we term catalysts. In addition, the earlier study in Parkstad Limburg showed that the use of crack by chronic heroin users and homelessness act as catalysts (Figure 4.1).

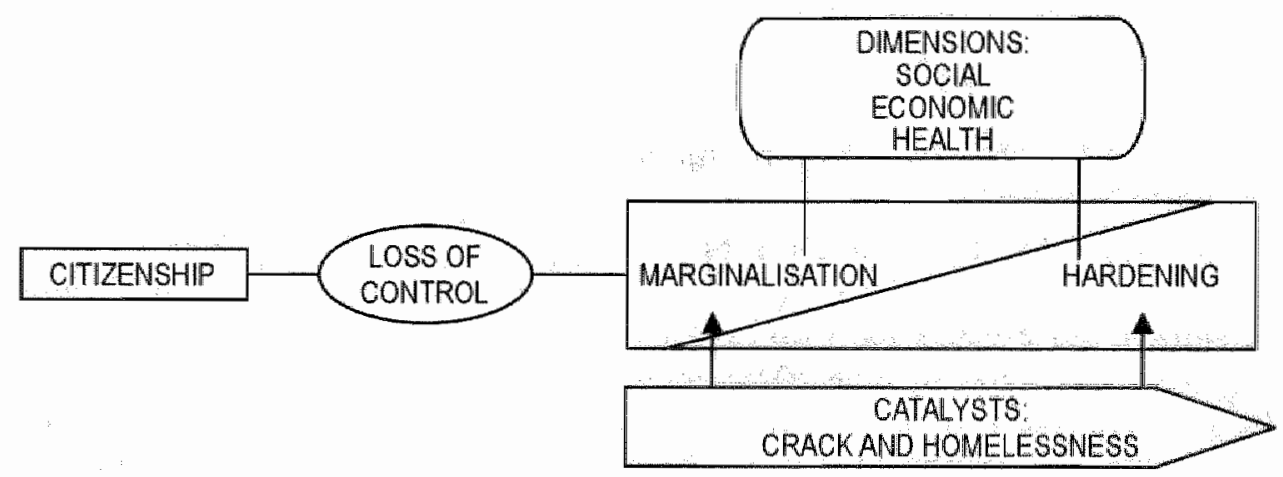

Figure 4.1: Ptocess of marginalisation and hardening: original model

After analysing the Parkstad Limburg data, we reported that the everyday life of chronic heroin users was characterised by marginalisation and hardening alone (Coumans et al., 2000). However, experts in the field of chronic heroin use criticised the unidirectional nature of our model and suggested adding to the model those processes that counteract those of marginalisation and hardening, in order to more adequately describe what happens in the everyday life of chronic heroin users.

In the present study we hypothesise that the process of matginalisation and hardening is not unidirectional but can be reversed towards integration and solidarity. We used a case study design to test this hypothesis and also to identify 
what conditions determine the extent to which marginalisation and hardening are counteracted by integration and solidarity. To test whether the model is multidirectional and under what conditions it is (or is not), we applied secondary analysis on the Parkstad Limburg data and used the city of Rotterdam as a second case; Rotterdam (a major port) is larger and more urbanised than Parkstad Limburg:

To test our hypothesis we first had to identify any relevant differences between the two cases. One major difference is that whereas in Parkstad Limburg the drug market has always been dominated by street sales (Coumans \& Knibbe, 2002a; Coumans et al., 2000), at the time of this study most dealing activities in Rotterdam took place at house addresses (Lempens et al, 1999). In addition, drug aid agencies in Rotterdam are better established and there is at least one interest group for drug users.

Taking into considering these local differences the two main research questions are:

1. To what extent are local scenes of chronic heroin users characterised by marginalisation and hardening alone or complemented by counteracting processes?

2. What conditions in a local drug scene determine the dominance of marginalisation and hardening or of socialisation and solidarity?

\subsection{Methodology}

\subsubsection{The Drug Monitoring System}

We used data from the Drug Monitoring System (DMS), which is a Dutch instrument designed to signal trends and developments in local drug scenes. Until recently, DMS projects have been running in the cities of Rotterdam, Parkstad Limburg and Utrecht. The DMS uses data from ethnographic community fieldwork, small survey samples among drug users, and interviews with key informants. The present study used community fieldwork and survey dara only.

\subsubsection{Grounded theory and case study design}

The concepts of marginalisation and hardening were developed by a grounded theory approach (Chenitz \& Swanson, 1986; Strauss \& Corbin, 1990) to the Parkstad Limburg field notes of ethnographic community fieldwork. The fiell thotes were written in 1998 and $1999(\mathrm{n}=119)$ by five freelance community fieldworkers, two coordinating community fieldworkers, and the researcher. The fieldworkers were instructed to distinguish between observations, interactions, and reflections. Reflections served as first analyses in order to keep the observations and interactions pure. At the end of each field note at least one question that emerged from the reflections had to be written down with the purpose to give direction to the next fieldwork sessions. 
In the grounded theory approach the theory gradually emerges from a continuous process of observation, interaction and reflection. To address the questions of the present study, a multiple case, teplication design was applied to the DMS data (Yin, 1984). As an exploration, the Rotterdam fieldworte data of the year 1998 were only globally consulted, wheteas the field notes of the year 1999 ( $n=236$, gathered by six community fieldworkers) were thoroughly analysed.

All the fieldwork data were typed out completely, and analysed with the help of the qualitative software program Ethnograph V5.06 (Seidel, 1998).

\subsubsection{Survey sample}

The quantitative survey data were mainly used as a framework to help interpreting the qualitative data. The Rotterdam survey data used for the present study were collected in 1998 by targeted sampling (nearly) daily users of heroin, cocaine and other drugs. Respondents were approached at known drug selling/using locations. To prevent interviewer bias, respondents were recruited in an a-select way. Interviewers approached systematically each thiid drug user they met and asked him or her to participate. Of the 242 drug users that were approached 204 drug users participated, i.e. the non-response rate was about $15 \%$ (Lempens et al., 1999).

The survey data of Parkstad Limburg were collected via a network sample in 1999 (Spreen, 1999; Spreen \& Coumans, 2001). We started with a random sample of 90 of the 435 clients registered with the local outpatient drug aid agency. After screening for drug users who were in detention, staying in an inpatient (drug) aid agency, or no longer in treatment, social workers of this agency approached the remaining 50 clients of which 40 were willing to participate. The researcher approached an additional 15 prostitutes at a location where prostitution was permitted at the time of the interview period. At the end of the interview all respondents were asked to mention up to 10 other drug users; this resulted in the nomination of 110 registered and 83 non-registered drug users. The next step was to randomly select at least one non-registered drug user per respondent: this yielded 21 non-registered users. To increase the total number of respondents we approached drug users at known locations and asked each third perron to participate (targeted sampling). Finally, we recruited 103 respondents.

We have to note that the type of sampling technique used may imply a certain selection bias. For example, in Rotterdam a disproportionately large number of drug users (47\%) was selected at dealing addresses. Since the most marginalised drug users generally do not buy at such (expensive) addresses, a too positive picture of the Rotterdam drug users may have emerged. However, because most of our conclusions are based on the fieldwork data, this unbiased source can be used to verify our quantitative findings.

Despite this potential bias related to sampling techniques in both cities, we decided to apply Chi-square and t-tests on the data. We argue that, since and the target populations and the questionnaire used was similar in both cities, assessment of the size of possible differences is worthwhile. 


\subsection{Results}

\subsubsection{Background characteristics}

Table 4.1 shows that although there are almost no differences between the two cases for age and gender, there are more immigrants in the Rotterdam sample. A more detailed analysis showed that whereas in Rotterdam Surinam drug users are the largest category of foreign drug users (almost 50\%), in Parkstad Limburg Germans $(54 \%)$ constitute the largest category of foreign drug users.

Compared to Rotterdam, in Parkstad Limburg significantly more drug users are homeless. Furthermore, in Rotterdam the use of cocaine has overtaken the use of heroin, while this was not (yet) the case in Parkstad Limburg. More drug users in Rotterdam buy their drugs at dealing addresses, while in Parkstad Limburg this occurs mainly on the streets. However, differences in sampling techniques used (see section 4.2) may have somewhat overestimated this difference.

\section{Table 4.1: Background characteristic of Rotterdam and Parkstad} Limburgl)

\begin{tabular}{lll}
\hline & $\begin{array}{l}\text { Parkstad } \\
\text { Limburg }(\mathrm{n}=103)\end{array}$ & $\begin{array}{l}\text { Rotterdam } \\
(\mathrm{n}=204) \\
\%\end{array}$ \\
\hline $\begin{array}{l}\text { Age (mean, in years) } \\
\text { Gender }\end{array}$ & 37 & 37 \\
Male & 75 & 70 \\
Female & 25 & 30 \\
Netherlands & 76 & 58 \\
Other countries & 24 & $42^{* *}$ \\
Place of birth & 37 & $22^{*}$ \\
Homeless & & 84 \\
Drug use & 89 & $90^{* *}$ \\
Heroin & 81 & 28 \\
Cocaine & 39 & $48^{* *}$ \\
Injecting drugs & & $88^{* *}$ \\
On the streets & 72 & $19^{* *}$ \\
\hline At dealing addresses & 34 & \\
By (cellunlar) phone & 43 & \\
\hline
\end{tabular}

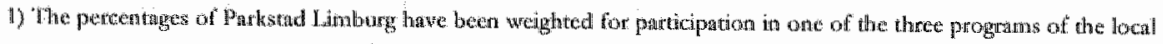

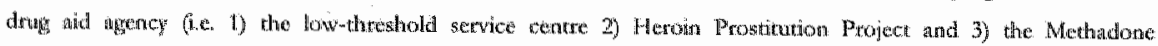
Maintendace Proggramy. 


\subsubsection{Marginalisation versus socialisation}

This section addresses to what extent local drug scenes are characterised by marginalisation alone of complemented by the counteracting process of socialisation. Therefore we focus on the most important aspects of marginalisation: losing control, and the social, economic and health dimensions.

\section{Losing control}

According to our earlier study in Parkstad Limburg the process of marginalisation starts when a drug user loses control of their drug use. This is usually related to the use of heroin, cocaine or tablets; historically, however, heroin is the first hard drug used leading to loss of control. The fieldwork showed that loss of control should be understood as a shift of priorities from positional roles to situationall role (Chapter 3). Positional roles structure a person's everyday life and their position in a social network, whereas situational roles are described in terms of obtaining short-term goals, such as eating, and shopping (Knibbe et al, 1987). For a drug user, loss of control means that getting and using drugs are more important in structuring everyday life than e.g. being someone's child, patent, spouse or employee.

Although we cannot differentiate between users of heroin and cocaine (because in both cities most drug users use both) the use of cocaine and especially crack implies specific problems with keeping control, e.g. the strong craving for crack after the first dose and the inability to quit.

The cities differed on two points: in Rotterdam the use of cocaine is more dominant than in Parkstad Limburg (see also section 3.1), and many Rotterdam dealers sell only cocaine.

The problem is that most dealers sell only cocaine and (...) you'te longing for cocaine so much that you forget all your plans and spend all your money on coke (...) So I try to avoid dealers of who I know never sell heroin and I look for the tare who besides cocaine also sell heroin. (Field note Rotterdam Decenber 1999)

The use of benzodiazepines ("pills") often leads to further deterioration. A specific problem with such pills with a long half-time is the risk of ingesting additional pills while the previous dose is still working. This can lead to loss of control or to an overdose (Chapter 3).

Ans sits on the benches too, she's heavily under the influence of something and can hardly keep her eyes open or talk properly (...) I notice she"s wearing clean clothes and thas lost her false teeth somewhere (...) She tells me she's been missing her false teeth all day ... put them down somewhere but doesn't remember where (....) she took a lot of Serestas and can't remember how many. (Tiield note Parkstad Limburg May 1998)

In the fieldwork data no major differences were found between Rotterdam and Parkstad Limburg concerning the loss of control mainly related to the use of heroin, cocaine or tablets. However, only in Rotterdam some users regained some 
control over their drug use and showed a tendency to reconnect with core institutions.

Des is of English origin. He sits at the table doing his homewrork, he's following a course in bookkeeping. Once or twice a week he smokes a few pipes with coke. That"s bettex than a few years ago, when he smoked for about 250 guilders (e114,-) a day. (Field note Rotterdam March 1999)

\section{Sociah economic and bealth dimensions}

As our earlier study showed, more control of the drug habit enables better maintenance of social relationships with non drug users, while less control implies having contact almost exclusively with other drug users (Chapter 3). In both cities loss of control led to a gradual alienation from social society.

In Rotterdam significantly more drug users earn money with a legitimate job (19\%) compared to Parkstad Limburg $(9 \%)(\mathrm{p}<0.05)$. Also, about $10 \%$ of the Rotterdam drug users earns money doing (temporary) jobs for "Topscore" (a job agency for drug users), whereas at the time of this study there was no such agency in Parkstad Limburg. Although the possibility to do legitimate work can be seen as an indication for socialisation, in both cities drug users often resort to other activities (mostly illegal or criminal) as a source of income, e.g. dealing drugs, assisting dealers, prostitution, and robbery with or without violence. This is discussed further in section 4.3 .3 .

Few drug users are without debts (16\% in Parkstad Limburg and $12 \%$ in Rotterdam), many have unpaid fines, and most drug users are always short of money.

In both cities the priority to score drugs often leads to neglect of personal hygiene and physical problems including dope-sickness, infectious diseases, abscesses, skin wounds, and respiratory diseases.

A quantitative comparison of infectious diseases shows that, compared with Rotterdam, Parkstad Limburg has significantly more drug users with hepatitis $C$ and slightly more drug users are HTV positive (Table 4.2, not statistically significant). This applies both to the total sample and to the injecting drug users (note that these are self-reported data and not based on medical tests). 
Table 4.2: Self-reported data on infectious diseases in Rotterdam and Parkstad Limburg ${ }^{\mathbb{1}}$

\begin{tabular}{lllll}
\hline & Total $^{2}$ & & \multicolumn{2}{l}{ Injecting drug users } \\
\hline & Parkstad & Rotterdam & Parkstad & Rotterdam \\
& Limburg & & Limburg & \\
& $\%$ & $\%$ & $\%$ & $\%$ \\
\hline Hepatitis C & $34^{* *}$ & 13 & $44^{* *}$ & 19 \\
HIV & 12 & 9 & 21 & 18 \\
\hline ** $<<005$ & & & &
\end{tabular}

1) The percentages of Parkstad Limburg have been wejghted for partichtaion in one of the three prograns of the lowal

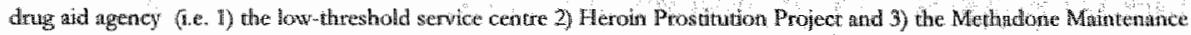
Program:

2) Note all doug users reportang to thave an infectious discase had boen rested.

Certain illnesses and diseases leave a physical mark and the drug users may behave differently due to illness or withdrawal symptoms (Chapter 3). This was the case in both Rotterdam and Parkstad Limburg.

(..) a woman (in her early forties) enters the room. Apparently she's dope-sick and asks Hein for "een Chineesje" (a little Chinese: a small dose of heroin) Hein notices her sickness and gives it to her inmediately. She gasps, stammers, and looks like she's dying. (...) After a few inhalations (...) she vomits into a metal litterbin. Bah! She makes excuses, and hiccoughs. She's already looking better. (Field note Rotterdam, dealer's house 1999)

Chronic drug use and the associated social and economic deteriotation may also increase the susceptibility for psychological problems; this was observed in both cities. However, it is often difficult to distinguish between behaviour caused by a psychiatric problem and deviant behaviour related to drug use.

\subsubsection{Hardening versus solidarity}

This section addresses three aspects of hardening (survival in a new world, getting money and, the social network) in the drug scene of the two cities, and the possibility to convert hardening into solidarity under certain conditions.

\section{Surwinal in a new world}

Once entering the drug scene the drug user is forced to find and maintain a place in the hierarchy of street life, in which attitude and vulnerability play an important role (Chapter 3).

Data from both cities showed that the extent to which one can avoid being fooled or robbed determines the place in the hierarchy, with robbers having a higher place in the hierarchy than others. Obtaining money enhances both one's position and the chance of survival. In both cities young Antillean (and other) dealers are often higher in the hierarchy than older Antilleans or Dutch drug users. 
The Antillean dealers Tommic, Noise, and Jack are playing a dice game ... there"s a lot of gambling involved (...) there's a lot of money on the ground where they re playing. Whille they're taking care of the customets, they just leave the money on the pavement. None of the users dares to touch it. (Field note Parkstad Limburg June 1999)

The Rotterdan data showed that especially young Antilleans operate in groups and use intimidation and their shared ethnicity to maintain their place in the hictarchy.

While I'm talking with one Antillean guy, another moves up behind my back. I turn towards him, because I don't trust it. Then Austin shows that he's my bodyguard (...) then the boy moves to another spot. I almost have to laugh about theit attempts to show they re really dangerous (...) then I get to hear a lot of tough stories, probably to prove they really are tough guys. (Fild note Rotterdam February 1999).

Another factor the drug buying behaviour. Those who buy or use their drugs on the streets are lower in the hietarchy than those who buy at house addresses, where drugs are more expensive. Moreover, drug users who buy on the streets are more likely to be homeless or prostitutes than others (Batendregt et al., 2000; Coumans \& Spreen, 2003).

Duting the day the women (prostintes) can't visit their usual drug dealers and are forced to visit a street dealet who's atound in the daytime (...) Another group that has to buy on the streets is the homeless. These people (...) are excluded from the more regular drug market... This forces them to buy on the streets (..) these two categories have become the scapegoat within the scene. (Field note Rotterdam September 1999).

That drug tourists are more vulnerable than local drug users was confirmed by field data from both cities.

In conclusion, data ftom both cases show that the position in the drug scene often depends on the attitude of the drug user towards fellow users, showing vulnepability often leads to victimisation.

I talk to Casper: He complains about the unsafe situation on the streets. Last month he was (almost), robbed several times. This used to happen at night when he was alone (...) Casper is well-known on the streets, he looks vulnerable and is thus "casy to rob". (Field note Rotterdam May 1999)

Conversely, being "tough" increases prestige often leading to intimidation of "weaker" persons.

\section{Gettung woney}

Being part of the street life requires drug users to devellop a range of strengths, abilities and skills (Chapter 3). The need for money (especially for cocaine) 
generally results in shoplifting, assisting a dealer, begging, cheating, stealing (money or drugs) and selling drugs (Table 4.3).

\section{Table 4.3: Ways of obtaining money ${ }^{11)}$ in Rotterdam and Parkstad} Limburg ${ }^{2}$

\begin{tabular}{|c|c|c|}
\hline & $\begin{array}{l}\text { Parkstad Limburg } \\
(n=103) \\
\%\end{array}$ & $\begin{array}{l}\text { Rotterdam } \\
(n=204) \\
\%\end{array}$ \\
\hline Prostitudion & 20 & 18 \\
\hline Selling drugs & 12 & 13 \\
\hline Assisting a dealer & 8 & 10 \\
\hline Selling pills or methadone & $8^{*}$ & 20 \\
\hline Shoplifting & $16^{* * *}$ & 26 \\
\hline \multicolumn{3}{|l|}{$* 0.005<p<0.01 ; * 0<0.005$} \\
\hline \multicolumn{3}{|c|}{ 1) Note that respondents could indicate more than one source of incoine } \\
\hline \multicolumn{3}{|c|}{ 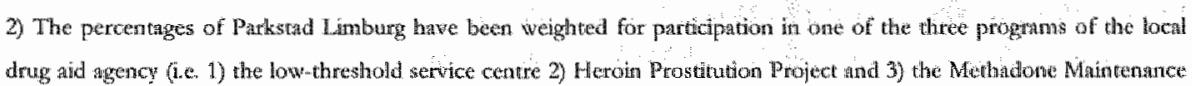 } \\
\hline
\end{tabular}

Selling pills or methadone and shoplifting were more popular in Rotterdam than in Parkstad Limburg (Table 4.3). However, in both cases getting money to score plays a major part in the lives of the drug users.

One thing that was on my mind today was that one client (Dutch, 30 years old) sold a laptop worth a few thousand guilders, just for two grams of brown, half a gram of white and 10 guilders cash. Not enough! (...) but he couldn't wait any longer. (Field note Rotterdam June 1999)

The ethnogtaphic data and the surveys show that begging in general (and begging dope from the dealer) occurs mote in Rotterdam than in Parkstad Limburg. In Rotterdam some drug users choose a strategic location (e.g. near a cash point) while others act helpless and try to gain sympathy.

\section{The sockal networte.}

In Parkstad Limburg we observed that the social network becomes cohesive without any support from family or non-using friends, and finally consists almost exclusively of drug users (Chapter 3)(Coumans et al., 2000). Self-interest is the standard; instrumentality dominates relationships and real friendship or longlasting alliances are scarce. The stress, arguments and aggression that occur are generally related to lack of money and dope, or the use of crack.

On this point, Rotterdam differs strikingly from Parkstad Limburg. In Rotterdam social relationships are not only determined by unsatisfied needs; drug users often consume their drugs together for social reasons, express concern for others, share or lend things, or warn each other about e.g. the police. Some drug users help those with physical disabilities and even offer each other protection. 
In the night shop I was involved in big fight and was suddenly standing in front of four Moroccans, one with a gun. I knew two of them were drug dealers. It is unbalievable, but Annic, a prostitute, came and stood right in front of me to protect me. This apparenty confused the guys, because the whole fight suddenly ended. Thank you Anniel (Field note Rotterdam June 1999)

In the netwotks of Rotterdam drug users there is also some social control, e.g. drug users sometimes confronted each other about their offensive behaviour.

I use drugs myself, but I always used on a discrete location when I wasn"t able to use in the consumption toom. I find it antisocial to use in the presence of women and children. (...) So I cross the street to give Said a scolding and take him to a dealing address. Further up I see Said him using drugs in a phone cell. I go to him and tell him what I think. (Field note Rotterdam November 1999)

Social control was also evident in the way that drug users notice the absence of others and enquire after a missing person. "This kind of social control can only occur within a teasonable stable group. Ethnic minorities tend to belong to such a group, while most local drug users operate on their own or with one other drug uset. Antillean and Surtiamese drug users often support each other or still get suppott from family members.

One of the dealers is Glenn, a Surinamese aged 43 years. He's from The Hague and has a sister who lives in (Rotterdam). Bccause he's got a brother-in-law here who provides him with cheap cocaine, he's started to sell balls (...) Another 22 year-old Suminamese man who came to live in (Rotterdam) also started selling cocaine a bit later (...) He's also got a family member who provides him with cheap cocaine. (Field note Rotterdam May 1999)

Thus, shared ethnic identity seems to have a positive effect on the social contact.

That solidarity among etllnic minorities was more appatent in Rotterdam than in Parkstad Limburg might be explained by the gteater number of Surinamese and Antillean drug users there (section 3.1). Moreover, Rotterdam has mote interests groups and dealing addresses or basements, regulated by dealers and drug users themselves, and one drug consumption room was initiated by drug users together with aid agencies and local residents. Such facilities provide some rest and protection that drug users obviously need.

\footnotetext{
A $\mathrm{basement}$ is a druy-dealing renue, facilitated by a non-governmental foundation, where matrinalised drug wers can buy and conswme heroin and cocaine in a relatively guict emviromment.
} 


\subsubsection{Catalysts}

\section{Crack}

The short half-time of cocaine combined with craving often leads to "bingeing": (Rosse et al., 1994). Our earlier study (Chapter 3) showed that continuous bingeing accelerates the process of marginalisation and hardening in that it leads to health and psychological problems as well as debts, fights and stress. In the description of crack related acceleration of marginalisation and hardening, we use three stages that Stetk-Elifson (1993) distinguished in the cycle of activities within base houses. In the first stage ("getting started") drug users form shortlasting alliances with one or two other drug users and pool their money to buy crack; this instrumental use of each other fits in with the hardening perspective. In the second stage ("getting high") drug users often are nervous when smoking and show agitation, paranoia and hostility towards others; this behaviour makes them more visible for the non-using environment and may accelerate the process of marginalisation. Under certain conditions using crack increases the risk of aggression (Chapter 3), especially when it is crowded, when drug users are "hunted" by the police, and when alcohol is used in combination with crack; thus crack also has a catalysing effect on hardening. In the third stage ("getting down") drug users often show a typical behaviour (e.g. constantly looking on the ground), which makes them more recognisable and thus increases the risk of (further) marginalisation.

Although in Rotterdam some drug users regained control of their cocaine use, the catalysing effect of crack on marginalisation and hardening was evident in both cities.

\section{Homelessness}

Homelessness is both an outcome and a catalyst of marginalisation and hardening (Coumans \& Spreen, 2003). This perspective fits in that of Johnson et al. (1997) who found that processes of social selection and social adaptation account for the association between homelessness and drug use. In an eatlier study, we identified homelessness as a catalyst of marginalisation because it increases the risk of social problems, unemployment and health problems (Coumans \& Spreen, 2003).

Data of both cities showed that once homeless, most drug users have difficulty finding a new place to live, and being an (illegal) foreigner can complicate this situation. Since homeless drug users are almost fulltime in the drug scene, homelessness also has a catalysing effect on hardening, forcing the drug user to develop certain survival strategies, consume drugs on the streets, and cope with any repressive police policy. 
It becomes increasingly hard for homeless drug users to survive. They te often hunted by the police - of ten without a clear reason. A while ago in the moming I wanted to wait on a bench until the basement opened. Then a police car passed by and they told me to "wallk". I asked them why, after all that bench is there for a reason. They told me not to get insolent. So I shut up (...) If they checked my data in thet system ...then I could go to jail to pay my fines. (Field note Rotterlam 1999)

With a repressive "keep mowing" strategy the social rights of the most visible and often homeless category of drug users seem to lose meaning.

Although the catalysing effects of homelessness are vallid for both cases, in Rotterdam $22 \%$ of the respondents are homeless compared with $37 \%$ in Parkstad Limburg $(\mathrm{p}<0.05)$. This could inply that in Parkstad Limburg more drug users are further in the process of marginalisation and hardening. Moreover, in Rotterdam there are more low threshold services than in Parkstad Limburg. In Rotterdam some of these services seem to suit in the lifestyle of drug users in that they allow dealers to sell drugs under certain conditions, or they support the intiative of a basement.

\subsection{Concluding remarks}

\subsubsection{Marginalisation}

A more or less continuous process of marginalisation chatacterises the lives of drug usets both in Rotterdam and Parkstad Limburg. This marginalisation is reflected in the social network, economic position and health status. Once drug use takes priority over other considerations, the drug user becomes allienated from 'nomal' social contacts and it becomes increasingly difficulit to keep a job or look after oneself.

Althougl the process of matginalisation accurted in both cities, some differences wete found between Rotterdam and Parkstad Limburg; i.e. in Rotrerdam some drug usets had regained some control over their drug use and ane less narginalised than in Parkstad Limburg. Examples are the lower number of homeless people, less drug users infected with hepatitis $C$ and HTV, more drug users who buy theit drugs at addresses and more people who have a regular job.

The condition allowing this include: less repressive measures against dealing addiesses, the presence of drug consumption rooms, interest groups, and an agency that supports drug users in finding (tempotary) jobs. That these contextual. factors are important in increasing the likelihood of maintaining and regaining control over drug use is confirmed by recent developments (taking place after the fieldwotk presented in this chapter) in both Rotterdam and Parkstad Limburg. In Rorterdam a mote restrictive policy on drug dealing addresses is associated with more users buying on the street and an increase in homelessness (van der Poel, Barendregt, Schouten et al., 2003). Meanwhile, in Parkstad Limburg a drug consumption room has been opened, employment for some drug users has been 
organised, and an interest group of drug users has been started. Both the outcome of the present study and the changes in both cities underline the importance of contextual factors on everyday life of the drug user (Zinberg, 1984).

Our main conclusion is that marginalisation (as defined in this study) is a concept that helps to describe and understand the deterioration of drug users extending from their social relations with core institutions to their own physical health. However, the original model of marginalisation and hardening needs to be revised to take into account the process counteracting marginalisation, that is socialisation. Moreover, the conditions which determine the extent to which marginalisation is counteracted by socialisation should also be included in the model of marginalisation and hardening (Figure 4.2).

\subsubsection{Hardening}

The process of hardening was similar in Rotterdam and Parkstad Limburg. In both cases social contacts are mainly instrumental, there is (almost) no social support from family or friends, aggression and violence are common, and money is obtained illegally. Especially drug tourists, prostitutes and drug users who show their vulnerability are "doubly marginalised", by society in general, and also within the drug scene.

One difference between Rotterdam and Parkstad Limburg is that more solidarity was evident in Rotterdam, probably due to the relatively large groups of Antilleans and Surinamese, and to the more structured and protective setting for drug use in Rotterdam compared to Parkstad Limburg. Shared cultural identity and the minority position in Dutch society may lead to more reciprocal social support in ethnic groups, and a more protective setting to buy and use drugs allows for checking the quality of drugs, selecting the customers, and more civilised behaviour between each other. This is line with the conclusions of Sterk-Elifson et al. (1993), who indicated the use of norms (such as sharing crack) as an explanation for the lower incidence of violence among users that gather in base houses.

In conclusion, although the concept of hardening characterises relationships in both cities, the original model should be revised to include the process of solidatity that counteracts hatdening, as well as the conditions that allow this.

\subsubsection{Catalysts}

Chronic heroin users using crack are at greatest risk to lose control. Since crack, compared with hetoin alone, is associated with an amplification and acceleration of matginalisation, we consider it to be a catalyst.

Although increased marginalisation associated with the use of crack was observed in both cities, in Rotterdam more drug users regained control over their cocaine use than in Parkstad Limburg. This difference may be due a learning effect, 
because crack was introduced in Rotterdam several years earlier than in Parkstad Limburg, allowing more time to develop ways of coping with this risk.

Another difference was the larger number of homeless (more marginalised) drug users in Parkstad Limburg. This may be because Rotterdam (being a large port) has a larger (and partly illegal) housing market making it easier for drug users to find a place to live.

\subsubsection{Conclusions}

It is obvious that losing controll over illicit drug use may initiate a process that is basically the same in both cities. However, closer inspection reveals differences between local diug scenes with respect to how fast and to what extent marginalisation and hardening takes place, and conditions and factors counteracting marginalisation and hardening. These processes towards socialisation and solidarity have therefore led to revision of the original theoretical model (Figure 4.2).

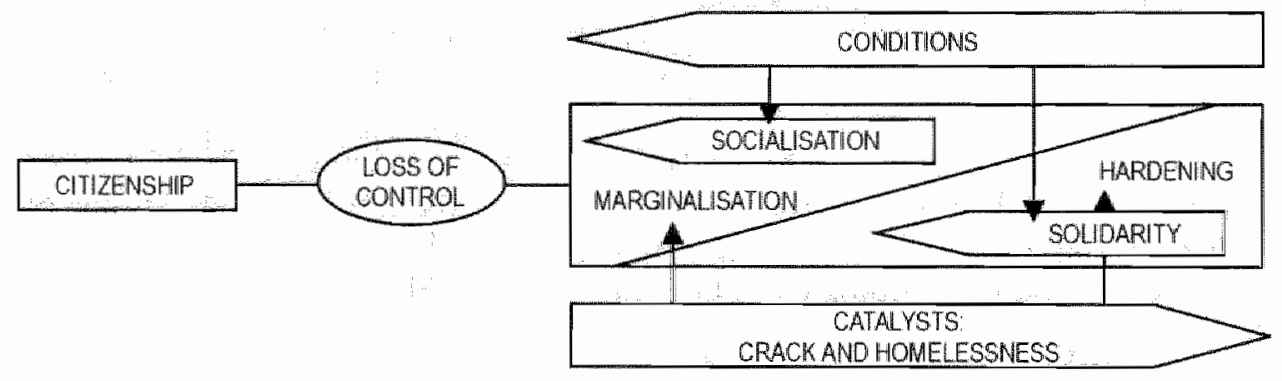

Figure 4.2: Revised model of the process of marginalisation and hardening

Finally, the factors leading to local differences in marginalisation and hardening have been observed from a theory-driven viewpoint rather than from a perspective to intervene. However, knowledge on which factors determine the extent to which the daily life of drug users is characterised by marginalisation and hardening versus socialisation and solidity are of major importance for a successful policy towards reducing harm for drug users and society. 


\section{References}

Barendregt, C., Lempens, A., \& van de Mheen, D. (2000). Drugs kopen op straat. Achtergtonden en motieven van Rotterdamse druggebruilkers die bij straatdealers kopen/ Buying drugs at the street. Background and motives of Rotterdam drug users who buy from street dealers. IVO Bulletin, 3 (1), 1-19.

Chenitz, W. C., \& Swanson, J. M. (1986). From practice to grounded theory. Qualitative reseands in mursing. California: Addison-Wesley Publishing Company.

Coumans, A. M., \& Knibbe, R. A. (2002). Druggebraikers in Parrestad Lingturg: Trends en profielen. Resultaten van bet Drag Monitoring System 2001-2002/ Drug users in Partestad Limburg: Trends and profites. Results of the Drug Montitoring System 2001-2002. Heerlen: Addiction Research Institute (TVO).

Coumans, A. M., Neve, R., \& van de Mheen, D. (2000). Hot procees wan manginalitiserving en werbarding in de drugscene van Partestad Limbung/The process of marginalisation and bardenting in the Parlestad Limburing drug sceme. Rotterdam: Addicrion Research Institute (TVO).

Coumans, A. M., \& Spreen, M. (2003). Drug use and the role of homelessness in the process of marginalization. Substance Ust do Misuse, 38 (3-6), 311-38.

Knibbe, R. A., Drop, M. R., \& Muytjens, A. (1987). Correlates of stages in the progression from everyday drinking to problem drinking. Sacial Science of Mediane, 24 (5), 463-73.

Lempens, A., Barendregt, C., Zuidmulder, L., \& Blanken, P. (1999). Kenmerken van Rotterdamse gebruikers: Enkele resultaten van de survey "drugs, huisvesting, schulden en gezondheid'/ Characteristics of Rotterdam drug users: Some results of the survey 'drugs, accommodation, debts and health'. IVO Bulletin, 2 (3), 1-20.

Rosse, R. B., Fay McCarthy, M., Collins, J. P., Alim, T. N., \& Deutsch, S. (1994). The relationship between coke-induced paranoia and compulsive foraging: $A$ preliminary report. Addictions, 89, 1097-104.

Seidel, J. (1998). Ethnograph w5.0 a user's guide. Thousand Oaks/ London: Scolati, Sage Publications Sofrware.

Spreen, M. (1999). Sampling persomal network strutures: Statistical inference in ego-graphs. $\mathrm{PhD}$ Thesis, Rijksuniversiteit Groningen, the Netherlands.

Spreen, M., \& Coumans, M. (2001). A note on network sampling in drug abuse research. Constections. Official Joumal of the International Network for Soctal Netzorte. Anabysis, 24 (3), $44-51$.

Sterk-Elifson, C., \& Elifson, K. (1993). The social organization of crack cocaine use: The cycle in one type of base house. Journal of Drug Issues, 23 (3), 429 - 41.

Strauss, A., \& Corbin, J. (1990). Basics of qualitative research: Grownded theory procedures and techniques. Newbury Park, CA: Sage Publications.

van der Poel, A., Barendregt, C., Schouten, M., \& wan de Mheen, D. (2003). De leefsituatic van gebruikers in de Rotterdamse harddrugscene (resultaten van de survey 2003)/ The situation of drug users in the Rottendam hard drug scene (results of the survey 2003). IVO Bulletin, 6, 1-19.

Yin, R. K. (1984). Case study research. Design and metbods (Vol. 5). Beverly Hills: Sage Publications.

Zinberg, N. (1984). Drug, set and setting. The basis for controdled intoxicant wse. New Haven/London: Yale University Press. 


\section{Chapter 5}

\section{Drug use and the role of homelessness in the process of marginalisation}

This chapter is published as the atticle AM Coumans \& Spteen, M (2003). Drug use and the role of homelessness in the process of marginalisation. Substance Use $\&$ Mswse, 38(3-6), 311-338. 


\begin{abstract}
The marginalisation theory of life histories implies that drug users who are considered as marginalised show more serious social, economic, physical and psychological problems than non-marginalised drug users. The degree of marginalisation is assumed to be an indicator of homelessness. The theory atgues that homelessness is a stage in the life of a user that is associated with the loss of control of use. In this chapter the effects of the dimensions of marginalisation on homelessness are reported.

The marginalisation theory emerged from ethnographic fieldwork research among the drug users population in Parkstad Limburg, the Nethetlands. Ethnographic fieldwork is often restricted to a (selective observed) part of the total population. To verify whether the marginalisation theory was valid for the total unknown population, we used quantitative data obtained in 1999 by a two-mode network sample $(n=58)^{2}$. As a conclusion homelessness was more likely to be present arnong marginalised than non-matginalised drug users.
\end{abstract}

\footnotetext{
T Notw that only the anselect recruited part of the total sample (n=103) has been included.
} 


\subsection{Introduction}

In this chapter we report about a study of the influence marginalisation has on homelessness in the daily life of drug users. To describe this influence we use data from the Drug Monitoring System (DMS), which is a Dutch project for: signalling trends and developments in urban drug scenes. Up to the present DMS-projects are employed in the cities of Rotterdam, Utrecht, and Parkstad Jimburg. In DMS projects qualitative as well as and quantitative information is continuously collected from the study population. For several reasons a mixed approach towards information about drug scenes has proven to be most appropriate. Qualitative fieldwork studies behaviours of drug users in their natural setting that cannot be signalled by quantitative approaches. However, ethnographic fieldwork has the disadvantage that processes observed by fieldworkers are restricted to the specific group observed. Although analytical generalisation (Wester \& Maso, 1991) can be obtained by abstraction of a phenomenon and comparisons between respondents, statistical generalisation is not the intention of qualitative research.

To collect a sample of drug users, in such a way that the observations can be considered as "representative", is frequently impractical. Often a sampling frame is lacking and members of so-called hidden populations are difficult to identify and/or to locate (Spreen, 1992). In literature some designs have been introduced to cope with specific sampling problems of hidden populations (Heckathom, 1997; Thompson \& Frank, 2000; Watters \& Biernacki, 1989). In this chapter a sampling design is introduced, which was specifically elaborated for our studly. This design, called a two-mode network design, is discussed in section 5.5. The Parkstad Limburg DMS consists of three different data collection methods of which two are qualitatively and one quantitatively oriented. The qualitative data collection methods are regular interviews with key informants, and structural ethnographic community fieldwork. The quantitative data collection method consists of a network survey sample.

From the field observations in Parkstad Limburg the impression emerged that homelessness is an important marker in the life. (histories) of drug users. Homelessness can be regarded as a time in the life of a user associated with the loss of control of his use. Once being homeless specific problems will even accumulate further in the daily life of the drug user. This accumulation is part of, what we define as the process of marginalisation of the drug user (Coumans et al, 2000).

The purpose of this chapter is twofold. The first aim is to consider the effect of several important dimensions of marginalisation on homelessness. The second aim is more from a practical nature. In the Parkstad Limburg study limited financial resources and other practical treasons led to the collection of crosssectional data. This is often the case in studies of hard-to-teach populations. However, it remains worthwhile to analyse the observed processes using quantitative cross-sectional data. Therefore the second aim of this study is to explore possibilities to infer the elaborated theory to the unobserved population of 
drug users using cross-sectional data. The limitations of this type of data to describe time-bounded processes will be discussed throughout this chapter.

The outline of the chapter is as follows. In section 5.3 the theory of marginalisation is introduced. Section 5.4 describes the translation of the qualitative observed processes into quantitative variables. The empirical research design is discussed in section 5.5 , while section 5.6 gives the results. Finally, section 5.7 gives some discussion. However, first some background information about homelessness and drug use in the Netherlands is discussed in section 5.2 .

\subsection{Homelessness and drug use in the Netherlands}

In the Netherlands several definitions of homelessness are used (Doorn van, 1994; Dutch Health Council, 1993; Dutch National Board for Homeless and Shelter, 1986; van Waveren et al., 1990). In the Parkstad Limburg study we have applied the definition of the Dutch Health Council (1993):

Homeless are those who do not have at their disposal or don't make use on the long term of private and regular housing or residential housing (including hospitals and prisons) or housing with family or friends. It concerns people who drift for a longer period of time (at least four weeks in a row) and spend:

1. the night on the streets, in parks, porches and public place that offer shelter against cold and wind

2. depending on the local regulation a limited amount of nights, in night shelter facilities

Dutch studies show two remarkable differences compared to foreign studies. In the first place Dutch studies usually make a distinction between several categoties of homeless, which are characterised by the "severity" of the housing circumstances. This severity refers to "the certainty of guaranteed shelter for the next night to come" (Health Council of the Netherlands, 1995). Therefore Dutch studies mostly distinguish between on the one hand people who are socially deteriotated, but still have the certainty of housing, and on the other hand the homeless who have actually lack of housing. The Dutch Health Council (1993) even distinguishes a third category, called the "marginal housed", which are persons with very poor housing circumstances and are at risk for becoming homeless.

A second difference is that non-Dutch studies focus at the economic association between developments at the housing market and becoming homeless, while the Dutch view on homelessness is characterised by the social-psychological tradition in which a lack of skills leads to an inability to develop and maintain contacts and to inadequate social support (Health Council of the Netherlands, 1995). Furthermore, studies about homelessness in the Netherlands are characterised by the exploration of need for care (Deben et al., 1992; Doorn van, 1994; Health Council of the Netherlands, 1995; Spierings, 1992; VNG/SGBO, 1990) and descriptive typologies of homelessness. 
The size of the roofless and homeless population in the Nethetlands is estimated between twenty and thirty thousand individuals (Health Council of the Netherlands, 1995), while their number is still increasing A comparative European study (Avramov, 1995) shows a relatively low number of homeless people in the Netherlands. Another study also points out that the number of homeless in the Netherlands is low compared to the USA (Spierings, 1992). However, it is important to note that international comparative studies show some limitations such as different definitions of the study population and different kinds of size estimations. Another remark is that homeless people in the Netherlands have more serious problems compared to the homeless people in other Europenn countries (Spierings, 1996). While the drug using component (according to the DSM IV) of the homeless population in the USA is estimated at eighty percent, in different Dutch cities this percentage varies from thirty percent to fifty-three percent (Drake et al., 1991; van Waveren et al., 1990).

In Parkstad Limburg the number of homeless people is estimated at 800 (Heyendael et al, 1990), while the estimated drug using component varies from $31 \%$ (Musch, 1998) to 37\% (Heyendael et al., 1990). The fraction of homeless among the drug using population in Parkstad Limburg, is estimated at $45 \%$ (Coumans et al., 2000), which is comparable with the Dutch city of Utrecht (Graaf de et al, 2000) and relatively high compared to the city of Rotterdam (Lempens et al., 1999).

\subsection{The process of marginalisation}

Homelessness can be considered as a key variable in the process of marginalisation. Observing drug users in their own social settings by intensive ethnographic fieldwork, Coumans (2000) introduced the concept of marginalisation to refer to a simultaneous process of social, economic, psychological and physical deterioration in which a drug user loses control of his use. During this process a user loses more and more the connection with key institutions of society (like education, housing and aid agencies) in which he/she also participates on a lower level (Buiks, 1983). Marginalised drug users usually do not participate in regular institutions, but rather seek help in low threshold services.

In the marginalisation process social deteriotation refers to the increasing homogeneity of social relationships of drug users. During the process, within th user his personal network, the fraction of outsiders (i.e. persons who are not drug users) decreases and the fraction of insiders (i.e. persons who are drug users) increases. As a result the personal network of a matginalised user will mainly contain insiders. In other words, users within the drug scene dominate the daily relational environment of a marginalised user. It is often around this moment in the process that a drug user is stigmatised as an addict because of the conceived nuisance by society.

At the same time the deterioration of a user has also an economic, psychological and physical dimension. As the control of drug use weakens, 
economic circumstances will decline for a drug user. A user may lose his job, he/she may become dependent of unemployment benefits, or he/she may be involved in illegal or ctiminal income activities. Also the susceptibility of several kinds of physical diseases such as dope sickness, infectious diseases and other physical complaints may increase. Psychological deteriotation may lead to several kinds of emotional and pswchiatric problems such as depressions, anxiety, and hallucinations.

One important key variable in the process of marginalisation is homelessness. On its own homelessness is an outcome of the marginalisation process and can be understood in the tradition of the social selection model described by Johnson at (1997) and supported by several studies (Spinner \& Leaf, 1992; Winkleby et al, 1992). Johnson et al (1997) also tested the social adaptation theory that suggests alcohol and drug abuse more likely to be a consequence of homelessness. In this model the use of alcohol and drugs is considered to be a means of adapting to street life (Strauss, 1946. Wiseman, 1978). Both models of social selection and social adaptation wete concluded to account for the association between homelessness and substance abuse and indicate that a multidirectional model is more appioptiate (lohnson et al, 1997). The proposed theory of marginalisation contributes to this model and considers homelessness not only as an outcome but also as a catalyst or drift factor that fastens the process of marginalisation. Buiks (1983) defines a drift factor as an individual or accidental factor, which causes a rapid in a certain direction, whereby free choices are no longer self-evident. In the underlying study apart from homelessness other important drift factors are: the loss of controlled use and the use of freebase cocaine (crack) (Coumans et al, 2001). Drift factors will lead to discontinuation of durable contacts with partners, family, and other outsiders. They also lead to problems in income acquisition such as keeping a legal job, and increase the probability of physical and psychological diseases.

The matginalisation process shows some resemblance with the social breakdown syndrome of Gruenberg (1974). The syndrome refers to the deterioration of psychiatric patients in terms of withdrawal, anger and hostility and combinations of these two. Analogue to the social breakdown process, the marginalisation process refers to withdrawal symptoms of a drug user implying the lost of interest in social functions such as labour responsibilities, housekeeping functions, and social obligations. Furthermore, like psychiatric patients, the decline of interest in personal appearance, dress, bodily cleanliness and toilet (Gruenberg, 1974), is characteristic for manginalised drug users.

Homelessness is also important in the transition from marginalisation to another phase, the so-called hardening phase (Coumans et al, 2000). Although an exhaustively description of the hatdening phase is beyond the scope of this article, it is important to mark that once a drug user becomes homeless he has to adapt to a new world in order to function daily in a variery of roles, contexts, environments and systems. Note that this process links up with the social adaptation perspective in which drug use is considered to be one of the means to cope with the new situation. Hardening refers to a likewise process of adaptation in which a drug user develops certain survival strategies, which is defined as the fulfilment of daily 
needs without taking into account long term goals, such as sawing money, paying the rent and take care of other recurrent expenses. Fot this purpose a drug uset develops several types of energies, strengths, skills and abilities to manage his life in which the use and ways of getring drugs plays a central role.

In Figure 5.1 the theoretical process of marginalisation is visualised. The figure shows that one contextual factor refers to the influence of external actors, such as the police, assistance and other people in the environment of the drug uset. Although the description of this influence is not of major relevance in this chapter it is important to notice that this study is about dynamic people whose behaviour is constantly influenced by the interaction with others.

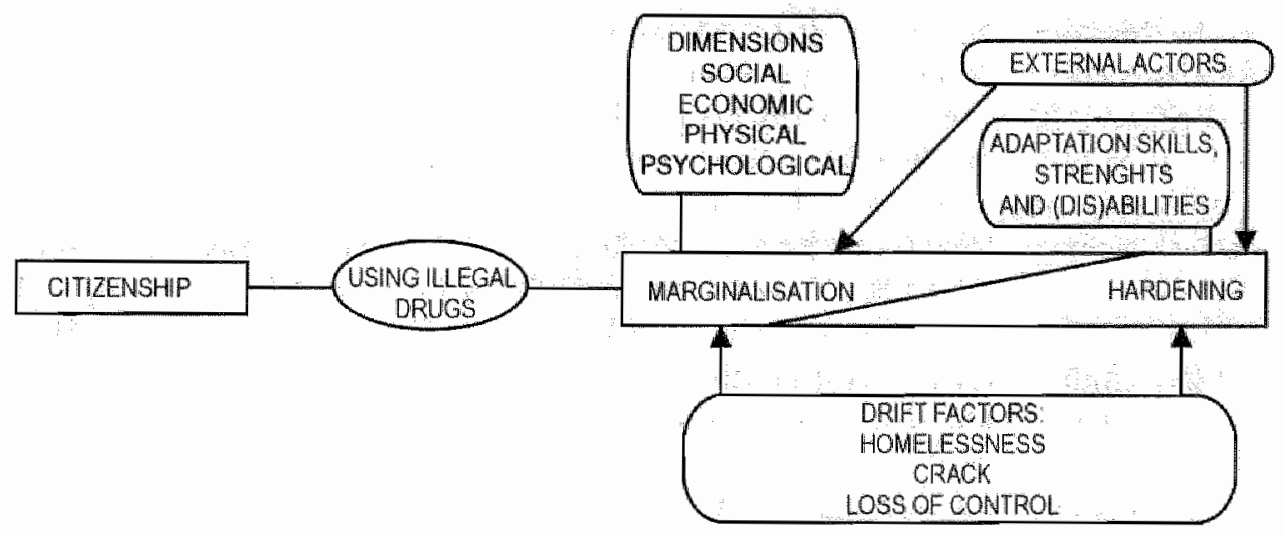

Figure 5.1: Theoretical model of marginalisation, hardening and catalysts

It is important to note that the marginalisation process is not a deterministic process. Marginalisation must be understood in terms of a complex, dynamic, multi-dimensional and directional phenomenon. Consequently phases do not necessarily manifest themselves chronologically. In fact two phases can occur simultaneously or occur even interchangeable in time.

\subsection{Hypotheses}

The observed marginalisation process emerged from a grounded theory approach (Chenitz \& Swanson, 1986; Strauss \& Corbin, 1990) to fieldwork data. As discussed in the introduction, a purpose of this chapter is to explote whether it is possible to verify this qualitatively signalled process of marginalisation by quantitative data. For that purpose we have formulated hypotheses that are distracted from the proposed theory. Obviously, studying a marginalisation process requires a longitudinal research design. Due to limited financial and time resources in the Parkstad. Limburg study only cross-sectional data could be collected, which restricts the interpretations of the findings. However when the sample is considered as a random cross-section of the different stages of the process in the 
life of the drug users it is possible to capture different manifestations of the marginalisation process. To translate the marginalisation process into observable quantiative individual characteristics we have defined several combinations of binary varibles, which intend to express the fout different deterioration edimensions of marginalisation (each variable indicates whether a user has a certain marginalisation characteristic or not). First the type of drug and manner of use needs specific attention.

\subsubsection{Control of drug use}

In this stady the type of drug used as well as the way of intake are considered to be a rough indication of the extent of control a drug user has over his use. According to the proposed theory people drug users who control their use are less likely to be homeless than drug users who don't control their drug use. We expect that homelessness is more likely to be present among people who use cocaine or inject theit drugs than among people who don't show this behaviour. On the other hand because the function of methadone is individual drag use management and harm-reduction we hypothesise that methadone using drug users are more stable and have more control over their drug use. Consequently they are less likely to be homeless than drug users who do not use methadone.

\subsubsection{Social dimension of marginalisation}

According to the proposed theory the drug user gradually becomes more drug use oriented and less involved with conventional society. Turning into a fulltime member of the drug scene the main priority of a drug user is to score drugs and to survive in a culture, which is determined by strict (hietarchical) rules. Close friends, i.e. people you may tust, ate rare in this setting. The alienation from civil society makes him dependent on facilities like (low threshold) drug aid agencies. The above is expected to count especially for drug users who are homeless. According to the minginalisation perspective we expect that the jointly occurrence of drug use and homelessness will lead to different network positions in terms of social integtation. Th other wonds compared to accommodated drug users homeless drug users will be less socially integrated in civil society and more socially integrated with other users who make use of low threshold services.

Another aspect of the social dimension of deterioration is the perceived behaviour of drug users by society. Drug users whose behaviour (or presence) is conceived as nusance by police and society are often the most visible and therefore likely to be homeless. Nuisance refers to street related social behaviour, which causes problems in the interaction between the drug user and other citizens. We hypothesise that while performing street activities a drug user causing such nuisance is more likely to be homeless than other drug users. 


\subsubsection{Economic dimension of marginalisation}

During the process of getting addicted most of the users become dependent of an unemployment benefit (Coumans et al, 2000). Due to drug related problems users are no longer capable of keeping their (legal) jobs. It is obvious that the performance of illegal or criminal activities in order to get money and drugs is inherently related to the adaptation to street life. These activities should be looked upon as survival strategies. From the marginalisation perspective typical economic street activities like selling drugs on the street market, working for a dealer and burglary at shoplifting are expected to fit mote in the lifestyle of homeless drug users than do legal sources of income acquisition. Therefore drug users who perform ctiminal activities are more likely to be homeless.

\subsubsection{Physicall dimension of marginalisation}

The degree of marginalisation will have an influence on the physical well-being of drug users. The priority of the more marginalised will be on scoring drugs and everything that support this activity. This focus will lead to ignorance of hygienic care, wounds, abscesses and other physical discomfort. Field notes of the Parkstad Limburg DMS support this physical aspect of marginalisation. This will often occur among those who have no shelter and thus are more subject to bad weather conditions and hectic circumstances. Therefore we expect drug users with severe physical health problems more likely to be homeless than less physical deteriorated drug users.

\subsubsection{Psychological dimension of marginalisation}

Like the shift of priorities from physical health to scoring drugs, the marginalisation theory also implies a shift from psychological well-being to drug related issues. This daily focus on drugs will lead to a neglect of psychological problems and problems will accumulate. Again this will count especially for drug users who are exposed to the stressing circumstances of street life. Therefore drug users with psychological problems are more likely to be homeless compared to those with less psychological deterioration.

\subsection{Research design}

\subsubsection{Sampling design}

The data we use are from a network sample held in 1999 among the population of drug users in the Dutch region of Parkstad Limburg. This region is located in the south of the Netherlands near the borders of Germany and Belgium. Parkstad Limburg comprises the city of Heerlen and eight surrounding 
municipalities (about 300000 inhabitants), and is nationally known as a drug problem area. The presence of the drug using population and accompanying problems is mainly concentrated in the city centre of Heerlen. In Parkstad Limburg 435 (nearly) dailly users of opiates, cocaine and other drugs were registered as a client of the aid agencies (at June 1, 1999). Local experts assessed this figure to be a substantial part of the total population. This auxiliary information was used to construct a special sampling design.

In this design we assume that the study population has a two-mode network structure, to reflect the fact that we consider two different sets of drug users (Wasserman \& Faust, 1994). In Parkstad Limburg we made a distinction between registered and non-registered drug users. This distinction was important for obtaining a representative statistical sample (Kruskal \& Mosteller, 1979-1980). To make statistical inference from a sample to a population a probability sample is needed; the probability of inclusion in the sample must be known and positive for all population members (Jansson \& Spreen, 1998). For the present study this was achieved as follows.

Frequently the sensitive nature of a hidden population does not allow some probability mechanism in the selection of respondents (Spreen, 1992). However in the Parkstad Limburg study we had the opportunity to draw at random 90 identification numbers from 435 registered users. The goal was to get a sample size of 60 clients of the aid agencies; the interviewers could not approach 40 clients because 31 selected persons could not be located and 9 persons were in prison or intramural. As a result local social workers approached 50 clients of the aid agencies of which 39 respondents were willing to participate. These respondents were actually interviewed by 8 interviewers of which 5 were drug users themselves and 2 were members of the research team. Before the start of the project all interviewers had been intensively educated in four training sessions. In order to cover the heterogeneity of the study population the drug using interviewers were selected on the basis of age (tange 30-45 years), gender ( 2 females and 4 males) and geographical location (4 from Heerlen and 2 from other municipalities).

Although the actual response rate was rather high (78\%), we have to be cautious with the high number of persons that could not be found by the fieldworkers. The majority of this group appeared to be heroin prostitutes implying that this special group was underrepresented in the final sample. The most obvious teason for the difficulties in finding the selected prostitutes was the summer holiday season, which implies less clients.

The respondents were told that personal data would be treated strictly confidential and that the reward for an interview was 15 Dutch guilders. Each selected aid agency respondent was asked to mention his/her relations with other users (alters) to a maximum of 10 . The criteria for the alters to be included in the sample were:

1. Respondent and alter must meet each other on a daily or regular base in Parkstad Limburg.

2. Respondent and alter must know each other's sur- and family name.

3. Alrer must know the respondent as a user of opiates (heroin and methadone) and/or other drugs (cocaine, pills, etc.). 
The 39 respondents mentioned 110 other registered and 83 non-registered users. The next step of the sample was to try to make a random selection of these non-registered users. This selection procedure was done as follows: per respondent two non-registered users were randomly selected (if possible) of which one had to be approached by the respondent. Each respondent could earn another 15 guilders (€6.80) by contacting the fieldworkers with the selected non-registered drug user. All 19 non-registered users who were actually approached participated, 5 clients did not mention other non-registered drug users, and the remaining 15 non-client users could not be traced due to practical problems.

The methodological rationale of this sampling design is that before sampling each member of the total study population has a positive inclusion probability to be observed in the final sample if we assume

1. that each individual drug user in Parkstad Limburg who is not a client of the aid agencies knows at least one drug user who is a client of the aid agencies

2. that there is no measurement error.

According to the local experts assumption 1 was valid; no expert expected a large group of users totally disconnected from the client group. Assumption 2 is much more difficult to meet. Especially the fact that $44 \%$ of the randomly selected non-registered users could not be traced will bias the final results. For the registered respondents we know that there is an under representation of heroin prostitutes, for the non-registered respondents we could not detect selective processes in the observed non-response.

An advantage of the Parkstad Limburg design is the possibility to compute design-based inclusion probabilities of each selected drug user. For the 39 selected aid agency users these are the sampling fractions; for the 19 selected users who are not clients their individual inclusion probabilities were computed according to their indegree (the number of clients that mention the specific non-registered drug user) (Snijders, 1992). The inclusion probabilities were used to weight the total sample. The sample in this study is understood as covering the major part of the drug using population in Parkstad Limburg except for the group of female heroin prostitutes. A statistical network study of this population is discussed by Spreen \& Coumans (Spreen \& Coumans, 2000; Spreen \& Coumans; 2001).

\subsubsection{Variables}

For each dimension of marginalisation we describe the variables used in this study. The administered questionnaire was partly based on the European Addiction Severity Index (Hendriks et al, 1991). Throughout the chapter each binary variable must be read as follows: showing the behaviour is coded 1 , otherwise 0 . First, the variables that indicate aspects of drug use control are introduced. 


\section{Control of drug wse}

The following variables are used as indicators of drug use control:

Cocaine whether the respondent used cocaine,

Methadone: whether the respondent used methadone,

Injecting: "whether the respondent injected his drugs.

Throughout this chapter all binary variables are valid for the last month before the interview.

\section{Social deterioration}

Social integration is measured by the following binary variables.

Parents: whether the respondent had contact with his/her parents during the last month,

Fitiends: whether the respondent has at least one close friend (not necessarily within the drug scene).

To measure the degree of integration within the (low threshold) institutions we used the network positions of personal networks. The proportion of registered drug users per respondent measures the network position. Figure 5.2 illustrates four hypothetical maximum network positions. The circles represent registered users ( $R D U-s$ ), the boxes non-registered users (nRDU-s). In Figures 5.2.1 and 5.2.2 the tespondent is a registered user (black) and in Figures 5.2.3 and 5.2.4 the respondent is a non-registered user (black).

In Figure 5.2.1 the focal registered drug user is sollely connected to three other registered users implying a proportion of 1 . In other words this registered user is considered completely integrated within the registered drug users subpopulation. Figure 5.2.2 represents the opposite situation; the focal registered drug user is now solely directly connected to non-registered drug users implying a proportion of 0 . This registered drug user is considered as completely disintegrated within the registered drug users subpopulation.

In Figures 5.2.3 and 5.2.4 the focal person is now a non-registered drug user. The proportion registered drug users in the personal network of the focal nonregistered user in Figure 5.2.3 is 1 while Figure 5.2 .4 illustrates the opposite situation. In other words: a high proportion for a focal non-registered user implies a high level of integration within the tegistered users subpopulation and a low level of integration with other non-registered users. The opposite interpretation applies to Figure 5.2.4. 

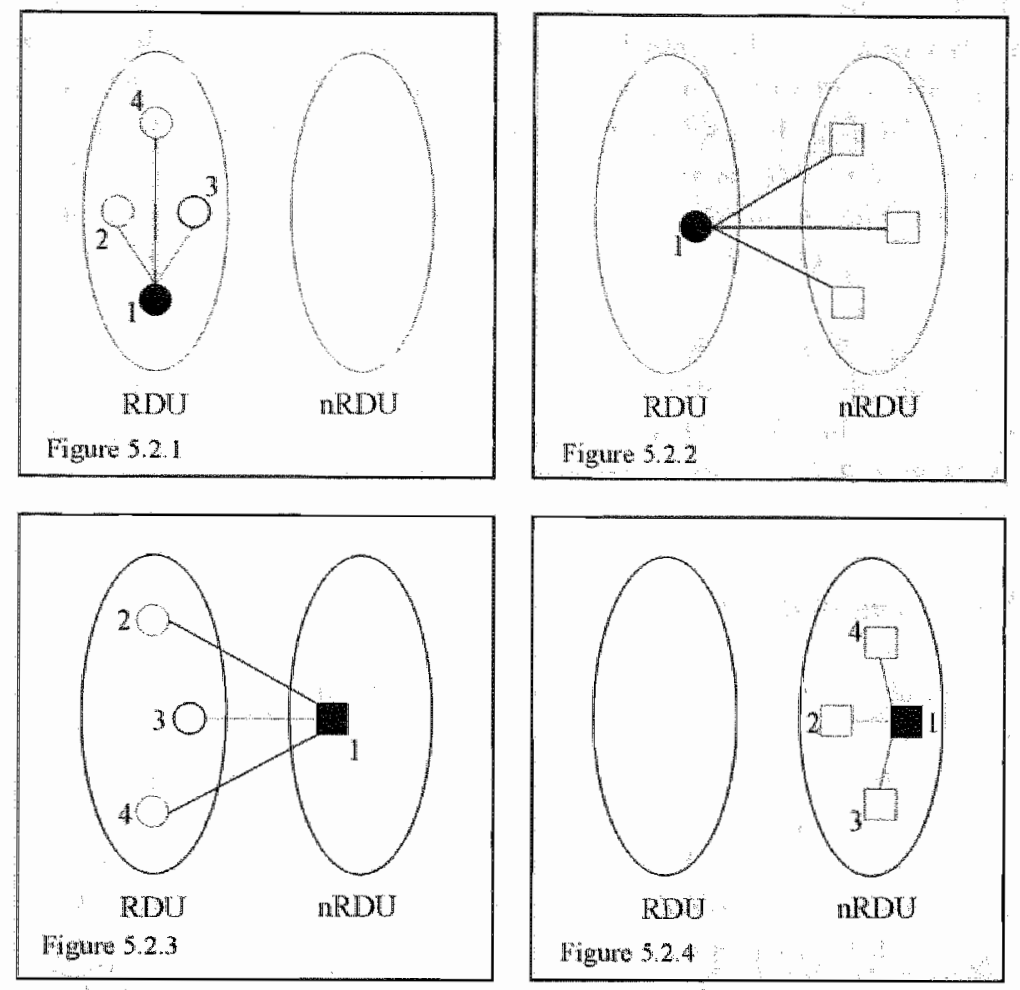

Figure 5.2: Four hypothetically maximum network positions

Another aspect of social deterioration is the increasing social life at street of a marginalised user. The resulting street related nuisance refers to potential problems in the interaction between a drug user and society. To measure the extent of nuisance we used the following variables.

Public use: whether the respondent uses drugs at public places.

Buying at street: whether the respondent buys drugs at the street market.

Arrested: whether the respondent has been arrested for wiolation of civil order.

\section{Economic deterioration}

To describe economic lifestyle we use different binary variables as an indicator of the degree of illegal or criminal resources of income acquisition.

Dealing:

Selling:

Running:

Offence: whether the respondent deals drugs for reasons of profit.

whether the respondent sells methadone or pills at the black market.

whether the respondent sells drugs as employee of a dealer.

whether the respondent earns an income from offences against property (burglary, shoplifting, etc). 


\section{Health detenoration}

For practical reasons in this study we have combined physical and psychological deterioration into two binary variables that roughly express absence or presence of severe physical diseases and psychological or emotional problems. Psychological or emotional problems are measured by:

psychological: whether the respondlent has feelings of depression, strong feelings of anxiety, and concentration problems and hallucinations.

Physical problems are measured by:

physical. whether the respondent has hepatitis $B$ or $C$, tuberculosis, venereal disease, HIV, pneumonia, other lung problems, abscesses, dental complaints and skin disorders.

\subsubsection{Statistical analysis}

Despite the possibility of design-based weighting of the respondents, the rather small sample size $(n=58)$ restricts the application of straightforward multivariate statistical techniques. For this reason we separately analysed the binary variables expressing each marginalisation dimension with as dependent variable 'being a homeless or not'. Due to the small sample size, before each separate logistic regression analysis we controlled for numerical problems. These problems may be caused by zero cell frequencies, complete separation between two outcome groups and collinearities among independent variables (Hosmer \& Lemeshow, 1989). For those covariates causing numerical problems descriptive contingency tables are reported; for other (collection of) covariates logistic regressions were applied. By convention each table reports weighted percentages as well as unweighted numbers. The network position of homeless drug users was tested by a Mann-Whitney test. Throughout the chapter $\alpha=0.05$.

\subsection{Results}

\subsubsection{Background characteristics}

The total number of drug users in Parkstad Limburg was estimated to be about 800 consisting of $80 \%$ male and $20 \%$ female users. Men were about 38 years old and women about 32 years. The overall design-based weighted proportion of homeless drug users (hereafter referred as HDU -s) in the total study population was estimated 0.48; the proportion of HDU-s that is client of the aid agencies was estimated 0.51 , while the proportion of $\mathrm{HDU}$-s that is not a client was estimated 0.30 .

Age as well as gender of the HDU-s in Parkstad Limburg did not deviate from the population distribution. The gender distribution of the HDU-s was estimated about $76 \%$ male and $24 \%$ female. The male HDU-s were about 38 years, the fernale $H_{D U}$ s about 31 years. In Table 5.1 some further descriptive information 
about the monthly use of drugs within the about the weighted sample data is provided.

Table 5.1: Monthly use of drugs $(\mathrm{n}=58)$

\begin{tabular}{lllll}
\hline Awerag number of days of: & HDU & (SD) & ADU & (SD) \\
Heroin use & 25 & $(9.5)$ & 18 & $(13.2)$ \\
Cocaine use & 15 & $(11.8)$ & 7 & $(9.9)$ \\
Methadone use & 11 & $(14.6)$ & 19 & $(14.4)$ \\
Alcohol use & 10 & $(12.2)$ & 9 & $(12.1)$ \\
Dary intake in gram's: & & & & \\
Heroin & 0.92 & $(0.73)$ & 0.58 & $(0.68)$ \\
Cocaine & 0.81 & $(1.08)$ & 0.32 & $(0.38)$ \\
Methadone (milliliter) & 17 & $(23)$ & 28 & $(25)$ \\
Alcohol (in glasses) & 6.6 & $(8.16)$ & 3.5 & $(5.6)$ \\
\hline
\end{tabular}

As can be observed in Table 5.1 homeless drug users tend to use more and more frequently drugs than accommodated drug users (hereafter teferred as ADUs), except for methadone.

\subsubsection{Control of drug use}

The degree of control a drug user has about his use is an important variable in the marginalisation process. The type of drug and whether a drug user injects are considered to be behaviour that indicates the extent of loss of control. According to the theory among people who use cocaine or inject drugs homelessness is more likely to be present. Furthermore methadone users are less likely to be homeless. Table 5.2 gives the final logistic regression model of the control of use dimension.

Table 5.2: Logistic regression of control of drug use on homelessness

\begin{tabular}{lcccc}
\hline & Coefficient & $(\mathrm{SF})$ & Odds Ratio & $(95 \% \mathrm{CI})$ \\
\hline Cocaine & 0.51 & $(0.25)^{*}$ & 1.67 & $(1.03 .2 .72)$ \\
Methadone & -1.45 & $(0.21)^{* * *}$ & 0.23 & $(0.16-0.35)$ \\
Injecting & 1.37 & $(0.21)^{* *+}$ & 3.92 & $(2.58-5.95)$ \\
Constant & -0.39 & $(0.22)$ & & \\
\hline
\end{tabular}

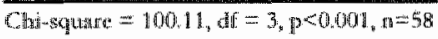

*aw $p<0.001$; * $p<0.01 ; * 0 \times 0.05$

Injecting drugs and cocaine use is generally accepted as problem behaviour. From Table 5.2 we observe that these behavioural factors are important predictors for homelessness. Corrected for the other variables in the model cocaine users are more likely to be homeless than non-cocaine users, and injectors are almost 4 times as likely as non-injectors to be homeless. Conversely methadone users have a lower probability to be an HDU than non-methadone users. 


\subsubsection{Social deterioration}

The network position of a drug user is measured by the proportion of relations he/she has with other registered drug users. To test whether HDU-s are more integrated with registered users (thus users who participate in aid agencies) we applied a Mann-Whiney test. The results are displayed in Table 5.3.

Table 5.3: The network position of HDU-s versus ADU-s

\begin{tabular}{|c|c|c|}
\hline Registered Drug Users & Mean tank & \\
\hline Homeless (HDO) & 252 & \\
\hline Not homeless(ADU) & 186 & $p<0.001$ \\
\hline Non-wegistered Drug Users & Mean tank & \\
\hline Homcless (HDU) & 52 & \\
\hline Not homeless (ADU) & 35 & $\mathrm{p}<0.01$ \\
\hline
\end{tabular}

Registered HDU-s as well as non-registered HDU-s have a significant higher mean rank (and thus a higher proportion) than ADU-s. Recalling that a high proportion implies a strong integration of a drug user with registered users, the network positions of homeless drug users are mainly located within or close to the registered subpopulation.

The results of the logistic regression of the two other social integration variables, i.e. "Parents" and "Friends", are displayed in Table 5.4. Both social integration indicators are negatively related to homelessness implying that drug users who do not have contact with their parents and do not have any close friends are more likely to be homeless.

Table 5.4: Logistic regression of social network variables on homelessness

\begin{tabular}{lllll}
\hline & Coefficient & $($ SE & Odds Ratio & $(95 \%$ CI $)$ \\
\hline Parent & -0.43 & $(0.19)^{*}$ & 0.65 & $(0.45-0.94)$ \\
Friend & -0.65 & $(0.18)^{\text {*** }}$ & 0.52 & $(0.36-0.75)$ \\
Constant & 0.59 & $(0.20)$ & & \\
\hline
\end{tabular}

Chisquare $=16,67,05=2, p<0,001, n=58$

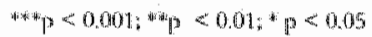

Another obvious aspect of the marginalised user is life at street. A multiple logistic regression with the three "street life" covariates, i.e. "buying at street", "public use" and "arrested", was statistically not allowed because of numerical problems. Of the $26 \mathrm{HDU}$-s one respondent reported not buying at the street (Table 5.5a), while of the $32 \mathrm{ADU}$-s two had been arrested because of nuisance (Table 5.5b). 
Table 5.5a: Crosstabs of buying at street and homelessness

\begin{tabular}{llc}
\hline & \multicolumn{1}{c}{ Buying at street } \\
\hline & Yes & No \\
\hline Homeless & 25 & 1 \\
Not Homeless & 13 & 19 \\
\hline Odds rario: 32, p $<0.001,95 \%(\mathrm{CI}=17-61)$ & &
\end{tabular}

Table 5.5b: Crosstabs of arrested and homelessness

\begin{tabular}{lcc}
\hline & & Arrested \\
\hline & Yes & No \\
\hline Homeless & 10 & 16 \\
Nor Homeless & 02 & 29 \\
\hline
\end{tabular}

Odds ratio: 6, $\mathrm{p}<0.001,(95 \% \mathrm{Cl}=4-10)$

Table 5.5c: Crosstabs of public use and homelessness

\begin{tabular}{lcc}
\hline & & Public use \\
\hline & Yes & No \\
\hline Homeless & 22 & 4 \\
Not Homeless & 10 & 22 \\
\hline
\end{tabular}

Odas ntio: $13, p<0,001,95 \%(C)=921)$

The very low occurrence of certain characteristics does not necessarily imply that this is a result of a low sample size, and thus hard to interpret. Recalling that the respondents were drawn at random from the aid agency list and from the nominated alters, and no extra effort was made to sample homeless users, we argue that a low prevalence of certain characteristics is a strong indication that such characteristic is simply rare among the population and not purely the result of a low sample size. Therefore we report three separate contingency tables (Table 5.5). We decided to teport also the weighted odds ratio, to illustrate the prominence of the rare characteristics. Apparently the most marginalised users in terms of being arrested, using in public and buying at street ate more likely to be homeless compared to less marginalised users.

\subsubsection{Economic deterioration}

From the marginalisation perspective drug users who employ typical economic street activities such as selling drugs on the street market, working for a dealer and shoplifting are expected more likely to be homeless than drug users who do not perform such criminal activities. Also in the analysis of the economic dimension we encountered some numerical problems. Inspecting the contingencies tables in Tables $5.6 \mathrm{a}$ to $5.6 \mathrm{c}$ we observe a category of $31 \mathrm{ADU}-\mathrm{g}$ who are nor involved in the respective criminal activities. This would cause separation in a multiple logistic regression. 
Table 5.6a: Crosstabs of dealing and homelessness

\begin{tabular}{lll}
\hline & Yes & Dealing \\
\hline & 8 & No \\
\hline Homeless & 1 & 18 \\
Not Homcless & 31 \\
\hline
\end{tabular}

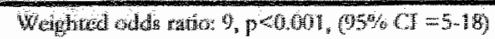

Table 5.6b: Crosstabs of selling and homelessness

\begin{tabular}{llc}
\hline & Yes & Selling \\
\hline & 1 & No \\
\hline Homeless & 1 & 25 \\
Not Homeless & 31 \\
\hline
\end{tabular}

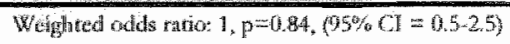

Table 5.6c: Crosstabs of running and homelessness

\begin{tabular}{llc}
\hline & Yes & Running \\
\hline & 9 & No \\
\hline Homeless & 1 & 17 \\
Not Homeless & 31 \\
\hline
\end{tabular}

Weighted odds ratio: 63, p $00001,(05 \% 01=16-256)$

Table 5.6d: Crosstabs of offences against property and homelessness

\begin{tabular}{lcc}
\hline & Yes & Offences \\
\hline & 4 & No \\
\hline Homeless & 5 & 22 \\
Not Homeless & 27 \\
\hline Weighted odds ration $0.8, \mathrm{p}=0.34,(95 \%, \mathrm{CI}=0.5-1,3)$ &
\end{tabular}

Focusing on the prevalence of the abovementioned economic activities we see that selling drugs and oflences against property has no effect on the likelihood of being homeless. Concordant with the marginalisation theory drug users who are dealing drugs are 9 times as likely to be homeless than non dealing drug users. The very strong positive effect of Running can be understood as an indication of the (nearly) absence of this activity among the ADU-s in Parkstad Limburg. Considering the three drug market activities (Tables $5.6 \mathrm{a}, \mathrm{b}, \mathrm{c}$ ) the few observed 'marginalisation' activities ate mainly due to the HDU-s. This observation is in line with the proposed theory. 


\subsubsection{Health deterioration}

Health condition is also an indicator of marginalisation. In this study we introduce two variables to express the state of health of a drug user, Table 5.7 presents the results.

Table 5.7: Logistic regression of health variables on homelessness

\begin{tabular}{lllll}
\hline & Coefficient & $($ SE) & Odds Ratio & $(95 \%$ CD \\
\hline Psychological & -0.47 & $(0.22)^{*}$ & 0.62 & $(0.41-0.95)$ \\
Physical & 1.22 & $(0.22)^{* * *}$ & 3.40 & $(2.20-5.20)$ \\
Constant & -0.63 & $(0.23)$ & & \\
\hline
\end{tabular}

Chisquare $=35,33_{3} d f=2, p<0.001, n=58$

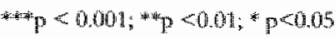

Table 5.7 supports the marginalisation perspective of the physical dimension. Drug users who have severe physical diseases are 3 times as likely to be homeless than drug users who have no severe physical problems. Surprisingly, among drug users with psychological and emotional problems homelessness is less likely than among others.

\subsection{Discussion}

For the sake of clarity this section consists of two parts. The first part deals with some methodological remarks with respect to issues of design, sample size, response rate and external validity. In the second part the emphasis is on the substantial question about the relationship between matginalisation and homelessness.

\subsubsection{Methodological remarks}

This study employs cross-sectional data to examine longitudinal processes. Acknowledging the facts that marginalisation is a time-dependent process and our network sample is an observation at one point in time, the sample of respondents is considered as a sample of individual positions in the process of marginalisation. Furthermore the distribution of these individual positions in the process is understood to be a cross-section of the possible stages of marginalisation, which is inherent to the randomness of the sample. Nevertheless in order to inctease the validity and facilitate the interpretation of the results, in future research a longitudinal clesign in which respondents are followed over a longer period of time is more appropriate. Also for future needed hypotheses building a longitudinal design is recommended, because the present study only explores necessary conditions for the process to operate.

Another methodological issue is that of quantification of a phenomenon that is qualitative in nature. Such an approach seriously limits the richness of 
ethnographic data and therefore we argue that quantification is only valuable if presented in combination with observations from ethnographic fieldwork. Without this qualitative foundation the quantitative analyses would be meaningless and interpretation would be very difficult. The present study pointed out that qualitative and quantitative information complements each other well. Results from the quantitative analyses are used to place certain qualitative observations into a population perspective. Due to the specific circumstances we were able to network sample drug users randomly, which provided us a sample that could be considered as representative for the major part of the population. Therefore we could vetify the elaborated marginalisation theory of drug use that originally emerged from the qualitative fieldwork. $A$ mixed approach in which quantification is supplementary and serves as a statistical verification is a promising model for future studies of hidden populations.

Another remark concerns the non-response rate. Although the actual response rate among registered drug users was rather high (78\%), there was a fairly high number of persons that could not be found by the fieldworkers. The majority of this group were heroin prostitutes implying that this special group was underrepresented in the final sample. To solve such practical problems is difficult. In future studies special attention must be paid to hard to reach subcategrones of drug users or homeless. For example, in our study the heroin prostitutes should be better approached in the winter season and a regularly update of the registration system would help to find the heroine prostitutes. Considering the non-registered drug users we saw that although all the actually approached drug users participated, $43 \%$ of these selected drug users could not be traced in spite of the extra reward for the clients. Although we have no reason to believe that this observed nonresponse is selective, in future research this issue should be considered.

Our last methodological remark concerns the external validity of our findings. Although a secondary analysis has already been executed on ethnographic data of the city of Rotterdam (see Chapter 4), we recommend for future research to further explore the external validity of the findings in other urban areas. In general the mixed approached of qualitative and quantitative research and network sampling could be a guiding principle for further conceptualisation in order to continue our exploration in this challenging dynamic area.

\subsubsection{Marginalisation and homelessness}

Marginalised drug users are more likely to be homeless than non-marginalised drug users. Taking into account the abovementioned methodological limitations, this is the main conclusion of this study. This counts for all independently of each other analysed dimensions of the concept of marginalisation. More specifically the following behaviour increases the odds on homelessness within each particular dimension: injecting drugs, using cocaine, having no contact with friends and family outside the drug scene, buying and using drugs at public places, having been arrested, dealing drugs, running and physical health. As could be expected using methadone is negatively related to homelessness. Methadone users are mostly 
more stabilised than others, which can be explained by the voluntarily nature of the methadone progtam. Taking part in such a program implies a certain motivation to maintain control of their life.

One remarkable finding was that psychological deterioration is negatively related to homelessness. Possibly this can be explained by our observation that drug users who do not report psychological problems are preoccupied with the possession of drugs and related activities. In fact psychological problems are repressed and overpowered by these drug related activities, which can be considered as adaptation strategies and thus will be especially be apparent in the lives of the homeless.

Another remarkable finding is that social networks of the homeless are structurally located within or near the aid agencies implying that HDU-s are less integrated in civil society. This corresponds to the observations of ethnographic fieldworkers; adapting to the dynamics of the drug scene HDU-s tend to visit especially low-threshold institutions. Their daily social contacts are located within or near these locations and their social lifestyle is concentrated around these institutions.

The main conclusion that marginalised drug users are more likely to be homeless than others could easily be translated into a deterministic model in which marginalisation leads to homelessness. However, this is not at all congruent with the proposed theory of marginalisation, which considers homelessness also as a drift factor that accumulates certain deterioration processes. As mentioned before the proposed theory can be understood in the tradition of social selection as well as in the tradition of social adaptation and contributes as such to the proposed multiditectional model of Johnson et al (1997). In accordance with the conclusions of Johnson et al (1997) we place the multidirectional model into a broader perspective, indicating that not only the relation between drug use and homelessness should be taken into account, but also the different dimensions of marginalisation and the three drift factors. Consequently the presented model in this chapter is considered to be multidirectional as well as multidimensional. Furthermore assistance should be in line with such a model; which means that apart from homelessness and drug use also social and economic circumstances, health constitution and loss of drug use control should be taken into consideration. In general during the process of marginalisation a drug user becomes more drug use oriented and less involved with conventional society as well as with non-drug users. This leads us to the final recommendation that interventions should focus on the reversion of the process of marginalisation in order to support the drug user in regaining control of his drug use and life. 


\section{References}

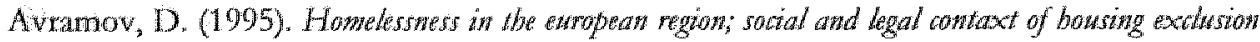
in the 1990's: Fourth restarb repont of the curoplan obsenatory of bamelessness. Brussels: FEANTSA.

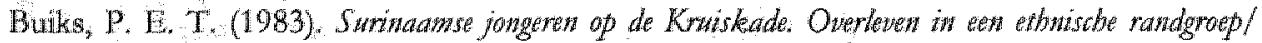
Surinawese younguters on the Krutskade Santwal anowg athwir drop-owts. Deventer: Van Loghum Slaterus.

Chenitz, W. C., \& Swanson, J. M. (1986). From pratice to grounded theory. Qualitatise meseand in nursing, California: Addison-Wesley Publishing Company.

Coumans, A. M., Barendregt, $C$, van der Poel, $A$, \& van de Mheen, D. (2001). Marginalisering en verharding in het perspectief van de Rottetdamse drugscene/ Marginalization and hardening in the Rotterdam drug scene. IVO Bullettn (1).

Coumans, A. M., Neve, R., \& van de Mheen, D. (2000). Het prowes wan marginalisening en werharding in de drugscene van Partestad Limburg/ The prowess of marginalisation and bardening an the Parlestad Limburg drug sane. Rotterdam: Addiction Research Institute (IVO).

Deben, D., Godschalk, J., \& Huijsman, C. (1992). Dakbogen in Asterdas en de rest wan de Randstadl The bosneless in Amsterdans and the rest of the regron of Randstad (No. 41). Ansterdam: University of Amsterdam.

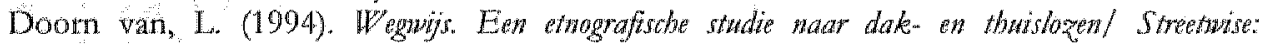
Ethograpbic study on bomelessmess. Utrecht: Nederlands Instirut Zorg en Welzinn (NIZW).

Drake, R. E., Osher, F. C.* \& Wallach, M. A. (1991). Honnlessness and dual diagnosis. Anurican Psybalogist, 56, 1149-58.

Dutch Health Council. (1993). Daklooshetd en psychiatrishe problentex; adves over openang vor

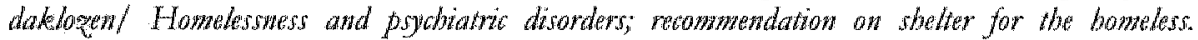
Publication no. 26/1993. The Hague: Dutch Health Council.

Dutch National Board for Homeless and Shelter. (1986). Policy paper for care of bomeless. The Hague: LSTO.

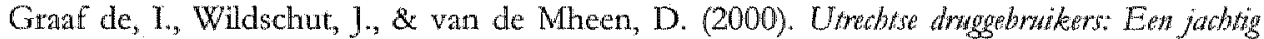

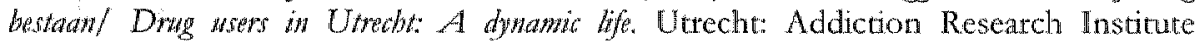
(IVO).

Gruenberg, E. M. (1974). The social breakdown syndrome and its prevention. In C. Caplan (Ed.), American bandbook of psychiary, part II. New York: Basic Books.

Health Council of the Netherlands. (1995). Dathogen en thwislagen/ Rooptess and boyneless (No. 1995/10). The Hague: Health Council.

Heckathorn, D. D. (1997). Respondent-driven sampling: A new approach to the study of hidden populations. Social Problems, 44 (2), 17499.

Hendriks, V. M., van der Meer, C. W., \& Blanken, P. (1991). De Addiction Sexarvy Index" ASI (R). Handlaidng bij traning an afname/The Addianon Senerity Index (R). Manual for training ayd adwiwystering. Rotterdam: Addiction Research Institute (TVO).

Heyendacl, A., Brouwers, M. H. R., \& Nuy, P. F. I. M. (1990). Tharishosheid in Oostelgte Zwid-

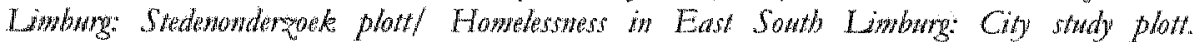
Nijmegen: Institut voor Sociale Gezondheid, Universiteit van Nijmegen.

Hosmer, W. D., \& Lemeshow, S. (1989). Applied loging regression. New York: John Wiley \& Sons, Inc.

Jansson, I., \& Spreen, M. (1998). The use of local networks in a study of heroin users: Assessing average local neworks. Bulletin de Methodologie Sorologigue, 59, 49-61.

Johnson, T. P., Freels, S. A., Parsons, J. A., \& Vangeest. J. B. (1997). Substance abuse and homelessness: Social selection of social adaptation? Addition, 92 (4), 437-45. 
Kruskal, W., \& Mosteller, F. (1979-1980). Representative sampling 1, II, II, and TV. Intermational Statistical Review, $47-48$.

Lempens, A., Barendregt, C., Zuidmulder, L., \& Blanken, P. (1999). Kenmerken wan Rotterdamse gebruikers: Enkele resultaten wan de survey 'drugs, huisvesting, schulden en gezondheid/ Chatacteristics of Rotrerdam drug users: Some results of the survey 'drugs, accommodarion, debts and health'. IVO Bulletin, 2 (3), 1-20.

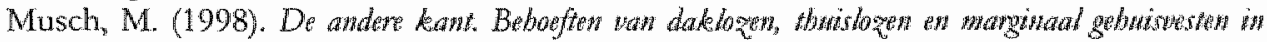
Oostelife Zuid Limburg/The other side. Nedt of bomeless in East South Limbrry Stichung Regionale Instelling voor Matschappelijke Opvang Parkstad Limburg (RIMO)/Universiteit Maastricht, Masstricht.

Snijders, T. A. B. (1992). Estimation on the basis of snowballsamples: How to weight? Bulletis de Methodologie Sociologique, 36, 59-70.

Spierings, F. (1992). Daklaoshed in Nederland en in de Verengde Stand Homelessmers in the Netherkands and the United States of Amerio. Rotterdam: SoZaWe.

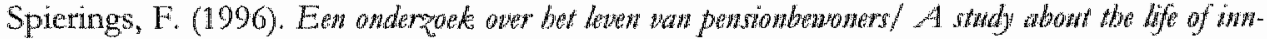
residents. Urecht: Uitgewerij SWP.

Spinner, G. F., \& lueaf, P. J. (1992). Homelessness and drug abuse in New Haven, Hospitat and Comonumity Pycbianty. 43, 166-68.

Spreen, M. (1992). Rate populations, hidden populations, and link-tracing designs: What and why? Bulletin de Methodologite Sociologique, 36, 34.58 .

Spreen, M, \& Coumans, A. M. (2000). Network sampling hard drug users: A structural analysis of the clients of aid agencies in Heerlen. Kivantitative Mothoden, 21 (65), 95-112.

Spreen, M. \& Coumans, M. (2001). A note on network sampling in drug abuse research. Connections. Official Joumal of the Intemational Nenwork for Social Netwonk Analysis, 24 (3), $44-51$.

Strauss, A., \& Corbin, J. (1990). Basice of qualitative reseamb: Grotuded theory procedore: and tedniques. Newbury Park, CA: Sage Publications.

Strauss, R. (1946). Alcohol and the homeless man. Quarterby jouryol of studies on alcobol, 7, 360404.

Thompson, S. K. \& Frank, O. (2000). Model-based estimation with link-tracing sampling designs. Surwy Methodology, 26 (1), 87-98.

van Waveren, B., Kocken, P., \& van de Ven, T. (1990). Dakw on thushloos/ Rooflews and bowneless. Rorterdam: Sociale Dicnst.

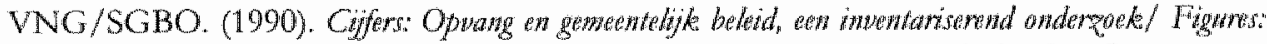
Shelter and wwicipal polioy, an inwewtory stwdy: Vereniging wan Nederlandse Gemeenten, afdeling Sociaal Geografisch en Bestuurskundig Onderzoek.

Wasserman, S., \& Faust, K. (1994). Social wetwonk analysis. Muthods and applications. Cambridge: Cambridge University Press.

Watters, J. K, \& Biernacki, P. (1989). Targeted sampling: Options for the study of hidden populations. Social Problenzs, 36, 416-30.

Wester, F., \& Maso, 1. (1991). The process of analysis in qualitative research. In $\mathrm{F}$. Wester \& I. Maso (Eds.), Moeilijkbeden en mogelijlebeden/ Trowble asud opportwnities. Ansterdam: SISWO.

Winkleby, M. A., Rockhill, B., Jatulis, D., \& Fortman, S. P. (1992). The medical origins of homelessness, American Journal of Public Health, 82, $1395-98$.

Wiseman, J. (1978). Stations of the lost: The theatment of skeid row alcobolics. Englewood Cliffs, N. Prentice Hall. 


\section{Chapter 6}

\section{The deteriorating effects of crack among chronic heroin users: a two case study in the Netherlands}

This chapter is based on the article "The deteriorating effects of crack among chronic heroin users: a two case study in the Netherlands", by Moniek Coumans, Ronald Knibbe and Dike van de Mheen. 


\begin{abstract}
This chapter describes the impact that crack use by chronic drug users has on their alteady deteriorating position in society (marginalisation), and on the relationships between drug users and the development of specific skills and strengths to survive in this setting (hardening). Ethnographic fieldwork and survey data from the city of Rotterdam and the less urbanised region of Parkstad Limburg (in the south of the Netherlands) have been used. The results showed that in both cases crack has a catalysing effect on both matginalisation and hardening. This affect is influenced by contextual factors, such as a repressive drug policy, a protective environment, and being a member of an Antillean network. To moderate the deteriorating effects of crack and help dng users regain control of their drug use and lives, these local contextual factors should be taken into account.
\end{abstract}




\subsection{Introduction}

Since the introduction of the recreational use of cocaine in the late $1970 \mathrm{~s}$ in the Netherlands, several changes have occurred. Nabben \& Korf (Nabben \& Korf, 1999) described in their study the "party period" and the "problem period", indicating that powder cocaine was initially used only in recreational settings, but in the $1980 \mathrm{~s}$ also became populat among heroin addicts and later in other marginalised subcultures. In the Netherlands the use of freebase cocaine or crack ${ }^{3}$ became widespread among chronic heroin users in the Netherlands by the end of the 1980 s and is now commonly used within this subculture. Earlier sample surveys (Lempens et al., 1999) show that in Rotterdam the use of heroin has even been superseded by the use of (mostly smokeable) cocaine. At first, most cocaine users smoked cocaine by "chasing", i.e. the cocaine-base is placed on tinfoil, heated from below, and the resulting vapors are inhaled through a small tube (Blanken et al., 1999). In the last decade cocaine is mainly smoked basing, i.e. the crack is put on a pipe and the vapors are inhaled through its stem.

Many studies have reported on the impact of crack on social, economic; physical and psychological wellbeing (Blanken et al., 1997; Erickson et al., 2000; Falck et al., 2002; German \& Sterk, 2002; Nabben \& Korf, 1999; Reinarman \& Levine, 1997; Sterk, 1999; Thane, 2002; Waldorf et al., 1991), and more specifically, on criminal behaviour (Inciardi et al., 1993), violence (Bourgois, 1995), reproductive functioning (Chasnoff, 1988; Chavkin, 1990; Leib \& Sterk-Elifson, 1995; Maher, 1990) and the mother role (Kearney et al., 1994). Other effects specific for crack-using prostitutes are also well documented (Erickson et al., 2000; Nabben \& Korf, 1999; Stetk, 1999), especially that "...all of their prostitution activities revolve around their crack habit" (Nabben \& Korf, 1999, page 646).

Some studies, especially from the USA (Bourgois, 1995; German \& Sterk, 2002; Reinarman \& Levine, 1997; Waldorf et al., 1991; Wilson, 1987) have stressed that it is not the psycho-pharmacological properties of the drug itself but rather the mode of ingestion and the (often poor and deprived) background of the crack users and circumstances that are responsible for many of the negative effects. The latter is partly a reaction to the media and politicians who used crack as a scapegoat for many problems in their sociery. A similar effect was described by Thane (2002), who studicd crack use in Hamburg. She reported how aggression is also often described by the media, lay people and drug users as a direct effect of crack. However, Thane (2002) states that aggression and violence are rather related to the circumstances of smoking crack on the street.

Except for Thane (2002), these authors pay little attention to the effect of the introduction of crack on the life and life circumstances of chronic heroin users. It is one thing that in more optimal circumstances crack may have less negative

\footnotetext{
${ }^{3}$ In the Netherlands there has been some debate about the difference between crack and freebrase or cooked cocaine. Waldorf ex al. (1991) described freebase as the result of a ptocess in which cocaine HCl is prepared in. water with ammoniac or ether. Crack is powder cocaine cooked in a bicarbonate solution. Simce (frec) basing in the Nethetlands has become almost identical to crack smoking and there are only differences in the one who prepares it (the user or the dealer), we use the terms "cracke" and "basing" interchangeablite.
} 
effects, it is another whether in the disadvantaged circumstances of chronic opiate users crack will increase the rate of deterioration of relations with ciwil society and relationships between drug users or will be relatively smoothly integrated into the consumption pattern of chronic drug users.

The present study differs from the above-mentioned studies in that it describes the effects of crack within the restricted population of chronic opiate users and that it focuses primarily on the negative effects of crack itself rather than an context. This is not to say that contextual factors are irrelevant. Also within the more restricted context of chronic drug users, effects of crack use have to be understood in relarion to the specific circumstances, and in fact some of these factors are elaborated in this chapter. Still, our primary focus is on the deteriorating effects of crack. More specifically, this study concentrates on the impact of crack on two major processes in the life course of the drug user, i.e. that of marginalisation of the drug user in society, and the hardening of relationships between drug users.

Other chapters (Chapter 3, 4, and 5) have reported on the physical, psychological, economic and social deterioration of chronic drug users; we referred to this as the process of marginalisation. The present chapter differs from the other chapters in that it focuses on the additional effect of crack use on deterioration in a population of chronic opiate users. We hypothesise that the adoption of crack by chronic opiate users accelerates deterioration in all aspects of life and, consequently; their general position in society.

We also expect that the adoption of crack will negatively influence relationships between drug users and increase the necessity to develop survival techniques: Thus, in our view, compared to the use of (mainly) heroin, crack will intensify and accelerate the process of hardening.

The present case study explores the impact of crack on marginalisation and hardening in two cities: the region of Parkstad Limburg, and the ciry of Rotterdam. The Parkstad Limburg region is located in the south of the Netherlands (near the borders of Germany and Belgium) and comprises the city of Heerlen and seven surrounding municipalities (about 300,000 inhabitants), and is nationally known as a drug problem area. The drug-using population of the region, and its related problems, are mainly concentrated in the city of Heerlen. Rotterdam is a metropolis (about 650,000 inhabitants) that is the largest port in the Netherlands (and second in the world).

For this study, the most relevant differences already existing between the drug scenes of Parkstad Limburg and Rotterdam are the following:

- whereas in Parkstad Limburg the drug market has always been dominated by street sales (Coumans \& Knibbe, 2002; Coumans et al., 2000), at the time of this study most of the dealing activities in Rotterdam took place at house (dealing) addresses (Lempens et al., 1999),

- the organization of drug aid agencies in Rotterdam is more diverse than in Parkstad Limburg,

- Rotterdam has at least one interest group for drug users whereas Parkstad Limburg does not, and 
- in Parkstad Limburg the intensive use of crack has developed mainly ovet the last five years (source: survey 2002), whereas in Rotherdan crack has a longer history.

The following research questions are addressed:

1. What is the impact of the use of crack on the matginalisation and hardening of chronic heroin users?

2. What are the similarities and differences in the effect of crack use between Rotterdam and Parkstad Limburg?

\subsection{Methods}

This study used data derived from the Drug Monitoting Systems (DMS) in both cities. The DMS is a system to signal trends and developments in local drug scenes, and involves three methods of data collection; i.e. interviews with key informants, community fieldwork, and surveys among drug users. For the present study we used data only from the community ficldwork and the survey.

\subsubsection{Community fieldwork}

A multiple-case, replication design was applied to the DMS fieldwork data (Yin, 1984) collected in Parkstad Limburg and Rotterdam. We applied secondary analysis to the field notes gathered in both cities from January 1999 to Januaty 2003.

In both cities data were gathered by freelance community fieldworkers (5 in Parkstad Limburg and 6 in Rotterdam), the co-ordinators of the community fieldworkers (4 in Parkstad I.mburg and 1 in Rotterdam), and the researchers (1 in each city). Especially the freelance community fieldworkers fulfilled a key role in this study, because all were current drug users and thus had easier access to various categories of drug users. Most fieldworkers were selected during several ficldwork sessions by the researcher and one experienced coordinator of the ficldwork. An important criterion to include a person as a fieldworker was that they had to be famillar through their own experience with the behaviour, rituals, habits and social networks of drug-using populations. Especially drug-using fleldworkers appeared to meet this criterion.

In their field notes, the fieldworkers were instructed to distinguish between. observations, interactions, and reflections. Observations refer to all events, actors and setting factors the fieldworker observed during participating in the drug scene. Whereas the researchers' and the co-ordinators' role was that of a participaring observer, the drug-using freldworkers played an observing participant rolle. Interactions refer to all conversations the fieldworket was persowilly inwolwed in. "The reflections served as the first analyses in order to keep the observations and interactions pure and included all kinds of personal thoughts, methodological issues and questions about the observations and interactions. At the and of each 
field note, at least one question that emerged from the reflections had to be written down with the purpose to give direction to the next fieldwork sessions (Strauss \& Corbin, 1994).

Although the use of drug users as fieldworkers has the advantage that they have access to situations which non-drug users are not likely to have, there are also potential problems (Power et all, 1996). A rough distinction can be made between problems related to the (potential) unreliability of the drug user as a freelance worker and related to the quality of the data. Concerning the reliability of drug users as fieldworkers we took special care in recruitment of drug users as fieldworkers (e.g. interviewing several candidates), and gave intensive 'on the job' training (in which the researcher accompanied the (potential) fieldworker) and supervision at least once a week. Especially the weekly supervision allowed the researcher to assess whether the fieldworker had the essential skills for the job, e.g. being able to observe, write up these observations, structure the field note properly, come to the researcher's office regularly and on time, and being able to reflect on their own observations and interactions. This weekly supervision and comparison of the field notes from the different fieldworkers provided us with a good impression of the reliability of the observations and the trustworthiness of the interpretations. All in all, it can be said that the use of drug users as fieldworkers enlarges the scope of observations and increases the trustworthiness of the interpretations. The main problem we encountered in Rotterdam, Parkstad and other cities when using drug users as fieldworkers was that the amount of time drug users could invest in fieldwork was restricted. Most of this restriction is due to the lifestyle of drug users, e.g. going to prison or giving priority to more luctative activities (e.g. dealing), necessitating the recruitment and training of new fieldworkers.

To address the specific questions of the present study, analysis took place by selecting all coded segments with the following codes: "cocaine", "coke" and "free-basing". These segments were analysed by means of the software program Ethnograph V5.7 (Seidel, 1998).

\subsubsection{Survey among drug users}

The ethnographic data were verified and supplemented with quantitative data from a survey among drug usets. The sampling methods differed between Parkstad Limburg and Rotterdam.

Parkstad Limburg data were gathered in 1999 by a "network sample" (Coumans \& Spreen, ; Spreen, 1999; Spreen \& Coumans, 2001). We started with an a-select sample of 90 from a list of 435 clients. registered with the local drug aid agency (CAD). Included were (nearly) daily users of heroin, cocaine and other drugs. Social workers from this agency approached 50 clients of whom 40 were willing to participate and to return the informed consent form. Additionally, the researcher approached 15 prostitutes at a location where prostitution was toletated. At the end of each interview the respondents were asked to name at the most 10 fellow drug users. This resulted in the naming of 110 registered and 83 non- 
registered drug users. The next step was to select at random at least one nonregistered drug user per respondent; this yielded 21 non-registered users. To acquire about 100 respondents, we decided to approach drug users at their regular locations and asked each thirc person to participate ("targeted sampling"). Finally, we acquired 103 respondents.

The Rotterdam survey data used for this study were collected in 2000 among (nearly) daily users of heroin, cocaine and other drugs by means of "targeted sampling" (in the north and west part of Rotrerdam) and "snowball sampling" (in the south part of the city). With "tatgeted sampling" respondents were approached at known drug-selling locations, where drug use and sale is permitted under certain conditions. To prevent interviewer bias, the recruirment of respondents was done in a systematic way; interviewers approached each, for example, fourth drug user they met and asked him or her to participate. Finally 140 drug usets agreed to participate. In the south of Rotterdam a "snowball" has been initiated, starting with two users of methadone; they named other users, of whom a number has been interviewed and who in turn named other users. This method yielded 63 respondents.

In Rotterdam and Parkstad Limburg data were collected by community fieldworkers that had been intensively trained for the job, and by DMS researchers. Each fieldworker had to sign a statement to protect the confidentiality of the data. In both cities a similar questionnaire was used, which addressed the sociodemographic situation, drug use (frequency and amount used), health (social, physical and psychological) and help-seeking behaviour; the questionnaire was mainly based on the Addiction Severity Index (Hendriks et al, 1991). In Parkstad Limburg an additional section addressed basic characteristics of the nominees and was included in order to estimate the size of the population. Each interview lasted 1 to 1.5 hours.

\subsection{Findings}

Table 6.1 presents the background characteristics of the participants from the two cities; it can be seen that most drug users are male with Dutch nationality, with an average age of 37 years old. Most drug users use both heroin and cocaine. In Parkstad Limburg more drug users are German, homeless and unject drugs. In Rotterdam there are more Surinamese drug users and the use of cocaine has already superseded that of heroin. 
Table 6.1: Background characteristics of the drug users in Parkstad Limburg and Rotterdam (Sources: DMS survey 1999 Parkstad Limburg, and DMS survey 2000 Rorterdam)

\begin{tabular}{|c|c|c|}
\hline & $\begin{array}{l}\text { Parkstad Limburg }(\mathrm{n}=103) \\
\%\end{array}$ & $\begin{array}{l}\text { Rotterdam }(n=203) \\
\% / 0\end{array}$ \\
\hline \multicolumn{3}{|l|}{ Gender } \\
\hline Male & 75 & 69 \\
\hline Age (in years) & 37 & 37 \\
\hline \multicolumn{3}{|l|}{ Narionality } \\
\hline Dutch & 84 & 91 \\
\hline \multicolumn{3}{|l|}{ Culfural origin } \\
\hline Dutch & 76 & 62 \\
\hline German & 14 & - \\
\hline European & 3 (other than German) & 5 \\
\hline Surinamese & 0 & 17 \\
\hline Ancillean & 3 & 3 \\
\hline Moroccan & 2 & 6 \\
\hline Other & 1 & 7 \\
\hline \multicolumn{3}{|l|}{ Substance use* } \\
\hline Heroin & 88 & 93 \\
\hline Cocaine & 80 & 96 \\
\hline Basing crack & 78 & 86 \\
\hline Injecting & 39 & 22 \\
\hline Homeless & 37 & 28 \\
\hline \multicolumn{3}{|c|}{ Drug used in the month preceding the inverview } \\
\hline $\begin{array}{l}\text { The percentages of Parkstaci on } \\
\text { Irug and agency (t.e 1) the low-the }\end{array}$ & $\begin{array}{l}\text { been weighted for participation in or } \\
\text { ce centre 2) Feroin Prostitution Projec }\end{array}$ & $\begin{array}{l}\text { (the three program } \\
\text { d 3) the Methadone }\end{array}$ \\
\hline
\end{tabular}

\subsubsection{Marginalisation and hardening}

The adoption of crack by chronic opiate users can best be seen as a 'new' or 'different' way of 'losing control'. From a social point of view the main aspect of loss of control is that situational roles offering immediate gratification (e.g. drug use) supersede mote important roles, especially positional roles in which obligations to others are fulfilled: employment, parenthood, partnership (Knibbe et al., 1987). The fieldwork yielded many observations indicating that crack use leads in a rather specific way to loss of control and how this loss of control leads to a deterioration in social and economic functioning, health status and material condition (i.e. homelessness). In this section, we will first describe the specific way in which crack leads to loss of control. We then describe how this is connected with marginalisation; i.e. how this loss of control relates to (further) deterioration in social and economic functioning, health and quality of housing. Throughout this chapter we use marginalisation as an umbrella term to indicate social, economic and health detetioration. Finally, we will describe how the adoption of crack leads 
to deterioration of relations between drug users (hardening), and more specifically the economic and social relations.

\section{Marginalisation}

\section{Loss of control}

Reflection: Many of these women are being "stalked" by coke. They are not safe anywhere; coke is always waiting for them at the door, or somewhere else. When you are being stalked, there's no place where you're safe, so you have to stay alert: before you know it you're involved with coke again. The best thing seems to destroy the stalker by smoking it. However: coke is a stalker with many heads; when you chop one off, three new ones appear in its place... (Field note Rottexdam January 2002)

Because of cocaine's short clearance time, the craving returns very quickly (Blanken et al., 1997). Data from both cities clearly indicate that the use of crack becomes problematic when the drug user loses control. For many drug users it is hard to quit smoking crack once they have started (Blanken et al, 1997; Thane, 2002; Waldorf et al., 1991). This phenomenon is also referred to as "bingeing", i.e. "a period of time during which significant amounts of cocaine are still in the addicts' system" (Rosse et al., 1994).

Data from both cities show that many drug users end up bingeing and spend all their money on crack cocaine. As will be shown in the next paragraphs bingeing and uncontrolled spending of money on crack accelerates the process of deterioration and causes problems in all areas. Many periods of bingeing succeed each other over several months:

A woman (Aranja, about 25 years old) is here (sleeping project for prostitutes) today for the first time. She tells me that she has worked as an escort since she was 17 years old, she used XTC, sniffed cocaine and learned to use base-coke from an acquaintance. She also worked as a prostitute, also in the times she didn't use cocaine. She works as a prostitute in The Hague and has been smoking cocaine since Christmas 2000. The usual partern: smoking for a few days in succession, sleeping for a day and then smoking again. (Field note Rotterdam January 2002)

During the wholle period 1999 to 2002 Rotterdam and Parkstad Limburg showed opposite trends in the number of observations about uncontrolled use of crack. Initially there was more evidence for controlled crack use in Rotterdam than in Parkstad Limburg. However, over time, in Rotterdam there were increasing reports of users losing control over their use of crack, whereas in Parkstad Limburg the majority of autochthonous drug users had learned a more controlled way of using crack. 


\section{Sacial dimenision}

During their drug career (which generally started with heroin), drug users have already lost most of their social contacts with people outside the drug scene. The use of crack seems to amplify and accelerate this process of alienation.

In both cities we observed that it becomes increasingly difficult for crack users to take part in normal social intercourse, even with other drug users. The main factor is that the use of crack (and especially bingeing) makes drug users even more selfcentered than when they were using only heroin.

Most users who based crack the last 2 or 3 years look back at a battlefield. It's cost them a lot. If don't want to go into the financial aspects, but just looking at what they've destroyed in their relationships. Many of them regret losing control and giving anything just to smoke that "fucking" base. Best friends have fought over a pipe of coke, and husband and wife have accused each other of being dishonest while craving for coke. (Fiteld note Parkstad Limburg February 2001)

As with heroin, losing control over cocaine use implies that positional roles (such as being a mother, child, spouse or employee) are overruled by situational roles offering immediate gratification (Knibbe et al., 1987).

Theo reacts exactly as I expected after smoking one base and is almost psychotic. There's only one thing on his mind, and he would even sell his own mother, who luckily is not around at the moment. (Field note February 2002)

Since crack use and especially bingeing is a full-time occupation, it also drastically reduces the time available for socialising, i.e. for time together without the pressure of wanting to smoke crack or getting money to buy crack.

\section{Health}

The main health problem associated with crack was physical exhaustion. We regularty met drug users who did not sleep for many days. They walked the streets and were exhausted at the end of the crack bingeing cycle.

Many drug users who use crack repeatedly stay awake and keep on walking, sometimes for days; this obviously adversely affects their physical condition. Other bodily signs of cocaine use are emaciation and open wounds or skin infections caused by scrarching.

The dope was $\mathrm{OK}$, and so was the atmosphere. Until the moment she took off her pants (it was good weather). The open wounds and ulcers smiled at mel I saw what white has caused, and just as though I was not there, she started scratching. (Field note Rotterdam June 1999)

Also, some characteristic physical reactions to the use of crack increase their visibility to the outer world and thus their deviancy. The following field note describes such a reaction: 
While Maestto is telling this story, he performs a real play. He waves his ans and has an unsteady gat. His movements betray his crock use. He mowes in a shaky way, as if his body is dancing, and he"s pulled after it. (Field note Parkstad Limburg March 2001)

Another typical reaction after the crack is finished is what one of Waldorfs respondents (1991) called "the carpet crusade", i.e the drug users seem to be constantly looking for something on the ground. Although they must realize that the crack is gone, they keep on looking for crack. They hope to find something, even just one small crumb.

The Parkstad Limburg survey showed that, compared to other drug users, relatively mone users who smoke crack reported health problems. Unfortunately these data are not available for Rotterdam. Parkstad Limburg drug users reported respiratory problems (including pneumonia); $74 \%$ of the drug users who smoked crack cocaine had these problems, compared with $40 \%$ of the drug users who did not smoke cocaine $(p=0.01)$. The use of cocaine also appeared to be positively related to the prevalence of certain psychiatric symptoms. The survey data showed that about one third of the cocaine users reported strong anxiety during the month preceding the interview, whereas of those who did not wse cocaine only $10 \%$ reported anxiety $(\mathrm{p}=0.05)$. About half of those who used cocaine and $40 \%$ of those who did not, reported problems with keeping their aggression under control $(0.05<\mathrm{p}<0.10)$.

Sometimes it is difficult to differentate between drug-related and psychiatric symptoms:

The basing became a race against the clock. Anyway, that's what it looked like. Pipe after pipe was smoked away. The portions became bigger and I saw a real metamomphosis talking place in Diem. (...) He was walking up and down between the living room and the front door, and was cursing under his breath...almost overwhelmed by his emotions. Totally fucked up. (...) I have to consider the fact that he uses medication. Some kind of Prozac. His medicine is lying on the table. (Field note September 2002)

\section{Econowac dimewsion}

For most chronic heroin users it is almost impossible to get or to keep a regular job. In Rotterdam $13 \%$ has a regular job, compared with $9 \%$ in Parkstad Limburg. Most of the drug users in Parkstad Limburg (83\%) and in Rotterdam (82\%) receive unemployment benefit, or some other kind of benefit. Although in both cities some drug users paid theit regular expenses and went shopping first, many spent their money immediately after receiving it. 
When the post office opened, the trade started; people who came out with their moncy went straight to a dealer, they had to pay their debts or were forced to give money to others. Of the Dutch people, three were dealers and I noticed that one of them attracts the most customers, probably because he sold coke. The 25 guilders (about 611) disappeared and the ball of coke was smoked immediately by the buyet. One puff and the 25 guilders is gone. (Field note Parkstad Limburg December 1998)

In contrast to heroin, with crack use the craving for more drugs does not diminish until all the money is gone. One drug user described payment day as a "day of celebration".

\section{Howhelestinest}

In both cities many drug users are homeless; 37\% in Parkstad Limburg and $28 \%$ in Rotterdam. Although many users of heroin lost their homes before they started using crack, in both cities drug users ended up homeless because they lost control of their crack use.

When a drug user still has a room of their own, they are at risk of losing it, because after basing crack they generally have no money left to pay the rent. Crack users who are already homeless often have problems finding a home; their crack use not only leaves them no money, it also interferes with performing most activities that are not crack-related. Conversely, being homeless makes it difficult to quit using crack. Being a fulltime member of the drug scene makes it hard to withdraw; drug users are pulled into the hectic circumstances of the drug scene, and using crack is one way to cope with it. To quit using crack some homeless drug users may choose to leave the scene:

Together with Melvin I walked in the direction of the scene (station). We talked about his crack use, which is very intensive. Melvin thought the same way about it and tells me he has rented a room for a week to get rid of his coke habit. (Fidd note Parkstad Jimburg December 1998)

\section{Handenting}

\section{Soldid divingustom}

In both cities we observed that, drug users form short-lasting "alliances" with other drug usars, and may pool their money to buy crack. These alliances are, however, more instrumental than social.

We also observed that the one who pays the most has the strongest rights.

In Rotterdam and Parkstad Limburg many drug users complained about the changing attitude of the drug users and relate this to the use of crack. The attitude that "it's everyone for" themselwes" seems to prevail.

Contrary to users of other drugs (such as cannabis, powdered cocaine or ecstasy), during the actual use of crack the users express no need to socialise with fellow users. As Waldorf et al. express it "an unsocial, or even antisocial, ethic seems to take hold of crackheads and basers" (Waldorf et al., 1991, page 121). 
Rein's reaction to this pipe of coke is surprising. He just sits there staning for minutes without saying a word. When Ad and Jo smilingly ask how he is, he says he wants to be left in peace and walks a bit further. Then he just stands, visibly enjoying his flash. (Field note Parkstad Limburg July 2000)

Apparently, drug users have to toughen-up in order to survive in the drug scene. Although this hardening of relations may occur between drug users independent of the particular drug, our data indicate that this process has been intensified and acceletated after the introduction of crack.

During our own observations we noticed that reactions during the smoking of crack tanged from silence, or talking quietly, to agitation, paranoia and even hostility. This in turn influences how others react to defend themselves.

Stress and aggression seem to increase as a direct reaction to the use of crack. Although quarrelling among drug users has always been part of the drug scene the usual arguments are associated with more stress when crack is involved. Most arguments take place between drug users and the aggression is mainly verbal, occasionally drug users are aggressive to outsiders.

Furthermore, our data show that aggression is often associated with a lack of sleep and a lowered threshold for frustration. Similar to Thane (Thane, 2002), we observed that aggression and stress is not (only) caused by the psychopharmacological effect of cocaine, but is associated with the setting in which the use takes place. Crack-related aggression was often observed when it was crowded, when drug users were "hunted" by the police, and sometimes when alcohol had been used in combination with crack.

\section{Economic dimension}

Bingeing leads to less control over spending money and therefore drug users become more dependent on illegal sources of income than before. Table 6.2 shows the different (additional) sources of income reported by users in Rotterdam and Parkstad Limburg.

The main way of getting money is by theft.

Jack participates in the heroin project, but his main addiction is coke. He steals each day, but hasn't got a main hustle (...) Jack steals whatever cones his way, but he takes care of something actually coming up each day. He travels a lot by train to other cities to steal and in the train he often finds a way of earning something. (Field note Rotterdam May 2002)

Finding customers for a dealer is another common way of getting money in Rotterdam. As with legally earned money, this money is also spent on crack immediately.

This man is older, about 45 years and homeless. His name is Iwan and he eams his money and dope by finding customers. Since during the basing he talks with two dealers, he might work for them and is smoking up his salary. Field note Rotterdam May 2002) 
Table 6.2: Additional sources of income for chronic heroin users in Parkstad Limburgl) and Rotterdam (Sources: DMS survey 1999 Parkstad Limburg, and DMS survey 2000 Rotterdam)

\begin{tabular}{|c|c|c|}
\hline & $\begin{array}{l}\text { Parkstad Limburg } \\
(\mathrm{n}=103)\end{array}$ & $\begin{array}{l}\text { Rotterdam } \\
(n=203)\end{array}$ \\
\hline Selling the street paper & 6 & 14 \\
\hline Working wa Topscote" & - & 19 \\
\hline Prostitution & 20 & 20 \\
\hline Dealing drugs & 12 & 17 \\
\hline Assisting a dealer & 8 & 22 \\
\hline Selling pills/methadone & 8 & 29 \\
\hline Crimes against property & 16 & 46 \\
\hline Other (including robbery) & 14 & 9 \\
\hline
\end{tabular}

\subsubsection{Factors moderating the disrupting effect of crack}

We identified three factors that influenced the disnupting effects of crack. These were the drig policy (i.e. more or less repressive), the circunstances in which drugs are being consumed (e.g. at dealing addresses, or on the streets), and the social network a drug user belongs to (e.g. offering solidarity or not).

In both cities we noticed that the catalysing effect of crack on hardening is even stronger in the presence of a repressive drug policy. Since the Dutch policy on using drugs in public places is fairly repressive, smoking crack often takes place in e.g. a street doorway. Furthermore, the "keep-moving" policy makes street life more hectic and stressful. When using crack, getring rest becomes harder than it already was, which again influences the attitude of drug users towards each other, which becomes even more characterised by instrumentality, stress, paranoia and aggression. A repressive policy also leads to nervous behaviour of the drug users during smoking. We observed many drug users who were still nervous even when no police were around ("mind police").

Especially in Rotterdam we observed that in a quiet, more protective setting the effect of cocaine on heroin users is different, i.e. less caracterised by agitation, stress, paranoia and aggression.

In both cities we noticed that having social contact within certain ethnic networks diminishes the tough characteristics seen outside this ethnic group. Especially in the social networks of Antilleans and Surinamese in Rotterdam, solidarity plays an important role. Shared ethnic identity or background appears to be a factor that positively influences social contacts. Antilleans did not lose control over crack use to the same extent as other drug users, and there was still room for some sociability while smoking crack. 


\subsection{Conclusions and discussion}

The results of this study show a very high risk of loss of control over crack use among chronic heroin users and a corresponding increase in social, economic and health problems. While many heroin users were already functioning poorly in these areas, data from both cities show that crack amplifies these problems. By using crack, drug users are excluded socially, are excluded from employment and often from proper housing. Moreover, using crack makes their deviance more manifest and visible because of crack-related health problems and the characteristic physical appearance of crack users. All in all, our study shows that crack is a catalyst in the process of marginalisation of chronic heroin users. This is in line with the findings of Erickson et al. (Erickson et al., 2000), who conclude that the use of crack by prostitutes increases their vulnerability and their alteady "highly deviant and stigmatized social image". Similarly, Waldorf et al. (1991) also reported that, compared with heavy cocaine snorters, crack users experience more problems with mental and physical health, families, finances and functioning in daily life. Moreover Nabben \& Korf (1999) conclude that for problematic youth, "crack contributes to multi-problem behavior within the context of their marginalized lifestyles".

The main conclusion is that crack is a catalyst in the processes of marginalisation and hardening in both ciries. However, during the three-year study period (1999. 2002) the number of drug users losing control over their crack use tended to increase in Rotterdam and decrease Parkstad Limburg. Factors that might explain this opposite trend ate changes in the drug policy in both cities (i.e. more or less repressive) and developments in the circumstances in which drug users are able to consume their drugs (e.g. at dealing addresses, or on the streets). Whereas in 1999 the drug policy in Rotterdam was less repressive towards drug users and dealing compared to Parkstad Limburg, in 2002 the policy had become as repressive as in Parkstad Limburg. As a consequence, also in Rotterdam, many drug users have returned to the hectic street scene. Futthermore from 1999 to 2002 in Rotterdam we observed a decrease of possibilities to consume crack in a relarively quite circumstances; i.e. the Basements and many dealing addresses had been closed down. In Parkstad Limburg, however, circumstances for crack users have improved with more low-threshold (time-out) facilities, a drug consumption room, and outreach work.

One might argue that the converging effect may be merely due to an observation bias. However, taking into account the large number of observations from several independent fieldworkers over a considerable period of time, we consider that the observations are trustworthy. Another issue is whether the converging effect is based on coincidence, or is teal. To address this question we used the survey data of both cities from 1998 to 2003 as repotted by van der Poel et al. (2003) and Coumans \& Knibbe (2002). In Rotterdam the proportion of homeless drug users increased from $22 \%$ to $40 \%$, the percentage of drug users buying their drugs at dealer addresses decreased from $88 \%$ to $29 \%$, and the percentage of drug users buying drugs on the street increased from $48 \%$ to $64 \%$ (van der Poel, Barendregt, Schouten et al., 2003). In Partkstad Limburg the 
percentages of these three themes temained about the same (Coumans \& Knibbe, 2002). This analysis indicates a convergence of deterioration berween the two cities over the study period and is in line with the growing similarity between the two cities in the number of observations of crack users losing control over the same period.

Another main conclusion is that the use of crack intensifies hardening of relationships between drug users. Although when using heroin alone their relationships were already caracterised by toughness and the development of strategies to survive in this world, the introduction of crack has increased the necessity to "get tough" and develop survival skills. Data from both cities showed that with crack use, social relationships are increasingly functional and instrumental, and devoid of social support. Especially in a setting with hectic circumstances, reptession, and simultaneous use of alcohol, outbursts of aggression are more prevalent when crack is used compared with heroin alone. Since the uncontrolled use of crack often means bingeing until all the money has gone, the necessity to get an illegal income increases.

All in all, we conclude that crack not only leads to deteriotation in the social and economic relations within the larger society but also to deteriorated relationships between drug users.

Although the negative effects of crack itself on (further) deterioration are shown by the results, we could identify some contextual factors that moderate the deteriorating effect of crack. The shared cultural background of Antilleans, and a quieter enwironment whete the drug user can buy and consume drugs are related to a less strong effect of crack use. Factors increasing the catalysing effect of crack include a repressive policy of the police, hectic circumstances, and being homeless.

\subsubsection{Methodollogical limitations}

Firstly; it is important to note that both in Parkstad Limburg and Rotterdam the sampling was not completely at random. In Parkstad Limburg, besides random sampling, targeted and convenience sampling was used to recruit respondents. In Rotterdam snowball sampling starting with users in methadone maintenance treatment was used to recruit part of the respondents. The consequence of using these different sampling techniques is that, strictly spoken, statistical inference from our sample to the population is not allowed. This means that caution is needed when interpreting the survey results from both cities.

Secondly, the snowball sampling in the south of Rotterdam led to an undesired selection of respondents; i.e. a disproportionate number of methadone users were interviewed. For the interpretation of the data this means that, when compared to the Parkstad Limburg situation, the Rotterdam picture may be too positive. This potential bias led to the decision not to apply statistical tests on differences between the two cities.

Finally, a definite proof for our main conclusion that crack leads to an accelerated deterioration when adopted by chronic heroin users, would require a 
longitudinal study where individual chronic heroin users are followed for an extended period of time. However, the fact that we were able to make observations in two very different cities and also extended the freldwork over a period of 4 years increases the confidence that the main conclusion is not highly dependent on specific local or historical circumstances. In addition, in our opinion, the use of qualitative methods to assess the effect of crack increases the trustworthiness of the data compared with using only standardised questionnaires relying exclusively on self-reports of drug users (Lincoln \& Guba, 1985).

\subsubsection{Implications for drug policy}

Our results have high potential relevance for drug policy, especially in cities and countries with drug scenes that have not yet adopted the use of crack on a large scale. Crack has not yet penetrated drug markets in several cities in Europe; in these cities, we recommend that the policy should include monitoting of the local drug market to signal the introduction of crack and then appropriately deal with its accompanying effects. For cities where crack has already been introduced but has not yet penetrated the drug market, we recommend health education whereby peers outline the risks of crack use to chronic heroin users. Such a community approach has alteady proven its use for injecting drug users in four European cities. With a "snowball project" injecting drug users were asked to inform their fellow drug users about the spread of HTV, in order to reduce the risk at HIV (Franken \& Kaplan, 1995).

In cities in which crack has been introduced for some time, our findings on the contextual factors that mitigate the deterionating effect of crack may help to formulate an appropriate policy. We recommend low-threshold (time-out) services that offer the opportunity to withdraw from the hectic circumstances, e.g. a daycare shelter, or drug consumption rooms. Outreach activities to help the drug users in their own environment would suit the crack user best, who may find any threshold to care and protection too high.

For the policy of the police, repression could perhaps focus on tracing the "anti-social" dealers and sparing the "decent" ones. Van de Mheen and Gruter (2004) argue that an agreement could be made with some house dealers about meeting quality criteria in exchange for a lower priority to get traced; this would prevent some drug usets buying on the stressful streets. Possibilities to regulate the settings where, as Blanken et al. (1999, page 609) describe it, "demand and supply meet", should not be ruled out. Avoiding the debate in the Netherlands about this sensitive subject could mean missing the opportunity to contribute to a solution of the current drug problem.

In conclusion, we can state that crack definitely has a catalysing effect on marginalisation and hardening, and that this effect is valid in both cittes. However, contextual factors can influence this effect and should be taken into account in the attempt to mitigate the deteriorating effects and enable drug users to regain or maintain some control over their crack use and their lives. 


\section{References}

Blanken, P., Barendregt, C., \& Hendriks, V. (1997). Op is op. Neets is wor alligh Een axderaek

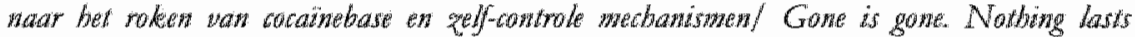
forwent A study on smaking frebase cocame and seffowholling mechanisms. (Vol. 14). Rotterdam: Addiction Research Institute (IVO).

Blanken, $P_{*}$ Batendregt, $C$. \& Zuidmulder, $L$. (1999). The evolution of crack and basing cocaine in the Rotterdam heroin scene. Jowmal of Drag Issues, 29 (3), 609-26.

Bourgois, P. (1995). In searts of respet: Selling crack in Ei Barrio. New York: Cambridge Unversiry Press.

Chasnoff, I. (1988). Cocaine, pregnancy and the neonate. What and Health, 15, 23-25.

Chavkin, W. (1990). Drug addiction and pregnancy: Policy crossraods. Amerion Jow of Pablic Heallh, 80, 483-87.

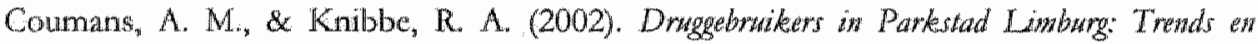
profuiten. Resultaten wan bet Ding Montoning System 2001-2002/ Trends and profules. Results of the Drwg Momitoring System 2001-2002. Hecrlen: Addiction Research Institute (IVO).

Coumans, A. M., Neve, R., van de Mheen, D. (2000). Het proces van margwalisening en werbarding in de drigscene wan Partestad Limburg/ The procesr of manginalisation and bardening in the Parkstad Limbong drug sone. Rotterdam: Addiction Research Institute (IVO).

Coumans, A. M., \& Spreen, M. (2003). Drug use and the role of homelessness in the process of marginalization. Swibsance Use ers Mistse, 38 (3-6), 311-38.

Erickson, P. G., Butters, J., MaGillicuddy, P., \& Hallgren, A. (2000). Crack and prostitution: Gender, myths, and experiences. Jourral of Drug Issues, 30 (4), 767-88.

Falck, R. S., Wang, J., Carlson, R. G., Eddy, M., \& Siegal, H. A. (2002). The prevalence and correlates of depressive symptomatology among a community sample of crackcocaine smokers. Joumal of Pyoboutive Drugs, 34 (3), $281-88$.

Franken, T. H. A., \& Kaplan, C. D. (1995). Risk contexts and risk behaviors in the Euregion Maas-rhein: The boule de neige intervention for aids prevention among drug users. AIDS edvication and Prevextion, 9 (2), 161-80.

German, M. P. H., \& Sterk, C. E. (2002). Jooking beyond stereotypes: Exploring vartations among ctack smokers. Jowrwal of Pyctoactive Drwgs, 34 (4), 383-92.

Hendriks, V. M, wan der Meer, C. W., \& Blanken, P. (1991). De Addiction Severity Index: ASI

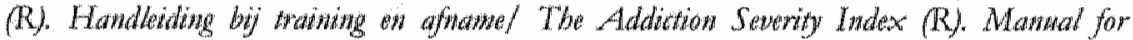
tratming and administengy Rottetdam: Addiction Research Institute (IVO).

Inciardi, J., Tockwood, D. \& Pottieger, A. (1993). Wonen and wack cowine. New Yotk: Mac Millan Publishing Company.

Kearney, M., Murphy, S., \& Rosenbaum, M. (1994). Mothering on crack cocaine: A grounded theory analysis. Social Scince of Medicine, 351-61.

Knibbe, R. A., Drop, M. R., \& Muytiens, A. (1987). Cortelates of stages in the progtession from everyday drinking to problem drinking. Social Srience eto Medine, 24 (5), 46373.

Lieb, J., \& Sterk-Elifson, C. (1995). Crack in the cradle: Reproductive decision-making among crack cocaine users. Jowntal of Contemponon Drry Problems, 12 (4), 678-706.

Lempens, A., Barendregt, C., Zuidmulder, I., \& Blanken, P. (1999). Kenmerken van Rotterdamse gebruikers: Enkele resultaten van de survey 'drugs, huisvesting, schulden en gezondheid"/ Characteristics of Rotterdam drug users: Some results of the survey'drugs, accommodation, debts and health'. IVO Bulletin, 2 (3), 1-20. 
Lincoln, Y. S., Guba, G. (1985). Natwratistic imating. Newbury Park, CA: Sage Publicarons.

Maher, L. (1990). Criminalizing pregnancy: The dowaside of a kindar gentlet nation. Chiminal justice, $117,111-35$.

Nabben, T., \& Kort, D. J. (1999). Cocane and crack in Amsterdam: Diverging subcultures. Jownal of Dryg Irome, $29(3), 527-652$.

Power, R. Jones, S., Kearns, G., \& Ward, J. (1996). An ethnography of risk matnagement amongst illicit drug injectors and its implications for the development of community based interventions. Socialogy of Health of $1 /$ wers, 18 (1), 86 106.

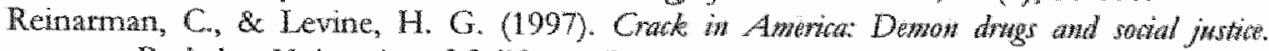
Berkeley: University of Califorma Press.

Rosse, R. B., McCarthy, F. M., Collins, J. P., Alim, T. N., \& Deutsch, S. (1994). The relationship between coke-induced paranola and compulsive foraging: $A$ preliminaty report. Addiction, 89, 1097-104.

Seidel, J. (1998). Ethnograph 25.0 a wre's gude. Thousand Oaks/ London: Scolati, Sage Publications Sofrware.

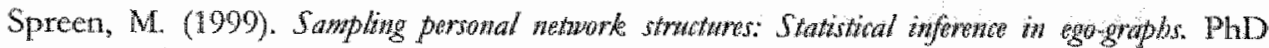
Thesis, Rinksuniversiteit Groningen, the Netherlands.

Spreen, M., \& Coumans, M. (2001). A note on network sampling in drug abuse research.

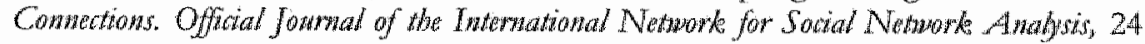
(3), 4451 .

Sterk, C. E. (1999). Fast lives. Women who wse rack cocatide. Philadelphia: Temple University Press.

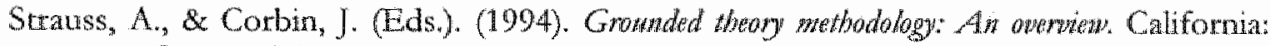
Thousand Oaks.

Thane, K. (2002). Crack cocaine use in Hamburg's open drug scene. Jommal of Drug Irsties, $32(2), 423-30$.

van de Mheen, H. \& Gruter, P. (2004). Interwentions on the supply side of the local hard drug market: Towards a regulated hard drug trade? The case of the city of Rotterdan. Jowryal of Drwg Istses, 34 (1), 145-61.

van der Poel, A., Barendregt, C., Schouten, M., \& wan de Mheen, D. (2003). De leefsituatie van gebruikers in de Rotterdamse harddrugscene (resultaten van de survey 2003)/ The sination of drug users in the Rotterdam hatd drug scene (results of the survey 2003). 160 Bulletin, $6,1-19$.

Waldore, D., Reinaman, C., \& Murphy, S. (1991). Cocaine dounges. The expenience of asing and quitring. Philadelphia: Temple University Press.

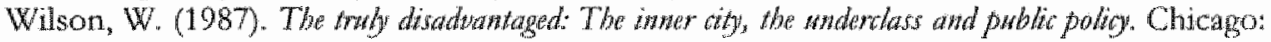
University of Chicago Press.

Yin, R. K. (1984). Case study reseamb. Design and methods (Vol. 5). Beverly Mills: Sage Publications. 


\section{Chapter 7}

\section{Street-level effects of local drug policy on marginalisation and hardening: \\ an ethnographic study among chronic drug users.}

This chapter will be published as the atticle A. M. Coumans, R. A. Knibbe \& H. van de Mheen (2006) Street-level effects of local drug policy on marginalisation and hatdening: An ethnographic study among chronic drug users. Jowrnal of $P_{\text {Sycboative Drugs }}$ (Accepted). 


\begin{abstract}
This chapter focuses on the effects of increased enforcement on marginalisation of and quality of relations between chronic drug users in the region of Parkstad Limburg (the Netherlands). Data were mainly gathered by ethnographic community fieldwork, verified by interviews with key informants and supported by a survey sample among 100 drug users.

The results show direct effects of repression on stigmatisation and marginalisation of drug users, and on the availability of drugs. More indirect effects are the hectic reactions of drug users and dealers, greater visibility of drug users in public places, and increased tensions in and deterionation of relations between the drug users. The impact of the increased enforcement on reports of drug-telated nuisance in general population surveys and on police control is also discussed.
\end{abstract}




\subsection{Introduction}

In most, if not all, countries legal and repressive measures tend to be more important than measures aimed at care for duug users. The Dutch drug policy is consideted an exception, because possession and use of small quantities of drugs rarely wartants legal measures. The Netherlands are also known for their relatively large variety of low-threshold services for drug users (e.g. methadone maintenance programs, user rooms and day care centres). Despite this relatively liberal drug policy, drug-related nuisance is still perceived as a major problem by the general public and the authorities. Although drug policy varies over time and regions, the general public and others need to see that the local authorities are addressing drugrelated nuisance. Because the range of repressive measures in the Netherlands is less than in other countries, study of the impact of a new, mostly repressive, drug policy on the lives of drug users is particularly interesting.

This chapter focuses on the effects of a repressive policy applied in the tegion of Parkstad Limburg on the position of chronic drug users in the larger society and on relationships between drug users. The position of drug users in society is often characterised by a gradual loss of connection with primary contacts (family, partner, children, friends) and core institutions (education, work and access to health care facilities). We indicate this phenomenon by the concept of marginalisation. Mote specifically this concept describes a social, psychological and physical deteriotation associated with the lifestyle of chronic drug users.

Once entering the drug scene, relationships between drug users are increasingly characterised by harshness. To buy drugs and get money, the drug user has to acquite specific skills and abilities. In other words: they have to "get tough" to survive. We indicate this process of adaptation with the concept of hardening. As with marginalisation, hardening has a social and an economic dimension. Social relationships often become purely instrumental and the sources of money are generally illegal.

Marginalisation and hatdening can also be influenced. by other factors (or catalysts), such as homelessness, use of crack, organisation of the drug market, and drig policy.

The literature on law enforcement and drug policy can be divided into studies focusing on high-level and retail-level enforcement (Kleiman \& Smith, 1990). The former concentrates on law enforcement and governmental policy (Buchanan \& Young, 2000; Bush, 2003; Duncan, 1994; Korf, 1995a; Maris, 1999; Ungerleider, 1976; Weatherburn et al, 1998; White, 2002), while the latter focuses on more specific and local street-level enforcement in terms of police actions and other measures (Hughes et al., 1974; Korf, 1995b; Maher \& Dixon, 1999; Verbtaeck, $1990)$.

The macro-level literature is mainly negative about law enforcement as performed in the USA ("the war on drugs") (Buchanan \& Young, 2000; Bush, 2003; Duncan, 1994; Marts, 1999; Ungerleider, 1976) and in several European countries (Dorn \& South, 1990; Korf, 1995a; White, 2002). Most of these studies conclude that this drug policy does not have the desired effect of reducing drug use, drug-related nuisance and crime. Others (Buchanan \& Young, 2000; Green, 
1998) go one step further and argue that "the policy fails to reduce drug taking and drug-related crime and contributes to stigmatisation and social exclusion of certain drug: users". Duncan (1994) showed positive associations between drug law enforcement and drug-related deaths, and Buster (2003) has concluded that "increasing heroin use within a repressive system creates a difficult situation, marked by stigmatisation and stressing of segregated, often self destructive addicts". Dom and South (1990) reported that certain law enforcement measures have left the drug market fragmented, volatile and increasingly violent. The study of Meares (1998) is more specific in that it concludes that high incarceration strategies at the individual level are more harmful than helpful and do not lead to a decrease of drug related problems in poor neighbourhoods; analysis suggests that community-based policies are more effective and beneficial in reducing drugrelated crime in certain neighbourhoods. The study of Weatherburn et al. (1998) is one of the few to mention positive effects of law enforcement: they found a reduction of heroin use and a reduction in overdoses. However, they note that "the benefits of reduced heroin use will be offset by the costs of increased stimulant use if a heroin shortage is accompanied with a strong increase of cocaine and other stimulants" (Weatherburn et al., 1998).

The micro-level studies focus on more immediate and specific effects of police measures on the drug users' behaviour. Although these studies differed in the applied method and focused on different drug settings, they all found similar and mostly negarive effects of most repressive measures. Benson et al. (2001) found that an increase in clrug enforcement in Florida was responsible for a reallocation of police resources that increased property crime. Others have applied ethnography and qualitative interviews to gain insight in the effects of law enforcement on drug users (Grapendaal et al, 1995; Hughes et al., 1974; Maher \& Dixon, 1999; Verbraeck, 1990). Two notable effects found are geographical dispersion and the urge to "keep on walking" in order to avoid the police (Maher \& Dixon, 1999; Verbraeck, 1990). Maher \& Dixon extensively elaborated on the negative effects of enforcement by the police as performed in Cabramatta, Sydney. They mention oral and nasal storage and transfer of heroin, reluctance to carry injecting equipment, increase in injection-related risk taking and a displacement (geographical, substance, temporal and social) of drug users and drug market (Maher \& Dixon, 1999).

Although few micro-level studies mention positive effects of repressive measures, Weatherburn and Lind (2001) report that seeing family members or friends imprisoned, or having experienced imprisonment themselves, was positively associated with entry into a methadone maintenance program. Another positive study is that of Kleiman and Smith (1990), who argue that tetail level law enforcement (crackdowns) focused on certain neighbourhoods has some potential benefits and a few indications that it works. However, these authors have not yet answered the question to which extent crackdowns lead to a displacement of the drug-related problems.

Although the literature covers a broad range of topics related to law enforcement and marginalisation and hardening, little is known about the effects of 
law enforcement on the lives of drug users in a country with a relatively liberal drug policy.

This study aims to answer the question: What are the effects of repressive police measures that aim to reduce drug-related public nuisance, on matginalisation and hardening of chronic drug usets at the local level?

In the Netherlands the term (drug related) public nuisance is mostly used as a diffuse concept without a clear definition (Garretsen et al., 1995). It refers to a wide variety of negative behavioural, social and physical consequences attributed to drug users by the community. We distinguish three main aspects of the concept: i.e. criminality (violence, theft and other), violation of civil order (annexation of public space) and audio-risual nuisance (deterioration, irritating, maladjusted and annoying behaviour). Compared to other cities in the Netherlands, Heerlen, as the central city of Parkstad Limburg, has a relatively small city centre, attracts drug tourists from neighbouring countries and accommodates a relatively high number of homeless drug users. These characteristics make drug users and related public nuisance more visible and notable than elsewhere.

Most of the repressive measures were in existence before the start of our study. However, atound 2000-2001 the general public and policy-makers fett that drug-related nuisance had increased to such an extent that a new initiative was necessary. In June 2001 a new policy was presented to improve control over drug. related problems in the centre of Heerlen, the central town in the region of Parkstad Limburg (Municipality of Heerlen, 2001). In order to increase manageability, the operation included mostly repressive measures directly aimed at controlling the behaviour of drug users in public environments, and measures to improve the quality of life of drug users by encouraging them to use the day care facilities.

This study focuses on the more general police measures in place before June 2001 and the new police measures after that date. The former comprise police supervision on the street and actions to prevent drug dealing. The latter concentrate on:

- $\quad$ more continuous and more repressive police supervision,

- a maximum use of formal punitive measures:

o territorial bans,

- bans on the gathering of drug users in public, and

- the introduction of special teams to actively prevent drug dealing on the street and at private addresses.

The thought behind the increased supervision and maximum use of punitive measures is that the drug problem becomes more manageable by a "keep moving system' (Grapendaal et al., 1995). For ease of use this term is used throughout this chapter.

Since our focus is primarily on the experiences of drug users, mainly ethnographic data have been used. However, in the discussion we use existing data from general population surveys (postal questionnaires) on nuisance to evaluate whether the new drug policy has had the intended effects on drug-related nuisance, as experienced by the general public. 


\subsection{Methods}

This study uses data from the Parkstad Limburg Drug Monitoring System (DMS) collected from 1998 to 2002. The DMS is a research methodology designed to signal trends and developments in local drug scenes. Untill tecently it has been running in the cities of Rotterdam, Utrecht and Parkstad Limburg using both qualitative and quantitative methods. For the present study, we used mainly ethnographic field notes, complemented with survey sample data among drug users (oral interviews) and incidentally verified with findings from in-depth interviews with drug users and interviews with key informants. Although these data sources are discussed below, details have been discussed earlier (Chapter 2-6; Coumans \& Spreen, 2003).

\subsubsection{Ethnographic community fieldwork}

From May 1998 to December 2002, several community fieldworkers, including the researcher, wrote 292 field notes. The field note was structured into actual observations and interactions with drug users, and personal reflections on these observations and interactions. Each field note was evaluated with the researcher and each fieldworker was asked to formulate at least one question about the content of the note; these questions gave direction to future observations and conversations. The field notes were coded and further analysed using the software program Ethnograph V5.06 (Seidel, 1998).

\subsubsection{Survey}

We used data from a random network sample $(n=100)$ (Coumans \& Spreen, 2003; Spreen, 1999; Spreen \& Coumans, 2001) held in March and April 2002 among drug users. The final sample survey among drug users consisted of 100 respondents, of which 72 were randomly selected from a register compiled by the local drug aid agency. Each selected aid agency respondent was asked to name (up to 10) other users (nominees) known to him/her. Per respondent, two nonregistered users were randomly selected (if possible) of which one had to be approached by the respondent. All 10 non-registered users who were approached participated in this study, 34 clients did not name any other non-registered drug users, and the remaining 28 non-client users could not be traced due to practical problems. Since we aimed for a final sample of at least 100 drug users, we also approached drug users at locations where drug users usually concentrate, such as the railway station and neighbouring streets. This yielded an additional another 18 drug users who had not been registered by the aid agencies in the siz months preceding the interview.

The respondents were interviewed by 7 interviewers, of which 5 were drug users themselves and 2 were members of the research team. All interviewers had been intensively trained in interviewing techniques. All respondents were assured 
that their data would be treated in strict confidence. The reward for the interview was $€ 10$ and the aid agency clients could earn an additional $€ 10$ by contacting the fieldworkers with the selected non-registered drug user.

The questionnaire was partly based on earlier DMS studies in Rotterdam (Lempens et al., 1999) and partly on the Addiction Severity Index (Hendriks et al., 1991) and consisted of two parts. The first part addressed characteristics of the respondent, such as demographic data, living circumstances, income and debts, drug use behaviour, (physical, psychological and social) health, help seeking behaviour and contacts with the police. The second part addressed basic characteristics of the nominees and was constructed in order to estimate the size of the population. Each interview lasted from 1 to 1,5 hours. Simple statistical analyses were conducted with SPSS software.

In this article the results of the above survey sample ate sometimes compared with those of an earlier survey $(n=103)$ conducted in 1999 as part of the Drug Monitoring System (Coumans et al., 2000).

\subsubsection{In-depth interviews and interviews with key informants}

For the aim of the present study we performed an analysis on 20 interviews with drug users held in February and March 2001. To cover the heterogeneity of the study population we drew a convenience sample based on age (mean age 38 years), gender ( 5 females and 15 males) and geographical location (10 from Heerlen and 10 from neighbouring municipalities). This sample was compiled from drug users we met on the streets and/or from the methadone maintenance program. Some respondents had been named by other drug users that were interviewed.

Furthermore, from May to June 2002 we interviexwed 11 key informants about the drug users they knew. To get a better picture of the study population we selected these informants based on their perspective, experience and knowledge, i.e. key informants from the low-threshold day care service, the might shelter, community fieldwork facilities, police offices and the local group representing drug users. These interviews with key informants used a pre-structured checklist and were recorded and subsequently typed.

Both kinds of interviews were analysed using software program Ethnograph V5.07 (Seidel, 1998). 


\subsection{Results}

The results are structured around the effects of the main repressive measures on marginalisation and hardening. First we give a brief quantitative background of the study population.

\subsubsection{Background characteristics}

In Parkstad Limburg the number of drug users has been estimated by several estimators, such as the Bernoulli-estimator, the Bipartite Graph estimator, the multiple capture estimator, a simple ratio estimator, and the estimator of Chao (Chao, 1987; 1988; 1989; 1999; Spteen \& Coumans, 2000; Spreen \& Coumans, 2001). Based on these estimators, a "best estimation" resulted in a total of 800 drug users (Coumans et al., 2000); about $75 \%$ of this study population lives in Heerlen and the remainder in other municipalities of the Parkstad region.

Of the study population ( $\mathrm{n}=100) 73 \%$ is male, the mean age is 39 years, $87 \%$ has the Dutch nationality $(87 \%)$ and wete born in the Netherlands, about $10 \%$ was born in Germany and the remainder in other countries; $41 \%$ of the sample is homeless.

Most drug users use both heroin and cocaine. Recently, the percentage of cocaine users $(88 \%)$ has superseded that of heroin users $(86 \%)$. Methadone is used by $61 \%$ of the study population, and freebasing of cocaine $(78 \%)$ is more popular than injecting $(31 \%)$.

\subsubsection{Keep moving system}

\section{Effects an manginalisation}

One of the most important police measures has always been constant supervision of drug users. This means that during certain periods, the police are over-represented on the streets, constantly moving the drug users from one place to another. To keep the drug problem manageable, drug users are summoned to keep walking and in certain areas are not allowed gathering with two or more companions. We observed that this policy causes drug users to spread out over the town.

What you see is that they disperse. We used to have one centre. The scene used to be at the station. It was crowded and noisy, but at least it all happened at one place. With all these acrions the picture gets obscure. (Interview staff member, Medical Social Unit of the local drug agency).

During police actions it becomes quiet around the station and drug users move to the margins of the city centre. As alteady mentioned by Verbraeck (1990) and Grapendaal (1995), the mobility of the drug users increases during these actions. 
However, this geographical displacement is temporary, because when the police withdtaw the drug users return to their favourite spot.

At the moment, most drug users walk up and down the tunnel in small groups... One of the bans is on gathering of drug users in the stree. They walk up and down the turnel in small groups. That is, as far as that's possible, because if the police catches someone walking up and down the tunnel, they can send then to another place. This happens a lot. ( $\omega$ ) They take a short walk and stay away for a while, hoping that the police will leave too. As soon as this happens they return. (Interview B. 26102000)

It is really a dispersion of nuisance. When you start "sweeping" at, ler's say, point $\mathrm{X}$ they will switch to another place. That's just the way it is. If it gets quier again at X, then theyll return. Unless there are other options. (Interview police officer, Hectlen)

Because of the constant supervision and police actions on the street, drug users feel hunted, humiliated and treated differently from other civilians.

G: Another issue that has become abnormal in the Netherlands, is the behaviour of the police towards drug users. (...)

I: You'te only allowed to walk. What do you think of that?

$\mathrm{G}$ : We live in a free country, don't we? To them, all I am is a dng user. When I'm talking to someone, I'm ordered to keep moving, to leave, even if it's not a drug user! I find that humiliating. Just imagine, man! When you're standing somewhere for sure they'll come after you. One chases you over there, the other chases you back. (Interview G. 160201)

Some policemen/women are accused more than others of humiliating, stigmatising behaviour.

A few months ago I was hitchhiking, because I missed the last bus that night. There was one policeman, HP, who occasionally visits the day care centre He took me to the police station. And right in the middle of the streer, he makes me turn my purse upside down, while it was obvious I'd been hitchhiking. I really was not working (as a prostrtute), because $I$ was standing in the rain. Il cursed that man! He's notorious for being a holy terror. If he picks you up, he absolutely loves it. Right in the middle of the street, so that people stand and look at you, thinking you have done "God knows what". (Interview M. 090201)

An extreme example of this process is that some drug users feel outlawed. They are constantly hunted in the context of the keep-moving policy, but when they become the victim of robbery, battery ot rape themselves, they do not feel protected by the law. During our fieldwork, several incidents occurred which secm to justify this feeling of being outlawed.

Suddenly the blows fell thick and hard. Meanwhile a police car has arrived and the cop has got out, but doesn't feel like intervening and just stands watching. (Field note, June 1999) 
The following citation describes in more detail an occurrence after two dealers had cheated a German drug user.

Observation: Together we walk in the direction of the Promenade and halfway 1 see two men.

Interaction: Customer: "I want my money back, because you sold me rubbish. "Dealer: "Impossiblel I sold you good stuff". Thete is some quartelling and the customer says: If you don't give me my money back, I'll go to the police.

Observation: After those words, the Antilean and the African suddenly hit him in the face and start kicking him. After some blows, the customer screams out and ceases to resist. "The two men turn around gasping and walk away. "Well, now you go to the police". I help the man to ger up and accompany thim to the police office.

Thteraction: I: "Go and make complaint". Customer" "I will". We walk to the police office and I tell him I'll wait outside. After fifteen mimutes he returns and says: "They didn't take any notice of me and saly that $I$ have to sort it out for myself" I: "They didn"t register the offence?" Customer: "No". Disappointed he says goodbye and I wish him luck. (Field note, March 1999)

Thus, the keep-moving policy makes the drug users feel they are no longer accepted as a normal civilian and do not have the same rights as others.

I. From time to time the police increases the pressure. They chase the people away. Did you hear something about that? Fot example people who are complaining?

R: No, not really (...). "They say: "T was standing in a porch and I wasn't allowed to. A non-using person was standing next to me and $I$ got a fine and he didn't." Something like that "Why didn't he but I did, it was raining and I was shelrering for a while. Just because I happen to be a drug user, I get a legal action." (Interview, chauffeur methadone bus)

Since 2001 , the repressive policy by the police has been intensified in that the pressure on the drug users causing nuisance has been increased. In the survey we asked the drug users if they had noticed any changes in the policy of the police since the new operation had started (i.e. about 6 months prior to the interview). $78 \%$ said the police was more active and $22 \%$ did not notice any changes.

Although some drug users accept the police as an occupational hazard, the new policy has affected most drug usets, generally in a negative way.

Interaction: They (two drug users) criticise the policy of the police and tell me that theyve been arrested frequently and locked up in the police office for a few hours. One of them shows me a yellow ticket. "This isn't nomal anymote. When we walk or lie down somewhere, we get chased away immediately. When I ask a policeman why, he answers: "You belong to the target group and the mayor has ordered us to carry out this pollicy"s". (Field note, August 2002)

One specific measure of the keep-moving policy (introduced in October 2000 in Heerlen) is the territorial ban. Hereby, drug users get a waming for the first 
offence, by a second offence they are forbidden to enter certain atea in the centre of Heetlen for 48 hours, by a third offence the geographical area is extended and the time period doubled. What the police considers to be an offence varies, but it is often unclear to the drug user what he/she has done wiong, or they simply disagtee.

Until now I've seen a few people who were in breach of the law and were sentenced (...). In one case I found the reason for the ban particularly absurd. The girl walked up and down the tunnel a few times and the police summoned her to walk in a certain direction, but since she wanted to walk in the opposite direction, she objected and said: "Well, you can tell me to go this way, but I have to be there so I'll go there and that was when she received the ban (..) (Interview B. 26102000)

Some drug users feel they have no place to go anymote and have no alternatives for the hectic street life where they are constantly hunted by the police.

Interact: Esto starts to shout: "The police chases us all away. Here, he (points at Ralph) has also got a territorial ban. Where can we go now? They don't help us to find a home! (Field note, February 2001)

R: They are chased away, but don't get allocated another place to sit down.

I: So there ane no altematives left?

R. There is no altemative. That is always the problem. (Interview Fieldworker, Area Health Authority)

Howerer, the new drug policy also aimed to encourage drug users to visit the local day care facility. The survey data show that the number of drug users visining the local day care facility as an altemative has slightly increased from $20 \%$ in 1999 to $29 \%$ in 2002 (not significant). Since the start of the new policy, $4 \%$ visited the service more frequently and $5 \%$ percent less frequently. Thus, the new policy has not been successful in promoting the day care facility as an alternative for the stressful. street. However, there has been a significant increase in participation in the methadone maintenance program from 50\% (DMS survey 1999) to 61\% in 2002. Wheaterburn \& Lind (2001) also found a heroin user's own experience with arrest and imprisonment increased the likelhood of having tried treatment.

Nevertheless, the overall conchusion is that, from the standpoint of the chronic drug users, the policy measutes contribute substantially to theit marginalisation. At the same time, alternatives for drug users are insufficient and geographical dispersion rather than a dectease in drug-telated problems seems to be the main effect.

\section{Effects on hardening}

The keep-moving policy also affects effects telations between drug users. Since drug users have to keep on moving, transactions take place in hectic circumstances leaving litle opportunity to check the quality of the drugs. Grapendaal et al. (1995) have stated that "most drug users who buy in the street are ripped off sooner or 
later". We observed a similar effect and often heard that drugs were adulterated with sugar, baking powder, cough tablets or Epsom salts. The field notes emphasise that during active periods of the police, the quality of the drugs tends to get worse. This confirms the findings of studies on the influence of law enforcement on the supply side of the drug market (Kleiman \& Smith, 1990; Weatherburn et al., 1998). We observed that the established (upper level) drug dealers become careful and avoid the drug scene for a while. Thus, the supply decreases and the lower level dealers often adulterate the drugs with other substances.

Believe me when I tell you that what's happening in Heerlen is not tight at all. Because they"re selling a lot of trash. At the moment we take the killos off the road, the prices rise. The drug user has to cough up more money. And he has to do more burglary or whatever, because he has to have his fix. There are people who know that The stuff on the market "s no good anymore or it's strongly adulterated. (Interview police officer, Ketkrade)

Bad quality drugs and the hectic street life mean that social relations become more distressing than they were, often characterised by paranoia and aggression.

He tells us about the stress in the scene nowadays and how everybody screws and cheats one another. According to him this is one of the teasons why the number of drug tourists has drastically decreased in Heerlen. Only yesterday a German woman was sold trash for $600(€ 272)$ guilders. Nobody seems to be able to trust each other. (Field note, May 1999)

Moreover, the keep-moving policy means there is less time and opportunity for social behaviour among drug users. This development is negative because, although social relationships among drug users are characterised by instrumentality, they still need each other.

Since drug users always have to be alert for the police, they develop a kind of awareness, which we call "the mindpolice", i.e. they act as though police are always in the neighbourhood: constantly in a hurry, nervously looking around, and acting in a paranoid way towards each other.

A kid, I don't know him by name, joins us. He obviously feels like using and starts to inquire about how many pills there are and what Alex wants to get paid for them. I notice that the boy talked normally before, but now it comes to bargaining about a drug sale, he starts stuttering. He gets more nervous each minute and starts looking atound very agitated...(Field note, June 1999)

Lian: I did not use "white" (= cocaine), but I'm still paranoid. They made us this way, by chasing after us all the time. (Field note, February 2001)

An indirect effect on hardening is that, in order to avoid the police, the drug user has to find faster and more efficient ways to administer the drugs. Fortunately, 
in Heetlen injecting drugs has become less popular then it was, so there has been no increase in injection-related risks as observed by Maher \& Dixon (1999).

However, the new policy may have contributed to the increased popularity of crack cocaine, i.e. its fast administration (basing) and its instant effect. However, cocaine is known to be associated with stress. If introduced in a new population, the danger of losing control is high meaning that the use of crack combined with a lack of money, exhaustion, and the repressive policy decrease the threshold for frustration, leading to impatience, paranoia and aggression.

Han thinks it's very restless in the street. "That's because of that fucking white (cocaine) and the police who make you even more paranould. Saturday 1 used three grams of white and really, I heard the bullets whistle past my ears and I saw them thrive in. It really was that bad. Everyone is now "full on white". They are all as paranoid as a singing teaketrle." (Field note, February 2001)

\section{Actions to manage drug dealing}

One of the targets of the law enforcement policy in general, but given a higher priority in the context of the new policy, is to take action against drug dealing on the street and at dealing addresses. Dealing addresses offer the possibility to check the quality of the drugs to use drugs in a quieter setting (Grapendaal et al., 1995). When the transaction and the use of drugs takes place indoor, there is some safety and protection. Large-scale closure of dealing addresses forces drug users (back) to the stressful street, where the market is less stable and circumstances are hectic (Barendregt et al., 2000). We observed that the police actions lead to displacement of the locations where transactions take place.

Most Antillean drug dealers are known to sell their merchandise at the front of the station and on the Willemstrat (Figure 7.1, location 1), but during police actions they move to other places, such as the Promenade (Figure 7.1, location 2).

I move on to the Promenade, because I know that drugs are often sold there too, or otherwise in front of the fast-food restaurant.

Observation: Indeed the people there are that I usually saw hanging around near the railway station (Antillean dealers). I notice that everything goes on like always, except that the dealing takes place with more caution. (Fiveld note, October 2002) 


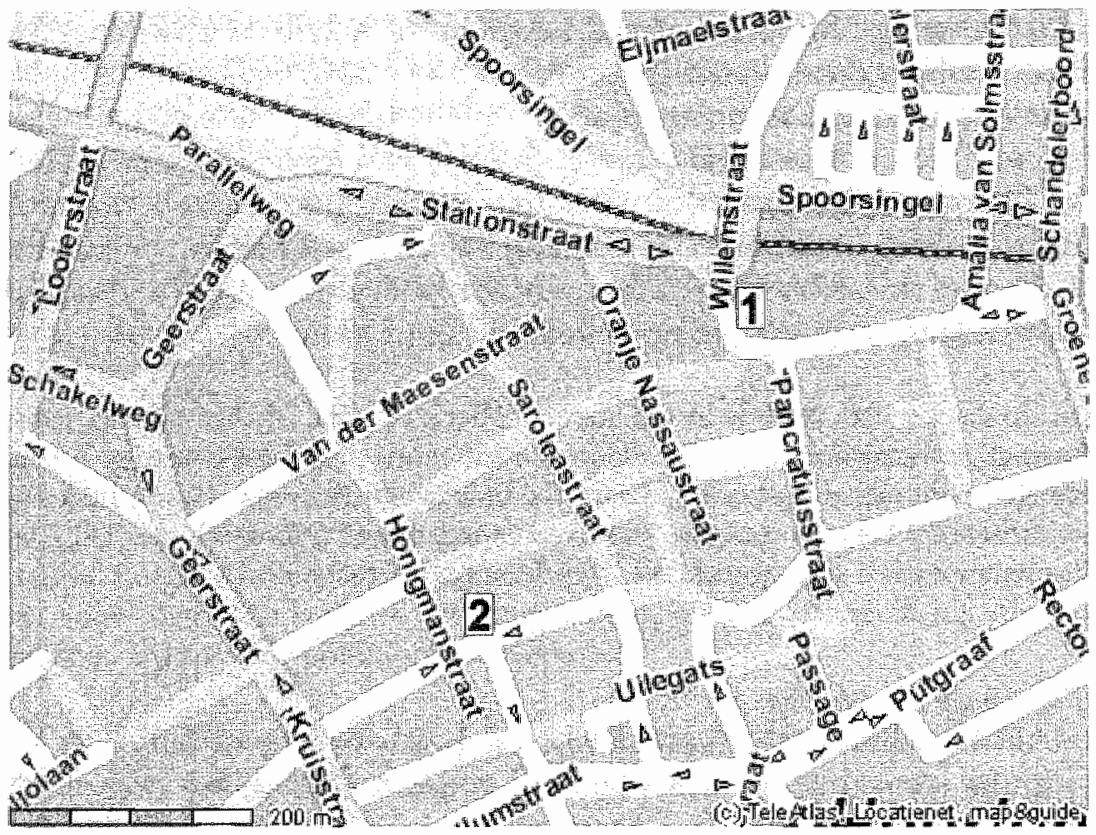

\section{Figure 7.1: Map of the inner city of Heerlen (Source: Internet address: htrp://www.internetgemeentegids.nl)}

When the police follow them there, they often return to their old places. Some dealers adapt to the repressive measures by developing a "system".

Background: Saby ( 42 years) is a Surinamese dealer who's been known for about ten years as one of the better dealers.

Interaction: He explains to me how he handles the problem of the police patrols. In earllier times there were at the most two or three assistants, these are boys who biought in customers and kept watch for the police in order to warn the dealers in time. Nowadays the drug squad works as follows: there are for example two teams of three men each, who try to enclose the dealers. One team approaches from the station, the other from the warchouse to arrest the dealer halfwing the street. Most of the time the tearns succed in gearing their motions to one another, in order to encounter the drug user at the same time. (Because the police stay in contact by walky-talky, the dealers have few chances to escape). A creative dealer, like Sady, arms himself by hiring four to six boys from the scene, who usually get paid one ball of brown or white an hour. Saby employs the following system: he "walks square", which means that on each angle of the square (block) he installs one person who is on the watch and is able to warn him in time when the criminal investigation department goes into action. If he hires six boys, two of them bring in customers to the Promenade or the station and take those customers to the (known) squate. Saby is smart enough to change square each hour. (Field note, April 2002) 
Thus, the intensified actions of the police against drug dealing means less supply, more buying and selling in the streets, and more hectic circumstances surrounding these transactions, all increasing the risk that drug users will be ripped off. Moteover, it becomes difficult to check the quality of the drugs and all this contributes to the hardening of relations between drug users.

One development that may have mitigated these measures against drug dealing before the onset of the new policy was the switch to street transactions by mobile phone. This kind of trade seems to be fairly safe for the drug dealer and the client (Barendregt et al., 2003). However, our survey showed that after the introduction of the new policy, the percentage of buyers by mobile phone decreased from $44 \%$ in 1999 to $27 \%$ in 2002 .

We conclude that the intensified repressive policy has had an impact on the quality of drugs, possibilities for social contact, use of crack, drug dealing and buying behaviour. Indirectly, the policy negatively influences the way drug users relate to each other and thus has increased hardening.

\subsection{Concluding remarks}

This section summarises the effects of divers repressive measures on marginalisation and hardening (7.4.1), discusses the results and places them in a wider perspective and offers an end conclusion and recommendations for future policy (7.4.3).

\subsubsection{Effects on marginalisation and hardening}

The results show that one of the main effects of the keep-on moving strategy is that drug users, apart from feeling hunted and humiliated, feel treated differently from other civilians. At the same time, drug users are often not protected by the police and, consequently, feel outlawed. Closing of dealing addresses leads drug users to the streets, where other measures (e.g. the keep-moving policy) are enforced, so that the circumstances become hectic and preclude checking drug quality or finding some rest. Moreover, drug activities become more visible to the society, which emphasises the contrasts between the drug user and other members of society.

Our data showed that drug users no longer have access to certain services or participate on a lower level; i.e. they have few alternatives to the stressful streets. Although the methadone maintenance program was better visited after the start of the new operation, this does not apply to the day care facility and the users room. A substantial number of drug users still do not visit these low threshold care facilities. A part of the drug-using population does not want to or is not allowed to visit even the low-threshold care facilities, and these people use their drugs in public places and sleep outside. Obviously, negative effects of repression are especially relevant for this latter category. 
The keep-moving policy also has effects on hardening. The scarcity of drugs, poor drug quality, paranoia, cheating and aggression are increasingly dominant and require special survival skills. The policy has led to more suffering in the constant struggle for drugs, which forces the drug users to fight and divide.

The negative influence on hardening is also related to the closing of dealing addresses since the start of the new repressive policy in June 2001. This policy often leads drug users towards the hectic street market, were, as we have already seen, adaptation skills are indispensable.

\subsubsection{Discussion}

The result that drug users feel treated differently from other civilians is the core of marginalisation: the different treatment is stigmatising and places the drug users in the margins of society. Especially the increased repression, territorial bans and bans on gathering emphasise the marginalized position of the drug user. Weatherburn and Lind (2001) also remarked that "aggressive policing can also lead to systematic violations of civil liberty".

With respect to hardening, our results confirm those of Lempens et al. (2003), who found that the policy of limited freedom of movement in Utrecht has had a negative influence, leading to mote violence and to an increased use of crack cocaine. However, thete is no consensus about the relationship between law enforcement, cocaine and increased violence. Dorn and South (1990) argue that fragmentation of the drug market and increased violence has little to do with crack, and is directly related to trends in law enforcement. Other studies (Lempens et al., 2003; Weatherburn et al., 1998) acknowledge the negative consequences of law enforcement and describe increased use of cocaine as a possible outcome of law enforcement. Our results confirm those of these latter studies and also demonstrate the effects on hardening.

Since the increased repression, getting good quality drugs becomes more difficult, but drug users rarely cease habit, as is argued by some authors (Weatherburn et al., 1998). We observed that mobility increases and new systems are developed to sell drugs. This is in agreement with the effects of law enforcement in Britain where the final effects are similar to ours, i.e. the markets being shaped are fragmented, volatile and increasingly violent (Dorn \& South, 1990 ).

In this study the impact of the new policy was explored primarily from the perspective of the drug users. However, a triangulation method was used to increase the validity and reliability of our results: i.e. the ethnographic data were verified with data from interviews with key informants. It is interesting to note that these data confirm the results on the following effects of the repressive policy: geographical dispersion of drug users and related problems, stigmatisation of drug users, decreased options to rest, and decreased quality of drugs. Remarkably, even the police officers we interviewed criticised the repressive law enforcement policy for its dispersing effects and also for its negative effects on the quality of drugs. 
From a wider perspective it is also important to establish the effects of repressive measures on the community, or more specifically, whether the general public has benefited from the enforcement policy. One main data source that helps to answer this question are the general population surveys in Parkstad Limburg, which address drug-related nuisance (Oostveen Studies of Policy and Advice, 2003).

The population surveys show that both in 2001 and $20036 \%$ of the population of the Parkstad municipalities report nuisance from drug dealing addresses (including coffee shops). Since most drug related problems as well as all specific measures of the new policy were focused on the city of Heerlen, changes in drug-trelated nuisance and dispersion of dnug-related problems may have been limited to this city. Table 7.1 presents survey results for the centre of Heerlen and four neighbouring districts.

Table 7.1: Nuisance from drug dealing addresses (source: general population surveys)

\begin{tabular}{lll}
\hline & \multicolumn{3}{l}{ Reporting nuisance from drug dealing addresses } \\
\hline & 2001 & 2003 \\
& $\%$ & $\%$ \\
\hline Heerlen-centre & 19 & 14 \\
District A & 9 & 6 \\
District B & 23 & 25 \\
District C & 4 & 8 \\
District D & 7 & 9 \\
Total & 8 & 8 \\
\hline
\end{tabular}

Table 7.1 shows, comparable to the whole region of Parkstad Limburg, no change in the overall percentage of the population of Heerlen that complained about nuisance caused by drug dealing. Although in Heerlen-centre and district $A$ the percentage of inluabitants complaining about drug dealing has decreased, this percentage has increased in the other three districts.

Therefore, from the perspective of the genetal public, the new policy has not been successful. Although the wish of the community for a new initiative to improve control over drug-related problems has been met, a redistribution of problems related to drug dealing over districts within the city of Heetlen can be observed.

The above provides an answer to the question posed by Kleiman and Smith (1990) to what extent crackdowns lead to a dispersion of drug users and related problems. Moreover, our results are in line with other studies in the Netherlands showing that repression at one location led to a displacement of drug dealing and drug users to other locations (Blanken, 1994; Blanken \& Barendregt, 1998; Lempens et al., 2003; Verbraeck, 1990). For example, after the closure of "the tunnel" near the railway station in the city of Utrecht (Lempens et al., 2003) and "platform zero" at the station in Rotterdam (both notorious places for drug users), which took place in the context of enforcement policy, a displacement has been 
observed. The drug market shifted its activities not only to other locations in the inner city, but also to districts surrounding the centre. Similar effects could be observed in the Red Light District in Amsterdam, where during the summer of 1987 more policemen were patrolling 24 hours a day in the area than in the years before (Verbraeck, 1990).

Thes, repression of concentrations of drug users leads to the dispersion of problems to other locations. The future will show whether such a situation is more desirable in terms of manageability and controllability, than a concentration in a more limited area.

\subsubsection{End conclusion and recommendations}

We conclude that the repressive policy has contributed to marginalisation and hardening of chronic drug users, and that the repressive measures in Parkstad Limburg have had catalysing effects on both ptocesses.

Therefore it is important to limit those measures that stress a different treatment of drug users, and those that make it hard to survive. On the other hand, the drug scene should not become a haven for drug users at the expense of liveability in the neighbourhood. Therefore, we should explore ways that slow down the processes of marginalisation and hardening, without avoiding the necessity to clecrease drug-related nuisance.

One way to prevent further marginalisation of drug users and hardening of relationships between drug users is to offer sufficient alternatives in terms of care facilities. More attention should be given to care outside the aid agencies. Community outreach activities enable to reach drug users in their own setting and facilitate cate for those who are not permitted to enter or do not wish to visit aid agencies. This kind of measure is in agreement with the so- called "assertive outreach" projects, which have been active in the Netherlands for several years, and since 1999 in Parkstad Limburg. (Area Health Authority Eastern South Limburg, 1999).

Furthermore, low-threshold services should be expanded and macle more attractive to all drug users. According to van der Poel er al. (2003), who described the cycle of compulsive diug use as related to drug consumption rooms, not only should the actual use of drugs within the facility be taken into consideration, but also how to get money and buy drugs (van der Poel et al., 2003). This would make the agency more attractive as an alternative to the stressful street. Both drug users and the environment take an interest in this kind of measures: on one hand they increase the drug users quality of life, while on the other hand drug-related nuisance is reduced. However, politically this kind of measures is not acceptable: even in a country with a liberal policy such as the Netherlands. Still, these measures should be considered while seeking constructive solutions for the drug problem.

Apart from offering alternatives in the area of care facilities, the policy should aim at calming down the drug market. In the city of Rotterdam there have been experiments with ways of dealing, which cause less nuisance, such as dealing at private addresses or by mobile phone; these methods of dealing received less 
police attention than street dealing. Van de Mheen and Gruter (2004) concluded that it is possible to come to an agreement with some house dealers about meeting quality criteria in exchange for a lower priority to get traced; this would prevent some drug users buying on the streets. Perhaps a comparable agreement could be applied to street dealing whereby the police could give more priority to tracing and arresting "anti-social" dealers and less attention to "clecent" dealers. In this way there would still be enough dealers to prevent scarcity and bad quality, and the serious troublemakers could be eliminated. However, in spite of the positive results in Rotterdam, such a differentiated policy is politically not acceptable. Nevertheless, we recommend to keep the discussion open in order not to miss interesting opportunities to reduce drug-related nuisance.

Acknowledging the fact that a successful policy should reduce drug-related nuisance and drug-related harm, we recommend to contimue improving projects with the medical prescription of heroin to chronic drug users. One study in the Netherlands reported that prescription of heroin in combination with methadone to chronic drug users not only led to an increase in physical, psychological and social health, but also to a decrease in criminal behaviout of the respondents (van den Brink et al., 2002).

Another way to slow down marginalisation would be to offer drug users the opportunity to show that they are not only a burden to society, but also civilians. Recent projects in Heerlen that recruit drug users to perform socially-oriented work in exchange for a small reward, have already proven their use (Council of Heerlen, 2002). Another possibility, especially for the police, is to offer drug users proper protection when they are threatened or assaulted.

In spite of these, hopefully useful, recommendations we end this section by acknowledging that the drug problem cannot be solved. We argue that the best possible solution lies in finding a strategy in which the burden of the drug problem is equally divided between the general public and the drug user.

\section{References}

Area Health Authority Eastern South Limburg. (1999). Profect Parkstad Limborgh bemoeizarg: De doelgroep nader onderzocht/ Project Partestad Limburg assertive outreach: A doser look at the varget group. Heetlen.

Barendregr, C., Lempens, A., \& van de Mheen, D. (2000). Drugs kopen op strat. Achtergronden en motieven van Rotterdamse druggebruikers die bij stratdealers kopen/ Buying drugs at the street. Background and motives of Rotterdam drug users who buy from street dealers. IVO Bulletin, 3 (1), 1-19.

Barendregt, C., van der Poel, A., \& van de Mheen, D. (2003). De mobiele telefoon in de harddrugsscene van Rotrerdam/ The cellular phone in the Rotterdam hard drug scene. IVO Bulletin, 6 (1), 1-20.

Benson, B. L., Leburn, I. S., \& Rasmussen, D. W. (2001). The impact of drug enforcement on crime: An investigation of the opportunity cost of police resources. Journal of Drug Issues, $31(4), 989-1006$. 


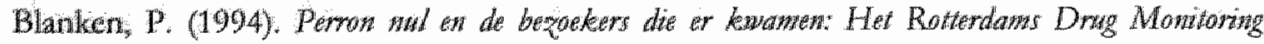

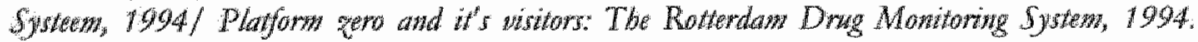
Rottrardam: Addiction Reseatch Instirute (TO).

Blanken, P., \& Barendregt, C. (1998). Veranderingen in de aanbod-en vraagzijde van de illegale drugsmatkt in Rotterdam: Enkele resultaten van het Rotterdams Drug Monitoming Systeem 1995-1997/Changes in supply and demand on the lllegal drug matket: Some tesults of the Rotterdam Drug Monitoning System 1995-1997. IVO Byilletin, $1(1), 1-11$.

Buchanan, J. \& Young, L. (2000). The war on drugs: A war on drug users? Drugs: Edwation, Proventon awd Polio, 7 (4), 409-22.

Bush, W. M. (2003). A misdirected crusade? Addition Research and Theory, 11 (2), 83-7.

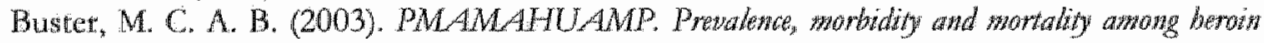
users awd motbadone putiterts. Amsterdam: Universicy of Amsterdam.

Chao, A (1987). Estimating the population size for capture recapture data with unequal catchability. Biowedrics, 43, 783-91.

Chao, A. (1988). Estimating animal abundance with capture frequency data. Jownat of Willife Mangugent, $52(2), 295-300$.

Chao, A. (1989). Jatimation population size for sparse daca in capture recapture experiments. Buthetrics, 45, 427-38.

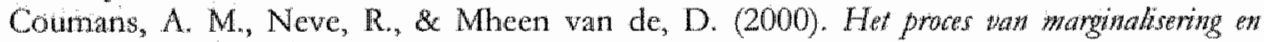

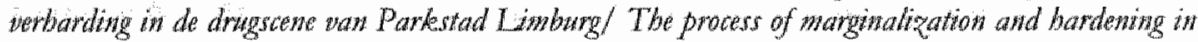
the Parkitad Limburg drug same. Rotterdam: Addiction Research Institute (TVO).

Coumans, A. M., \& Spreen, M. (2003). Drug use and the role of homelessness in the process of marginalization. Sxabstance Use \& Miswse, 38 (3-6), 311-38.

Council of Heerlen. (2002). Taussenbericht no2 aan de rad wan de gemeente Heerlen in bet kader man

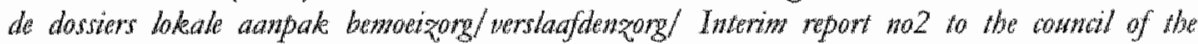
mannipation of Heerlen within the scope of the local poligy of asseriwe outreath/drug aid. Heerlen.

Dorn, N., \& South, N. (1990). Drug markets and law enforcement. British Jaurnal of Criminology, $30(2), 171-88$

Duncan, D. F. (1994). Drug law enforcement expenditures and drug induced deaths. Psychological Reponts, 75, 57-8.

Gartetsen, H. F. I, Blanken, P., \& van Mastrigt, H. (1995). Een onderzoeksperspectief op

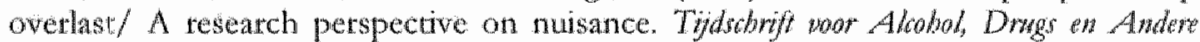
Protomope Stoffor, $21(2), 95-102$.

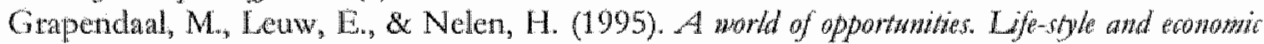
boldation of beroin addicts in. Ansterdan. New York. State University of New York Press.

Green, P. (1998). Drwgs traffing and criminal policy, the scapgeat strategy. Winchester: Waterside Press.

Hendriks, V. M, wan der Meet, C. W., \& Blanken, P. (1991). De Addichow Severity Index: ASI

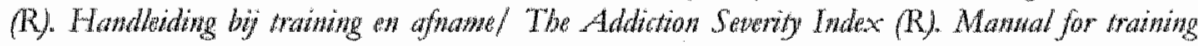
and administering. Rotterdam: Addiction Research Institute (IVO).

Hughes, P. H., Parker, R, \& Senay, E.C. (1974). Addicts, police, and the neighbourhood social system. Amerions Jowrwal of Oxthopsychaty, $44(1), 129-41$.

Kleiman, M. A. R. \& Smith, K. D. (1990). State and local drug enforcement: In search of a strategy. In M. Tonry \& J. Q. Wilson (Eds.), Drygs and wime (pp. 69-108). Chicago: The University of Chicago Press.

Kort, D. J. (1995a). Dwth trear. Fonnal cantrol and illicit drig wse in the Netberlands. Amsterdam: Thesis publishers. 
Korf, D. J. (1995b). Verhanding, verakelipking en verzieking/ Hardening becoming

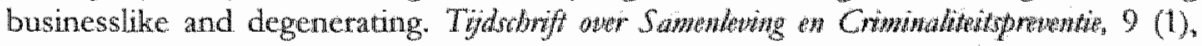
23-6.

Lempens, A., Barendregt, C., Zuidmulder, L., \& Blanken, P. (1999). Kenmerken wan Rotterdamse gebruikers: Enkele resultaten van de survey 'drugs, huisvesting, schulden en gezondheid//Chatacteristics of Rotterdam drug users: Some tresults of the survey "drugs, accommodation, debts and health". IV O Bulletin, 2 (3), 1-20.

Lempens, A., Wildschut, )., van der Most, D., \& Knibbe, R. A. (2003). "Na de whmishing".

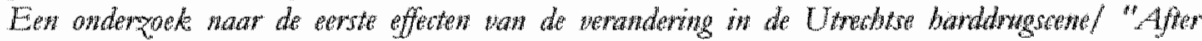

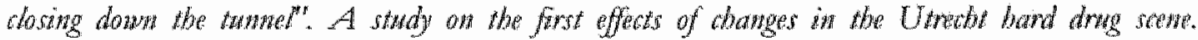
Rotrerdam: Addiction Research Institute (TVO).

Maher, I., \& Dixon, D. (1999). Policing and public health. Law enforcement and harm minimization in a street-level drug market. Brithis Jonmal of Craminology, 39 (4), 488-512.

Maris, C. W. (1999). The disasters of the war: American repression versus Dutch tolerance in drug policy. Joumal of Drug Issues, 29 (3), 493-510.

Meares, T. L. (1998). Social organization and drug law enforcement. The American Criminal Law Review, 35 (2), 191-227.

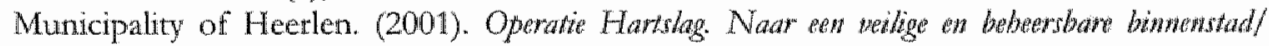
Operation Heartbat. Towards a safe and manageable wity centre. Heerlen: Gemeente Heerlen.

Oostween Studies of Policy and Advice. (2003). Monitor Parkstad Limburg Monitor Parkitad Limbarg Retrieved Retrieved September 1, 2003 htp:L/wwwparkstadlimburg.nl/monitor/framemonitos.htm

Seidel, J. (1998). Etbrograph 5.0 a user's gude. Thousand Oaks/ London: Scolari, Sage Publications Softrorare.

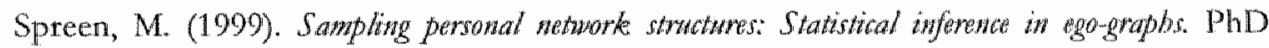
Thesis, Rijksuniwersiteit Groningen, the Netherlands.

Spreen, M., \& Coumans, A. M. (2000). Network sampling hard drug users: A structural analysis of the clients of aid agencies in Heetlen. Kunatitatietwe Mothoden, 21 (65), 95-112.

Spreen, M., \& Coumans, M. (2001). A note on network sampling in drug abuse research.

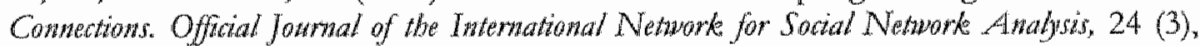
44-51.

Ungerleider, ]. T. (1976). The uneasy truce: Drug abuse treatment and enforcement. Jonghal of Polig Scionce and Administmation, 4 (2), 213-6.

wan de Mheen, H. \& Gruter, P. (2004). Interventions on the supply side of the local hard drug market: Towards a regulated hard drug trade? The case of the city of Rotretdam. Jourrat of Drwg Insues, 34 (1), 1.45-61.

wan den Brink, W., Hendriks, V. M., Blanken, P., Huijsman, I. H, \& wan Rec, J. M. (2002).

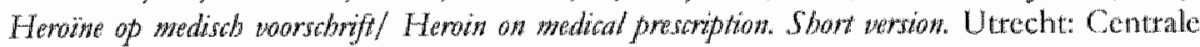
Commissie Behandeling Heroineverslaafden (CCBH).

van der Poel, A., Barendregt, C., \& van de Mheen, H. (2003). Drug consumption roms in Rotterdam: An explorative description. Eumpean Addiction Research, 9, 94 w00.

Verbraeck, H. (1990). The German bridge: A street hookers' strip. In E. Lambert (Ed), The callewion and interpretation of data from hidden popakations (Vol. 98, p]. 146 - 55). Rockville: National Institute on Drug Abuse research monogtaph series.

Weatherburn, D., Jones, C., Freeman, K., \& Makkai, T. (1998). Supply control and ham reduction: Iessons from the Australian hetoin 'drought'. Addition, 98 (1), 83-91.

Weatherburn, D., \& Lind, B. (2001). Street-lewel drug law enforcement and entry into methadone maintenance treament. Addiction, 96 (4), 577-87.

White, T. (2002). Controlling and policing substance use(rs). Substance Use ero Misust, 37 (8), 973-83. 
Chapter 8

Concluding remarks 



\subsection{Introduction}

This thesis focused on the processes of marginalisation and hardening among chronic heroin users. In this chapter the main results and conclusions are summarised (section 8.1), and the relevance of these conclusions are placed in a methodological and theoretical perspective (section 8.2 and 8.3). Finally, implications for (future) drug policy are formulated (section 8.4).

\subsection{Conclusions}

\subsubsection{Marginalisation and hardening}

One of the main goals of this study was to describe the daily life course of chronic heroin users by means of the concepts of marginalisation and hardening. Research questions that guided this description were:

1. How is the shift in social position of chronic heroine users related to deteriotation in social, economic and health aspects?

2. How are the changing social relations between chronic heroin drug users related to deteriotation in social and economic functioning?

3. Which specific factors increase the rate of deterioration of chronic heroin users?

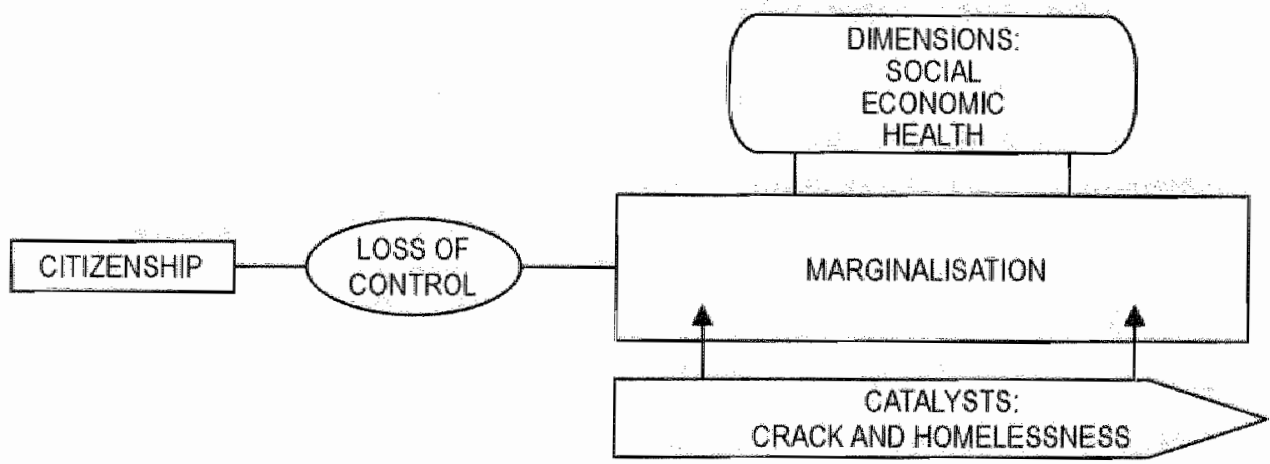

Figure 8.1: The process of marginalisation

In Chapter 3 the concepts of marginalisation and hardening were elabotated as they emerged out of the ethnographic fieldwork data of Parkstad Limburg. Marginalisation refers to deteriorating relationships with society. Figure 8.1 shows that this process is initiated by loss of control of drug use, which can be related to the use of heroin, cocaine and/or pills.

Marginalisation has also shown to be multidimensional; Figure 8.1 shows the social, economic and health dimension. The social dimension is described as a 
process of alienation in which the burden of the addiction is externalised from one sector to another; i.e. from primary contacts to sociery as a whole. Close friends are rare in this setting and drug users become dependent on low-threshold services. A cyclic connection was observed between control of drug use, especially of cocaine, and quality of social relationships. The economic dimension addresses a decline of possibilities to take part in legitimate economic activities. The health dimension describes how physical, lifestyle-related and psychological problems articulate the deviancy of the drug user, thus implying decreasing possibilities to fully participate in society.

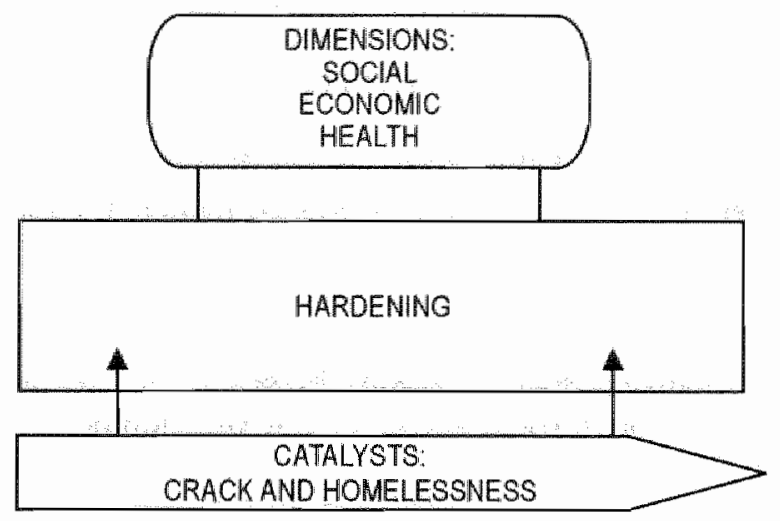

\section{Figure 8.2: The process of hardening}

Hardening addresses a process in which relationships between drug users are deteriorating. Figure 8.2 shows that hardening has the same dimensions as marginalisation. Since the deterioration in health coincides more with a change in social position in society than with social processes between drug users, only the social and economic dimension are elaborated in this study.

To make clear how drug users relate to each other, first the hierarchy in the drug scene was described. When someone enters the drug scene he or she has to adapt to circumstances that are largely determined by tough hierarchical rules. Whereas there are some positive factors that enable to survive in this world, there are also factors that decrease a drug user's opportunities and lead the drug user to "marginalise among the marginalised". This double marginalisation usually takes place when at drug user shows vulnerability or psychological problems, thas to a large extent lost control over their drug use, has no success in the hunt for money, or is dependent on the streets to buy drugs. Also, a drug tourist is lower in the drug user's hiexarchy than a "local" drug user. In this phase social networks are very homogeneous, i.e. they consist almost exclusively of drug users. At the same time, the relationships between drug users are characterised by instrumentality and selfinterest. Most drug users are dependent on an unemployment benefit and earn 
additional money by (often) illegal activities, such as selling drugs, pills or methadone, prostitution, shoplifting, and burglary.

The processes of marginalisation and hardening are closely relared, i.e. hardening becomes more relevant when a drug user (due to their matginalisation) increasingly spends time in the drug scene.

Crack and homelessness were identified to be specific factors that accelerate marginalisation and hardening. Figure 8.3 depicts the process of marginalisation and hardening integrated in one model.

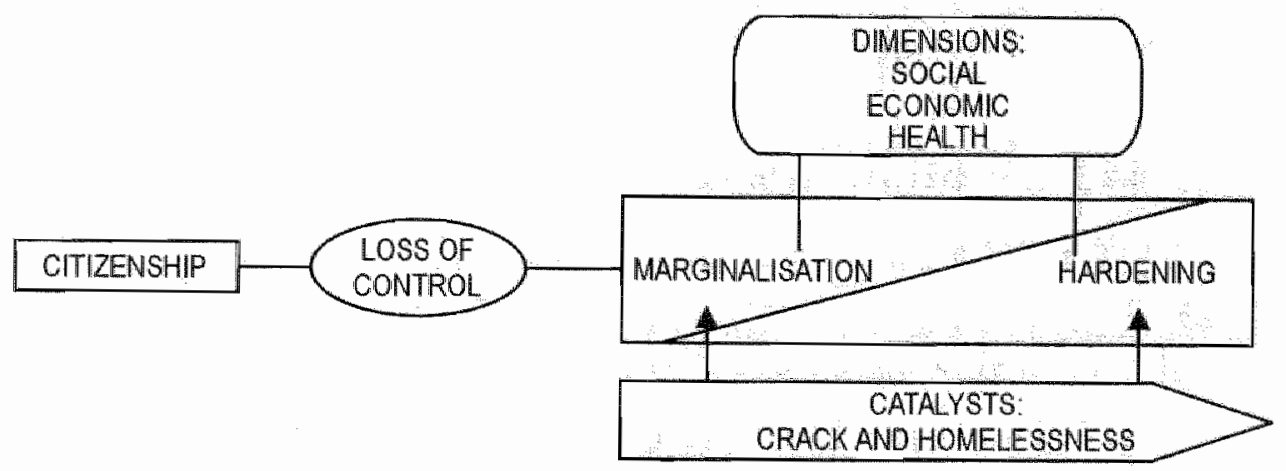

Figure 8.3: The process of marginalisation and hardening

\subsubsection{Counteracting movements to marginalisation and hardening}

In Chapter 5 an answer was formulated to the question whether marginalisation and hardening is counteracted by counteracting movements and, if so, what conditions lay behind these counteractions.

By comparing the Parkstad Limburg drug scene with that of Rotretdam in a two-case study, we observed that the basic processes of marginalisation and hardening took place in both cities. However, in Rotterdam there were more indications for socialisation and solidarity than in Parkstad Limburg: i.e. in Rotterdam more drug users regained control over their drug use, less drug users were homeless or had infectious diseases, and more drug users had legitimate work or bought their drugs at drug dealers' addresses. With respect to hardening we showed that in Rotterdam there was more solidarity. This solidarity was explained by more drug users from ethnic groups (Antillean or Surinamese) living in Rotterdam, and more possibilities to buy and use drugs in a more protective setting (basements or drug-dealing addresses). According to these conclusions, the original model has been revised (Figure 8.4). 


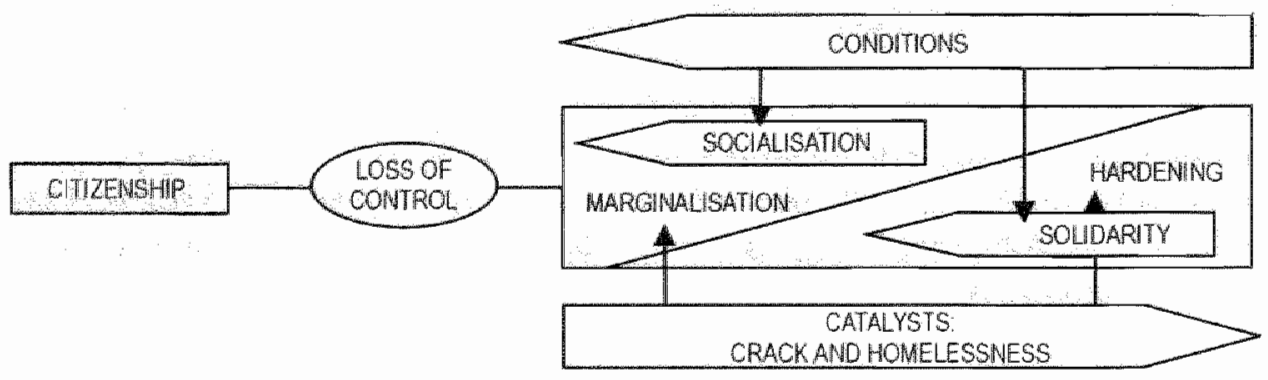

Figute 8.4: counteracting movements to marginalisation and hardening

\subsubsection{Amplifying factors}

Chapter 5, 6 and 7 focused on factors that potentially amplify marginalisation and hardening, i.e. crack, homelessness and a repressive street-level policy. The following questions guided this investigation:

- What is the impact of the use of crack on the marginalisation and hardening of chronic heroin users in Rotterdam and Parkstad Limburg?

- What is the relationship between several important dimensions of marginalisation and homelessness?

- What are the effects of repressive police measures that aim to reduce drugrelated public nuisance, on marginalisation and hardening of chronic drug users in the region of Parkstad Limburg?

Ethnographic analyses have shown homelessness to be a catalyst of marginalisation. Conversely, Chapter 5 describes in quantitative terms that the drug users who are marginalised (whether on a social, economic or health basis), are also mote likely to be homeless than non-marginalised drug users. Mote specifically, we found that injecting drugs, using cocaine, having no contact with friends and family outside the drug scene, buying and using drugs at public places, having been arrested, dealing drugs, drugs running, and having physical health problems increase the risk of homelessness. The network analysis also showed that social networks of homeless drug users are structurally located within or near the aid agencies, implying that homeless druy users are less integrated in society compared to drug usets with a roof over their heads. This shows that the daily social contacts of homeless drug users are located within or near these locations and their social lifestyle is concentrated around these institutions. It is important to note that in this chapter "loss of control" is used differently from the rest of the thesis: i.e. in Chapter 5 "loss of control" is used as a catalyst of marginalisation and in the rest of the thesis as a characteristic of marginalisation. This is due to the fact that Chapter 5 was written earlier than the remaining chapters. After that article was published, there has been progress in the elaboration of and thinking about the notion of "loss of control" and its place in the theoretical framework. 
In Chapter 6 uncontrolled use of crack was described as an important catalyst in the process of marginalisation and hardening. By using crack (and especially bingeing) drug users are increasingly alienated from primary social contacts and social society as a whole. Compated with using only heroin, the priotity lies with getting/consuming crack, there is no time for social contact, and crack users are increasingly excluded from employment and from proper housing. Moreover, using crack stresses their deviance because of specific health problems and a typical physical appearance.

In Chapter 7 a repressive street-level policy in the Netherlands was also described as a deteriorating factor, in that it amplified both matginalisation and hardening. Especially the keep-moving strategy, territorial bans, and bans on gathering emphasise the marginalised position of the drug user. These measures make the drug user feel treated differently, which is a core aspect of marginalisation. Closing of dealing addresses forces drug users to the streets, where circumstances are increasingly hectic and preclude checking drug quality before buying it, or finding some rest. The findings showed that since the start of a new repressive policy, the low-threshold services (such as the day-care facility and the users' room) were not better visited. This implies that these facilities do not function as alternatives for the hectic streets, at least not to the extent that was intended.

Also hardening is amplified by a repressive policy. Taking drug dealers from the streets leads to a scarcity of drugs and poor drug quality; this in combination with the constant "hunting" of drug users by the police make paranoia, cheating and aggression increasingly relevant and requiring special survival skills. All in all, the policy has led to more fighting and division in the struggle for drugs.

\subsection{Methodological remarks}

This section presents some methodological remarks about the results. Since the theoretical concepts were discovered mainly by means of the ethnographic part of this study, this section concentrates on the strengths and limitations of this kind of research.

One strength of this study is that it aims to offer an insider's wiew by the use of ethnographic research. However, as with each type of research, this kind of research also has its limitations. Since we agree with Lincoln \& Guba (1985) that the conventional criteria to address the quality of the research findings are not appropriate to naturalistic (or qualitative) research, we use different terms to tefer to the naturalistic equivalents of validity and relevance. In this study we applied the "trustworthiness" criteria of Lincoln \& Guba (1985) and related strategies as they were applied in the qualitative part of Drug Monitoring System (see Chapter 2 for more details). Table 8.1 gives an overview of the criterion area and related techniques applied in the present study. The third column presents potential pitfalls in the application of some techniques. 
Table 8.1: "Trustworthiness" criteria, techniques to meet them and some potential pitfalls

\begin{tabular}{|c|c|c|}
\hline Criterionarea & Applied technique & Potential pitall \\
\hline Credibility & $\begin{array}{l}\text { a. Activities in the freld: } \\
\text { - prolonged } \\
\text { cngagement } \\
\text { - persistent } \\
\text { observation } \\
\text { - triangulation } \\
\text { b. Peer debricfing } \\
\text { c. Negative case analysis } \\
\text { d. Menber checks (in } \\
\text { process) }\end{array}$ & $\begin{array}{l}\text { - Going native } \\
\text { - Premature closure } \\
\text { Reconstruction based on: } \\
\text { - general myths, } \\
\text { - or average position } \\
\text { reflecting no-one's } \\
\text { reality }\end{array}$ \\
\hline Transferalbility & e. Thick description & \\
\hline $\begin{array}{l}\text { Dependability* } \\
\text { Confirmability } \\
\text { All of the above }\end{array}$ & f. Reflexive jouryal & \\
\hline
\end{tabular}

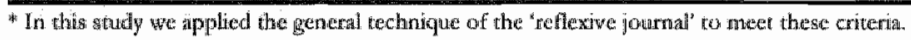

This section focuses on some specific issues within the criterion area of crecibility and how we handled pitfalls inherent to the application of techniques to meet this criterion.

One distortion of the credibility of our findings was the use of fieldworkers in the drug scene who were unfamiliar to the field. Whether the fieldworker preferred being an observer (the "fly on the wall") or a participant-observer (the "wasp"), in both roles he influenced the same reality he aimed to observe. Since we used also actual drug users as fieldworkers, we were able to "test" whether this kind of distortion seriously influenced the credibility of our data. We observed that the same aspects of marginalisation and hardening came back in the field notes of both types of fieldworkers, implying that the undeniable influence of fieldworkers strange to the field did not distort our findings.

Credibility can also be distorted by participants. Especially research with an "emic" perspective among drug users will raise questions about intentional misinformation. These doubts, regardless of whether or not they are justified, need to be addressed. Taking into account that for many daily drug users the use of drugs takes priority over other roles (e.g. being a spouse, child or mother) and that in order to survive in the drug scene they need to develop certain survivor skills, it is not hard to imagine that they would deliberately tell lies or make up stories in order to raise the fieldworkers sympathy, to receive a financial reward, or to get help. However, there are several reasons to support that this kind of distortion did not take place to a large extent, or at least could be detected. Firstly, by spending enough time in the drug scene the fieldworkers unfamiliar to the drug scene learned surprisingly quickly who was to be trusted and who was not. Secondly, drug users learned that generally there was no profit for them in misinforming us. Whereas in contacts with caretakers of drug aid agencies misinformation could 
sometimes yield certain foms of help, this was not the case with faldworkers. Whether they told true or made-mp stories did not lead to af diferent treatment or reward. Thirdly, in the few cases that a drug user persisted in minfoming ws, fellow users or drug-using fieldwotkers found out sooner or thet and informed the researcher about his misplaced confidence. Fourthly, the use of actual drag users as fieldworkers helped in building trust among drug usets. Trust is undoubtedly one of the most important conditions for drug users to tell their true stories.

One important pitfal of spending (too much) time in the drug scene (on: prolonged engagement) is "going native. In the present study one example of going native could have been that ron-using fieldworkets would have used drugs themselves. To our knowledge, this fom of going natve did not take place. However, what did happen was that two fieldworkers that had been actual drug users belore but did not use drugs when they statted the fieldwork felt anable to deal adequately with this issue. In both cases this meant that they immediately quit their job as a fieldworker. However, until that happened their field notes were still of invaluable worth to the study. Fieldworkes who were nctual drug users themselves can be viewed as already being "native", which will undoubtedly raise questions about trustworthiness.

To what extent can the observations of indigenous fieldworkers be perceived as professional? Since these fielcworkers were supervised very carefully and each field note was evaluated thoroughly with the fieldworker, we do not expect any serious distortions from their field notes. Moreover, being able to observe, to write up the freld note, to structure it properly, come to the researcher's office tregularly (in timel), and being able to reflect on the observation, tequires an investment of time and dedication that indicates a more or less professional attinde. One dngusing fieldworker once confided to the author of this thesis that it was certainly not for the (telatively) low reward alone that he persisted in doing this job. Overall, we let the invaluable worth of this source of information prevail above the relatively low risk of misinformation and subjectivity.

Another pitfall is inherent to the application of the technique of persistent observation, which means that only things that are relevant are incorporated in the study. In the present study we used the basic questions of the DMS, and the specific questions the fieldworker was asked to formulate at the end of each field note to distinguish between relevant and irtelevant issues. Whereas prolonged engagement provided scope, this technique offers depth. A possible pitfall is "premature closure", or focusing too soon on specific issues. Appliced to this study "premature closure" could have been a danger, because of the short term perspective inherent to participating observation. If, for instance, we had made our observations for a longer period of time, other conclusions about the infuence of repression might have been drawn.

It is important to note that the process of analysing ethnographic field notes is always interpretative in nature. In other words, the researcher's reflection and construction of reality does not necessarily reflect the drug user's perspecrive. There is always the danget that the researcher confuses his or her own perspective with the drug user's view. The most important technique to test whether such misinterpretation took place is the "member check", "whereby data, analytic 
categories, interpretations, and conclusions are tested with members of those stake holding groups from which the data were originally collected" (Lincoln \& Guba, 1985, page 314). We applied this technique in our study on several occasions. Firstly, during the development of the concepts of marginalisation and hardening, we discussed our reconstruction and interpretations with our drug-using fieldworkers and with drug users we met on the street. Secondly, we also handed out several final reports to some drug users in the field and asked for their reaction. Thirdly, for one specific part of our study a focus group was organised for key informants and drug users where the findings were presented. On all these occasions drug users agreed with our descriptions and recognised our interpretations. We acknowledge that there are some problems with this technique, such as common myths that may be shared by drug users or (in trying to be fair) reconstructing "an average or typical position that represents no one's reality" (Lincoln \& Guba, 1985). However, we have no reason to believe that our informants misinformed us about the credibility of our reconstructions.

\subsection{Theoretical remarks}

\subsubsection{Marginalisation}

Since many of the aspects we elaborated upon are not particularly new in themselves, the theoretical concepts could easily be viewed as commonsensical and overly descriptive. However, the main value of this study is that it offers a description that is systematic, provides scope and depth, and uncovers a thread that connects different aspects in the life course of chronic drug users. Moreover, this study makes clear that marginalisation is not self-eviclent and inherent to drug use, as it is often conceived. We mentioned in the Introduction that this concept has already been applied to many different domains from different perspectives but, except for the study of Anderson \& Levy (2003), has not yet been systematically applied to the domain of chronic drug use. Systematically means that we distinguished three dimensions of marginalisation and explained in detail how deterioration in these areas took place. Marginalisation as a concept contributes to our body of knowledge in that it describes in detail how exactly and under what conditions the deterioration of the drug user's position in society takes place. We agree with Zinbetg (1984) that drug use and the associated lifestyle and deterioration ate inbedded in context. If important aspects of this context change, the extent to which marginalisation takes place and even its direction might also change.

Another remark is that marginalisation is an interactive and dynamic process: the individual is distracted from the rules and prohibitions of society, and at the same time society reacts to this distraction itself as well as to the consequences of distraction (such as being a less reliable partner, parent or employee, petty crime or more serious violations of the law). This social reaction makes it hard to slow down or reverse marginalisation by emancipation or social actions. However, not only from an ethical point of view (i.e. the right of the drug user to survive), but 
also from a practical perspective (e.g. ADS prevention among injecting diug users) social initiatives to halt or teverse marginalsation are of great importance. This issue is further elaborated in the last secton (8.3.3).

One question that remains is how drug nsers expenicnce theit own matginalisation. Do drug users contimue using dugs, because of an aretsion against the same society that in their eyes disenfranchises hem and overteacts to their drug use? Or can marginalisation rather be viewed as one of the conditions for or even a prerequisite of oppression illness (Singer, 1999)?

By oppression illness, we refer to the chronic, raumatic effect of experiencing colonialism, racism, classism, and related oppressions ovet longra periods of time (...), combined with the negative emotional effects of intense self-disparagement associated with being the enduring target of social bigorry (1999, page 39$)$.

Closer study is required to answer the question to what extent marginalisation can only be understood from the reaction of social society or also from the artitude of the drug user.

\subsubsection{Hardening}

Hardening reflects marginalisation on the micro-level in terms of relationships between drug users and, as with marginalisation, is substantiated by means of a social and economic dimension. Hardening can be understood as the narrowing (social) world of the drug users, consisting increasingly of fellow drug users. Drug users have to survive in a setting with decreased (social and economic) resources, accompanied by fellow users who also suffer from decreased resources. It is this far-teaching state of deprivation that they share, rather than the euphoria of the nush.

Contrary to marginalisation, the concept is new in that it has newer been applied systematically to drug users, or to other categories. Furthermore, it is important to recognise that hardening has specific and mote universal aspects. Specific to the process of hardening are today's local trends and developments in the Parkstad Limburg and Rotterdam drug scenes. A more general or universal aspect to hardening is the similatity of hardening with individualisation in contemporary Western society. In an increasingly individualising and global society relationships can also be characterised by instrumentality, and solidarity is not seldom overruled by self-interest. This may imply that the process of hardening in the drug scene reflects the processes of individualisation in society as a whole. This would mean that hardening should not be viewed as an adaptation process taking place in a subculture independenty from society as a whole, but rather as a process embedded in that same society. However, one crucial distinguishing characteristic of hardening is that, whereas most people are part of supporting networks in which also solidarity and consideration play an important role, in the homogencous networks of drug users this kind of support is limited or absent. 
Moteover, if individualisation is conceived as a time-bound phenomenon of Western society, it raises the question whether hardening is also time-bounded; i.e. is hardening more relevant today than it was some decades ago, or does it take place in each drug scene, independent from time in history? Our fieldwork data showed that generally drug users see hardening as a trend over time in their own life. Whereas initially they shared things and experiences, further in the process it's everyone for themselves and fellow users are at the best people who are (potentially) useful:

\subsubsection{Moderating factors of marginalisation and hardening}

This study also offers an awareness of factors that amplify deterioration. An awareness, which implies insights into why some drug users deteriorate and others do not, or to a lesser extent. More pragmatically, this knowledge provides an opportunity to help drug users regain control of their drug use. This aspect will be further elaborated in section 8.4 of this chapter. Returning to the theoretical value of this study, we have to note that the emphasis in this study on marginalisation and hardening and deteriorating factors in these processes might have introduced a bias in that it does not sufficiently take into account the counteractions we found in the two-case study in Rotterdam. Moreover, we acknowledge that there are several other influences (whether deteriorating or counteracting) that are relevant in the deterioration of relationships of chronic drug users. Examples are the influence of age, injecting behaviour, gender, and of the prevailing national drug policy. Anderson \& Levy (2003) have successfully shown how age negatively influences the position of older injecting drug users in today's drug scene. However, that particular study took place in a specific context characterised by violence and dominated by street gangs. Future research should study whether the influence of age on marginalisation and hardening is transferable to other settings.

Although on the basis of the present study some general hypotheses can be drawn about the influence of gender, these do not point in one direction. On the one hand prostitutes are more likely to be homeless which would point in the direction of more marginalisation and hardening; on the other hand, female drug users can probably (mote than male drug users) depend on non-drug using relatives or clients. Thus, the differences between male and female drug users in terms of deteriorating relationships deserve special attention in a separate study.

Finally, the prevailing drug policy can influence the extent to which drug users deteriorate. As an example, in countries without an emphasise on harm-reduction policy (e.g. France or Germany), drug- related deaths are more prevalent than in countries that do emphasise such a policy (EMCDDA Scientific Report, 2001). Likewise, in countries with large socio-economic inequalities more drug users may marginalise than in countries with less inequalities. Future tesearch should further investigate the scope of this hypothesis. 


\subsection{Implications for future drug policy}

On the national level the use of drugs has always been surtounded by a strong rhetoric. Knibbe also emphasised the unanimity of almost all European countrics in the sense that repression and punishment should be the answer to illegal drugs (Knibbe, 2001). Until 1990-2000, in most European countries criminalisation in combination with offering therapeutic treatment aimed at abstinence was the core of drug policy. There appear to be drug users whose criminal behaviour indeed can not be changed without judicial coencion. However, it is not known whether incarceration leads to criminal behaviour, because the drug user has nothing to lose. Besides, there are many examples of incarcerated drug users who are unable to make basic arrangements (such as income or housing) for the period following imprisonment. In these cases, imprisonment obviously contributes to marginalisation.

The Dutch drug policy can be distinguished from other countries in that it embraces a more pragmatic approach in which harm-reduction prevails. In answer to the question whether a less strong criminalisation has led to a higher prevalence of marginalised drug users, Knibbe concluded that in the Netherlands the prevalence is not significantly higher than in European countries characterised by an active drug law enforcement (e.g. Germany, France and Sweden). As van de Wijngaard (1988) argued:

It has been observed (van de Wijngaard, 1985) that forbidding behaviour often leads to adverse effects. (...) Quality is questionable due to aduilterations and negligent preparation. It is difficult to exercise control over illegal substances. The suggestion that severe punishment will stop activities that are undesirable or illicit is not necessarily true. (...) Another suggested way to diminish unwanted behaviour is to control the supply of undesirable substances. However, the number of psychotropic substances is almost infinite (Shafer, 1985). Besides, the idea of controlling the supply of ghe to prevent sniffing is almost absurd. Moreover, there is the controversy berween use and abuse of phamaceuticals. In conclusion, punishment and control of supply are ineffective or even counterproductive (1988, page 493).

However, this thesis showed that even in a country with a telatively liberal policy with a very pragmatic harm-reduction apptoach, the position of and relationships between drug users deteriorates. Taking into account this ongoing deterioration and the conditions that amplify detetioration, a harm- reduction approach is strongly recommended. However, the minimisation of negative consequences of illegal drug use is only worthwhile when it is accompanied by decriminalisation. The trend towards a mote repressive drug policy on the street. level obviously counteracts harm-reduction, socialisation and solidarity. Rather than with control and repression, the harm-reduction approach should be accompanied by a more humanistic attitucle that takes into account the lifestyle of drug users and focuses on their needs. This attitude implies the acceptance of drug users who cannot or do not want to live without drugs. 
More in general, It tecommend not to emphasise the voluntary element of drug use. "This thesis has shown that their deterioration is not simply "their own fault", but emerges from a complex mixture of conditions associated with all aspects of life, including a deprived socio-economic background, a disconnection with core institutions of society, and the necessity to adapt to the tough world of the drug scene: "This is not to say that drug users should no longer be held responsible for their own life. On the contrary, by supporting drug users to rebuild and maintain a healthy social network, focus on the deteriorating effects of crack in prevention and intervention programs, offering rest and safety and linking up with the everyday life of drug users, drug users should be empowered to regain control over their drug use and life again.

\section{References}

Anderson, T. L., \& Levy, J. A. (2003). Marginality among older injectors in today's illicit drug culture: Assessing the impact of ageing, Addiction, 98, 761-70.

EMCDDA Scientific Report. (2001). Coordination of the impleswentation of the EMCDDA standard guidelines on the drug-related deaths in the EU mernber states and the collection and analysis of information on drug-related deaths. Lissabon: EMCDDA.

Knibbe, R. A. (2001). Roes, retorick en ratio. Een sociaal epidemialogische standpustbepaling ten aanzien van atobat en druggebruik/ Intoxication, whetoric and ratio. A social epidemiological niempoint regarding the ase of alcobol and drugs. Inaugural Speech, Maastricht University, Maastricht.

Lincoln, Y. S., \& Guba, G. (1985). Naturalistic inguigy. Newbury Park, CA: Sage Publications.

Singer, M. (1999). Why do Puerto Rican injection drug users inject so often? Anthropology or Medicine, 6 (1), 31-58.

van de Wijngaart, G. F. (1988). A social history of drug use in the Netherlands: Policy outcomes and implications. Joumal of Drung Issues, 18 (3), 481-95.

Zinberg, N. (1984). Drag, set and setting. The basts for controlled intoxicant ase. New Haven/London: Yale University Press. 


\section{Summary / Samenvatting}





\section{Introduction}

This thesis describes the development of the relationships of drug users wh society and of relationships bowe drug users, using the concepts of marginalisation and hardening.

Marginalisation is not a new concept, but has rately been applied to chronic heroin users. In this thesis marginalisation refers to the decline of the position of the chromic heroin user within civil socieg and his or her relation with core institations within society, including primary contacts, family, work, income and health care. Although the relationships between chronic heroin users have been described before, the concept of hardening in itself is new, as is a systematic description of the concept. Hardening means that that the overall needs of interaction, solidarity and reciprocity are overruled by survival, instrumentality and individualisation. The theoretical concepts of marginalisation and hatdening are presented in Chapter 1. Additionally this thesis focussed on specifie factors that potentially increase the rate of deterioration of chronic heroin users. In this respect we chose to focus on the impact of the local context, homelessness, crack cocaine, and a repressive policy.

\section{Methods}

To answer the research questions, we used data of the Drug Monitoring System (DMS) from the city of Rotterdam and from the less urbanised region of Parkstad Iimburg (in the south of the Nethetlands). A DMS is a local research system developed to continuously collect data about drugs, drug users and related topics. Usually three kinds of data are collected, i.e. ethnographic data, interviews with key informants and small survey samples among chronic heroin users. In Chapter 2 the use of these data sources as well as their application in the present study is elaborated (section 2.2). Adcitionally the value of triangulation and other techniques to increase the validity or trustworthiness of the study is described in section 2.3.

\section{Results}

In Chapter 3 the life course of chronic heroin usets in Parkstad Limburg is described as a process of matginalisation and hardening. This ptocess is negatively influenced by two so-called catalysts: use of crack and homelessness. The ethnographic method, complemented by survey data gathered in 1999 among chronic heroin users ( $n=103$ ), has been used to substantiate the concepts of marginalisation and hardening. Marginalisation is described as a multidimensional process and includes a social, economic and health dimension (section 3.3.2); we observed deterioration in each of these aspects. Hardening tefers to the development of specific skills in order to survive within the tough world of the drug scene and has the same dimensions as marginalisation (section 3.3.3). The health dimension is elaborated only for marginalisation. Relationships between drug users can be characterised by a social as well as an economic decline. In section 3.3.4 crack and homelessness are identified as two catalysts of marginalisation and hardening. In section 3.4 .2 we argue that a harm-reduction approach will 
contribute more to a successful drug policy than an approach aimed at drug-free existence or punishment.

In Chapter 4 an answer is formulated to the question to what extent marginalisation and hardening alone provide valid descriptions of local drug cultures or should be complemented by counteracting processes (such as socialisation and solidarity). Therefore, we analysed ethnographic and survey data gathered between 1998 and 2000 among chronic heroin users in Parkstad Limburg and Rotterdam in a two-case study design. Although the results show that marginalisation and hardening were relevant to describe the social processes among drug users in both cities, there were more indications for counteracting processes in Rotterdam. Conditions for socialisation and solidarity were: less repressive measures against dealing addresses, the presence of drug consumption rooms and interest groups of drug users, the possibility to work, being part of a network with shared cultural identity, and the possibility to buy and use drugs in a more protective setring. These results led to further refinement of the original analytical model (section 4.4.4).

Chapter 5 aims at considering the effect of several important dimensions of marginalisation on homelessness. The marginalisation theory emerged from ethnographic fieldwork research among the drug user population in Parkstad Limbutrg. Since ethnographic fieldwork is often restricted to a (selective observed) part of the total population, the second aim was to explore possibilities to infer the elaborated theory to the unobserved population of drug users using cross-sectional data (the limitations of this type of data to describe time-bounded processes are discussed throughout Chapter 5). To verify whether the marginalisation theory was valid for the total unknown population, we used quantitative data obtained in 1999 by a two-mode network sample $(n=58$; see also section 5.5 for the research design). It was concluded that homelessness was more likely to be present among marginalised than non-marginalised drug users. This applies to all (independently analysed) dimensions of the concept of marginalisation. More specifically, the following behaviout incteases the chance to become homeless: injecting drugs, using cocaine, having no contact with friends and family outside the drug scene, buying and using drugs in public places, having been arrested, dealing drugs/running, and physical health. The main recommendation is that interventions should focus on the teversion of the process of marginalisation in order to support the drug user in regaining control of his or her drug use and life.

Chapter 6 describes the impact that crack use by chronic drug users has on their already deteriotating position in society, and on the relationships between drug usets and the development of specific skills and strengths to survive in this setting. Ethnographic fieldwork and survey data from Rotterdam and Parkstad Limburg, gathered in 2000 and 1999 respectively, have been used. The results showed that in both cases crack has a catalysing effect on marginalization and hardening. This effect is influenced by contextual factors, such as a repressive drug policy, a protective environment, and being a member of an Antillean network. To moderate the deteriorating effects of crack and help drug users regain control of their dnug use and lives, these local contextual factors should be taken into account. 
In Chapter 7 the effects of increased police enforcement on marginalisation and quality of relations between chronic drug users in Parkstad Limburg are described. Data were mainly gathered by ethnographic community fieldwork, verified by interviews with 11 key informants and supported by a survey sample among 100 drug users.

The results show direct effects of repression on stigmatisation and marginalisation of drug users, and on the availability of drugs. More indirect effects are the hectic reactions of drug users and dealets, greater visibility of drug users in public places, and increased tensions in and deterioration of relations between the drug users. The conclusion is that repression can be seen as a catalyst of marginalisation and hardening.

\section{Conclusions and discussion}

The concepts of marginalisation and hardening offer good descriptions of the life course of chronic drug users. However, based on the two-case study the original model has been refined taking into account the counteracting movements of socialisation and solidarity. We consider that application of the concept of marginalisation offers valuable insights into how and under what conditions marginalisation takes place. In addition, the importance of social initiatives to halt or reverse marginalisation is stressed. Future research is needed to determine whether marginalisation should be understood as atising from reactions from non drug users on drug use, and/or from the attitude of the users themselves. In this study using crack, homelessness, and police repression are identified as important catalysts in the process of marginalisation. However, additional influencing factors (e.g. age, injecting behaviour, and prevailing drug policy) that wete not explored in this thesis warrant attention in future research.

It is argued that a drug policy accepting drug use and aiming at harm-reduction rather than a policy primarily aimed at a drug-free existence or punishment will be effective to slow down or reverse the process of marginalisation and hardening. Emphasis on the voluntary nature of drug use should not overrule the social support needed by chronic drug users to more fully participate in society. Without such support chronic drug users may be condemned to a life of survival on the fringes of our society. 



\section{Introductie}

In dit proefschrift wordt de ontwikkling beschreven wan de thelate wan chronische heroinegebruikers met de samenleving en wan ondeninge relates tussen heroinegebnukers. Hiebiy wordt gebruik gemaakt van de concepten marginalisening en verharding.

Matginaliseting is geen nieux concept, mat is zelden toegepast op chronische hetoinegebrukers. In dit proefschift verwist marginaliseting naar een verslechtering van de positie wan de chronische heromegebruker in de matschappij en wan zijn of haar relatie met kerniastitaties in deze maatschappij, zoals primaite contacten, familie, wetk, inkomen en genondhedszorg Hoewel de relaties tussen chronische heroinegebrulkers eerder zijn bescheven is het concept wan verharding, evenals een systematische beschrijving exwan, nieuw. Vethardhg betekent dat de algemene behoefte an interactie, solidatiteit en wederketigheid worden overschaduwd door overlevingsdrang, intrumentalitet en indwidualisering. De theoretische concepten van marginahseting en vetharding wijn bescheven in Hoofdstuk 1. Aanvullend ticht dit proefschrift zich op specifieke factoren din in potentie de mate van verslechtering van chronische heroinegebruikers vethogen. We hebben ervoor gekozen om ons te richten op de invloed van sociale context, dakloosheid, crack en een repressief politiebeleid.

\section{Metbode}

Om de onderzoeksvragen te beantwootden hebben we gebruik gemaakt wan data wan het Drug Monitoring Systeem (DMS) in Parkstad Limburg en Rottexdam. Het DMS is een lokal onderzoekssysteem om op continue basis gegevens te verzamelen over drugs, druggelotukers en gerelateerde onderwerpen. Doorgans wotden hiet drie types van gegevens voor verzameld, te weten: etrografische gegevens, interviewgegevens met sleutelcontactpersonen en gegevens uit surveys onder chromische heroinegebruikets. In hoofdstuk 2 worden deze methodes en hun toepassing in onderhavig onderzoek nader toegelicht (paragrat 2.2). In aarvulling daatop wordt in paragrat 2.3 ingegaan op de warde van triangulate en andere technieken ter verhoging van de validiteit of "trustworthiness" van het onderzoek.

\section{Rewilutan}

In Hoofdstuk 2 wordt het beloop van de gebrukerscarriète van chronische heroinegebruikers in Parkstad Limburg beschreven als een proces van marginalisering en verharding. Dit proces wordt negatief beinvloed door zogenaamde katalysatoren: het gebruik van crack en dakloosheid. De etnogtafische methode, aangevuld met surveygegevens verzameld in 1999 onder chronische heroinegebruikers $(n=103$ ), is gebruikt om invulling te geven an de concepten wan marginalisering en verharding. Marginalisering wordt beschtreven als een multidimensioneel proces met een sociale, economische en gezondheidsdimensie (paragraat 3.3.2). Op al deze dimensies werd een verslechtering geobservect. Verharding verwijst naar de ontwikkeling van bepaalde vaardigheden on te overleven binnen de harde wereld van de drug scene en heeft, op gezondheid na, dezelfde dimensies als marginalisering (paragraaf 3.3.3). Relaties tussen 
druggebruikers worden gekenmerke door verslechtering zowel op sociaal als op economisch gebied. In sectie 3.4.2 wordt uitgelegd dat een benadering van "harmreduction"s meer bij zal dragen aan een succesvol drugbeleid dan een benadering gericht op een drugrnij bestaan of sanctionering.

In hoofdstuk 4 wordt een antwoord gegeven op de vraag in welke mate matginalisering en verharding alléên valide beschrijvingen bieden van locale drug culturen of aangevuld zouden moeten worden door tegengestelde processen (zoals socialisering en solidariteit). Hiervoor hebben we etnografische en steekproefgegevens geanalyseerd die verzameld zijn tussen 1998 en 2000 onder chronische heroinegebruikers in Parkstad Limburg en Rotterdam in een two-case onderzoeksdesign. Hoewel de resultaten uitwijzen dat marginalisering en verharding televant zijn om de sociale processen te beschrijven onder druggebruikers in beide steden, zijn er meer indicaties voor tegengestelde bewegingen in Rotterdam. Voorwaarden voor socialisatie en solidariteit waren: minder repressieve maatregelen tegen dealadressen, de aanwezigheid van gebruikstuimten en belangenverenigingen, de mogelijkheid om te werken, deel uitmaken wan een netwerk met een gedeelde culturele identiteir en de mogelijkheid om drugs te kopen en te gebruiken in een beschermende setting (paragraaf 4.4.4).

Hoofdstuk 5 richt zich op het effect van een aantal belangtijke dimensies op dakloosheic. De marginaliseringstheorie is naar boven gekomen uit etnografisch veldwerk onder de druggebruikende populatie in Parkstad Limburg. Omdat etnografisch veldwerk vaak beperkt blijft tot een (selectief geobserveerd) deel van de totale populatie, was het tweede doel om de mogelijkheid te onderzoeken om de theorie te generaliseren naar de niet geobserveerde populatie druggebruikers. Hierbij werd gebruik gemaakt van cross-sectionale data (de beperkingen van dit soort gegevens worden bediscussieerd in Hoofdstuk 5). Om the onderzoeken of de marginaliseringstheorie valide was voor de totale onbekende populatie, hebben we kwantitatieve gegevens gebruikt die verzameld zijn in 1999 door een netwerksteekproef ( $n=58$; zie ook paragraaf 5.5 roor het onderzoeksdesign). Geconcludeerd werd dat dakloosheid meer voorkomt onder gemarginaliseetde dan onder nietugemarginaliseerde druggebruikers. Dit geldt voor alle (onathankelijk van elkaar geanalyseerde) dimensies wan het concept van marginalisering. Meer specifiek verhogen de volgende factoren de kans om dakloos te worden: het injecteren van drugs, het gebruik van cocaine, geen contact hebben met familie en vrienden buten de drug scene, kopen en gebruiken van drugs in het openbaar, gearresteerd zijn geweest, het dealen van drugs/runnen en gezondheid. De belangrijkste aanbeveling is dat interventies zich zouden moeten richten op de omkering van het proces van marginalisering om de druggebruiker te ondersteunen de controle te herwinnen over zijn of haar druggebruik en leven.

In Hoofdstuk 6 wordt ingegaan op het effect van crack gebruik door chronische druggebruikers op hun reeds verslechterde positie in de matschappij en op de relaties tussen druggebruikers en de ontwikkeling van specifieke vaardigheden om te overleven in deze setting. Er werd gebruik gemaakt van atnografisch veldwerk en steekproefgegevens van Rotterdam en Parkstad Limburg die respectievelijk verzameld werden in 2000 en 1999. De resultaten lieten zien dat in beide cases crack een katalyserende werking heeft op marginalisering en 
vetharding. Dit effect wordt beinvloed door contextuele factoren zoals een repressief drugsbeleid, een beschermende omgeving en het deel uitmaken wan een Antillians netwerk. Om de verslechterende effecten van crack te modificeren en druggebruikers te helpen de controle te herwinnen over hun druggebruik en leven, zou rekening moeten worden gehouden met deze contextuele factoren.

In Hoofdstuk 7 worden de effecten wan toegenomen politiedruk op marginalisering en de kwaliteit van relaties tussen chronische druggebruikers in parkstad Limburg beschreven. De gegevens werden voomamelijk verzameld door etnografisch veldwerk, geverifieerd door interviews met 11 sleutelinformanten en ondersteund door steekproefgegevens onder 100 druggebruikers.

De resultaten laten directe effecten zien van repressie op stigmatisering en marginalisering van druggebruikers en op de beschikbaarheid van drugs. Meer indirecte effecten zijn de hectische reacties van druggebruikers en dealers, de vergrote zichtbaarheid van druggebruikers op openbare plekken en toegenomen spanningen in en verslechtering van relaties tussen druggebruikers. De conclusie was dat repressie gezien kan worden als een katalysator wan marginalisering en verharding.

\section{Conclusies en discussie}

De concepten van marginalisering en verharding bieden goede beschrijvingen van de levensloop van chronische heroinegebruikers. Toch werd op basis van het two-case onderzoek het oorspronkelijke model herzien, rekening houdend met de tegengestelide bewegingen van socialisering en werharding. De toepassing van het concept van marginalisering biedt watdevolle inzichten in hoe en onder welke voorwaarden marginalisering platatsvindt. Bovendien wordt de waarde van sociale initiatieven om marginalisering te stoppen of om te keren benadrukt. Toekomstig onderzock is nodig om vast te stellen of marginalisering begrepen moet worden vanuit de reactie van de niet druggebruiker op druggebruik of (ook) vanuit de houding van de druggebruiker zelf. In dit onderzoek werden het gebruik wan crack, dakloosheid en een repressief politiebeleid gëdentificeerd als belangriike katalysatoren in het proces van marginalisering. Toch zouden er in toekomstig onderzoek ook aandacht besteed moeten worden aan andere beinvloedende factoren die niet in beschouwing zijn genomen tijdens dit onderzoek, zoals leeftijd, injecteergedtrag en het heersende beleid.

Er wordt naar voren gebracht clat een drugsbeleid waarin druggebruik wordt geaccepteerd en dat zich ticht op "harm-reduction" in plaats van een beleid dat primair gericht is op een drugvrij bestaan of straffen meer effectief zal zijn om het proces van marginalisering en verharding te keren of af te remmen. Het vrijwillige karakter van druggebruik zou niet meer benadrukt moeten worden dan de sociale steun die druggebruikers nodig hebben om volwardig deel te nemen aan de maatschappij. Zonder deze steun worden druggebruikers veroordeeld tot overleven in de marges van onze maatschappij. 



\section{Dankwoord}

Hoewel dit proefschrift zoals het hoort vooral door eigen noeste arbeid tot stand is gekomen, heb ik door de tekst heen toch terecht de "wijvorm" gebruikt. Terecht, omdat ik tijdens de gehele loop van het onderzoek altijd her gevoel heb gehad dat het "ons". werk was. Ik wil dan ook een aantal personen expliciet bedanken.

Allereerst bedank ik mijn promotor, Ronald Knibbe. Hij heeft mij niet alleen de kans geboden dit proefschrift te schrijven, hij heeft me altijd gesteund en liet, ook -of misschien juist- vootal op die momenten dat ik het even niet meer zag zitten, blijken een groot vertrouwen in mijn kunnen te hebben. Door een goede balans tussen het bieden van wetenschappelijke vrijheid en sturend begeleiden heeft Ronald veel bijgedragen aan mijn gedachtevorming rondom dit proefschrift. Een bijzonder woord van dank richt ik ook tot Dike van de Mheen. Zij heeft eerst als mijn projectleider en later als copromotor, mijn artikelen grondig gelezen en van bruikbaar commentaar voorzien. Daarnaast heeft ze me, weliswaar op enige afstand, als dat nodig was met raad en daad bijgestaan. Ook Marinus Spreen verdiend mijn dank woor zijn adviezen van statistische aard en de samenwerking bij het opzetten van de steekproefonderzoeken en het analyseren van de netwerkgegevens. Marinus, je bent de enige met wie ik aan de computer ben gaan zitten om analyses uit te woeren en artikelen te schrijven en dat heb ik altijd zeer gewaardeerd. Andere mensen die ik op deze plaats speciaal wil noemen zijn Ron Scheilings, Peter Blanken, Chatlie Kaplan en Rudie Neve. Tijdens de uitvoer van het Drug Monitoring Systeem (DMS) in Parkstad Limburg hebben zij achtereenvolgens, vanuit hun eigen specifieke deskundigheid begeleiding en supervisie geboden.

Verder wil ik graag de druggebruikers bedanken voor hun medewerking tijdens het veldwerk en de steekproefonderzoeken. Toen ik begon met mijn werk aan het DMS in Heerlen wist ik vrijwel niets van de drug scene. Al snel leetde ik een aantal. mensen kennen die mij letterlijk en figuurlijk wegwijs hebben gemaakt. Mijn ecrste rondleiding kteeg ik wan Jo Schrijen en Henk Rullens, die optraden als gids, beschermer en adviseur. Henk, je hebt me vaker "boss" genoemd, maar eerlijk gezegd denk ik dat ik meer van jou heb geleetd dan andersom! Ook de freelance community fieldworkers Reinhold Ruther en Hanneke Weijers hebben door hun wekelijkse komst naar mijn kantoor om veldnotities in te leveren en te bespreken een onschatbare bijdrage geleverd aan het onderzoek en uiteindelijk dit proefschrift. Ook de minder frequente, maar zeker zo waardevolle bijdrage van Ger van de Loop, Billie Hillman, Marjan de Boon, Hein Crutzen mag hier niet onvermeld blijven. Tijdens het veldwetk ben ik achtereenvolgens ook bijgestaan door Hub Cuijpers, Lars-Erik Rob, Joost Krop, Joep Roex. Allemaal personen die met één been in de scene stonden. Zij legden contacten met gebruikers, schreven veldnotities, namen interviews af en bespraken hun ervaringen met mij. Voor dit alles ben ik ze erg dankbaar.

Ik wil hierbij ook de (ex-)collega's van het IVO bedanken en dan in het bijzonder de onderzoekers aan het DMS in Rotterdam en Utrecht: Ireen de Graaf, 
Janine Wildschut, Ankic Lempens, Cas Barendregt en Agnes van der Poel. Cas, Agnes, Dike en ook Miranda Audenaerdt hebben et tijens de maanden dat ik voor mijn onderzoek in Rotterdam heb gewerkt (van mei tot augustus 2000) bovendien voor gezorgd dat ik mij zeer welkom voelde bij het WO en me een beeve thuis voelde in de "grote stad".

Naast de periode in Rotterdam heb ik tijdens de loop van het onderzoek op verschillende locates in Heerlen en Maastricht gewerkt. Achtereenvolgens had ilk mijn werkplek bij de GGD-OZI. (vanaf 1998), RIMO Parkstad (vanaf begin 2002) en de Universiteit Maastricht (vanaf eind 2002). Hoewel ik bij de GGD op een heel andere verdieping zat dan de andere medewerkers van Collectieve Preventie en Volksgezondheid (CPV), waar $i k$ bij ondergebracht was, heb ik met een aantal medewerlkers een pretrig contact gehad. In het bijzonder noem ijk hier Jeroen Lammers, die als collega-onderzoeker werkte an de Monitor Alcohol en Drugs (MAD) en wat ik djdens de beginperiode van het onderzoek lief en leed mee deelde. Ook bij het RIMO had ik met enkele medewerkers intensiever contact. Jimmy Nass was iemand die een luisterend oot bood en die zorgde voot gezelligheid op de werkplek. Ten slotte heb ik min huidige werkplek gekregen bij de Universiteit Maastricht. Ik heb me vanaf het begin zeer op mijn gemak gevoeld bij de sectie Medische Sociologie. Met name de AJO's van de sectie wil ik hier noemen. Ook al heb ik vaker nict dan wel deelgenomen aan de AlO-soep, ik vond het gezellig en de soepjes lekker. Een speciaal woord van dank richt ik aan Daksha en Marike, beide mijn kamergenote en paranimf. We hebben onze zorgen met elkaar gedeeld, maar ook lol gemaakt. Ook hebben ze me geholpen met vele praktische dingen, zoals het bekijken van de laatste concepten van mijn proefschrift. Dames, we gaan er iets moois van maken!

Ten slotte verdienen mijn familie en vilienden een plaats in dit dankwoord. Mijn vader heeft mij, zoals het een onderwijzer betaamd, altijd gestimuleerd on goed mijn best te doen op school. Mijn moeder heeft mij meegegeven anderen onbevootoordecld tegemoet te treden. Ik denk dat deze twee ingtedienten in mijn achtergrond van wezenlijk belang zijn geweest bij het omgaan met de doelgroep en het schrijven van mijn proefschrift. Bep Rijkers bedank ik voor al die keren dat ze op de kinderen is komen passen, zodat ik ongestoord kon werken aan "mijn boek". Ama, je bent een fijne schoonmoeder. Frwin bedank ik voor de interesse die hij steeds toonde en de gesprekken die we hebben gehad over het werk en het leven. Erwin, ik vind het echt jammer dat je er niet bij kunt zijn als mijn paranimf. Wie altijd met me heeft meegeleefd en bij wie ik altijd terecht kon met mijn zorgen is Mar. Daarnaast, mijn beste, hebben onze vakanties en avondjes uit voor de broodnodige afleiding gezorgd. Dat laatste geldt ook voor Saskia. Miriam bedank ik voor ons emailcontact. Uit het oog is bij ons zeker niet uit het hart.

Last but not least wil ik John, Servé en Stas bedanken voor hun begrip en geduld als ik weer eens liep te stressen in een drukke periode. Ik weet dat ik soms onuitstaanbaat" geweest ben. John, bedankt voor je onbegrensd vertrouwen in mijn capaciteiten en natuurlijk voor het omslagontwerp. Het is echt mooi! 


\section{Curriculum vitae}

Monick Coumans (1971, Wessem) spent her childhood in Thorn, and received her secondary education at St. Ursula in Hom, the Netherlands. She then trained as a nurse at the HBO-V in Sittard. After she graduated in 1993, she studied Health Sciences at Maastricht University specialising in Epidemiology. She graduated in 1996 and started work as a researcher at the Institute for PsychoSocial and Socio-Ecological Research (IPSER; allied to Maastricht University) on a national study addressing the intensity of care of residents within sheltered homes. In May 1998 she started working for the Addiction Research Institute (IVO) on the Drug Monitoring System (DMS) in the region of Parkstad Limburg. All findings in this thesis are based on data collected within the DMS. Since the end of 2002 the author has been working on this $\mathrm{PhD}$ thesis at Maastricht University (Department of Health Care Sciences, Section of Medical Sociology). Besides this project, she has been involved in several other research projects, including the Quick Scans of homeless people/drug users in Parkstad Limbuig and Maastricht, a literature review on purchase attempts as a method to determine compliance with the laws on alcohol and tobacco sales, and creating an ethnographic map for a project conceming the reach of a hepatitis B campaign in the south of Limburg. The author is currently working as a researcher on an IVO project investigating domestic violence in the south of limburg. Her current place of work is Maastricht University (Medical Sociology).

Moniek Coumans (1971, Wessem) bracht haar jeugd door in Thorn, waanna ze de HAVO aan St. Ursula in Hom succesvol afrondde. Na haat afstuderen werd ze opgeleid tot verpleegkundige aan de $\mathrm{HBO}-\mathrm{V}$ in Sittard. Nadat ze haar diploma behaalde in 1993, studeerde ze gezondheidswetenschappen aan de Universiteit Maastricht met als specialisatie Epidemiologie. 'Ze studeerde af in 1996 en begon als onderzoeker te werken bij het Institute for Psycho Social and Socio-Ecological research (IPSER; gelicerd aan de Universiteit Maastricht) aan een landelijk onderzoek naar begeleidingsintensiteit wan bewoners van beschermende woonwormen. In mei 1998 ging ze werken voor het Instituut voor onderzoek naar Leefwijzen \& Verslaving (IVO) aan het Drug Monitoring Systeem (DMS) in de regio Parkstad Limburg. Alle bevindingen in dit proefschrift zijn gebaseerd op gegevens verzameld tijdens het DMS. Sinds cind 2002 heeft de auteur gewerkt aan haar proefschrift aan de Universiteit Maastricht (capaciteitsgrocp Zorgwetenschappen, sectie Medische Sociologie). Naast dit project is ze betrokken geweest bij verschillende onderzocksprojecten, zoals Quick Scans onder gemarginaliseerde druggebruikers en dak-en thuislozen in Parkstad Limburg en Maastricht, een literatuuronderzoek naar (schijn-)aankooppogingen als onderzoeksmethode ter bepaling van de naleving van wetten op de verstrekking van alcohol en tabak en het ontwikkelen van een ethnographic map ten behoeve van een project naar het bereik wan de Hepatitis B campagne in Zuid Limburg. Momenteel is de auteur werkzaam voor het TVO als onderzoeker aan een project over huiselijk geweld in Zuid Limburg. Haar werkplek is aan de Universiteit Maastricht (Medische Sociologie). 